\title{
Agua, arquitectura y poder en una capital del Islam: la finca real del Agdal de Marrakech (ss. XII-XX)
}

\author{
Water, architecture and power in an I slamic capital: the royal country state of \\ the Agdal of Marrakech $\left(12^{\text {th }}-20^{\text {th }}\right.$ Centuries)
}

\author{
Julio Navarro Palazón ${ }^{a}$, Fidel Garrido Carretero ${ }^{a}$, José Manuel Torres Carbonell ${ }^{\mathrm{b}}$, Hamid Trikic \\ aEscuela de Estudios Árabes. CSIC. Granada. e-mail: julionavarro@eea.csic.es, fidel.garrido@eea.csic.es \\ bLaboratorio de Arqueología y Arquitectura de la Ciudad. LAAC. Granada. e-mail: josetorrescarbonell@hotmail.com \\ cHistoriador. Marrakech. e-mail: triki_naima@yahoo.fr
}

\begin{abstract}
RESUMEN
El Agdal es una finca real situada al sur de Marrakech y anexa a la kasba, fundada en época almohade. El perímetro amurallado actual contiene 340 ha que en su mayor parte son huertas que se han mantenido cultivadas ininterrumpidamente. En su interior se han estudiado más de 40 edificios conservados y numerosos restos arqueológicos; los más significativos han permitido identificar el recinto de Dar al-Hana como el área residencial de la finca almohade y saadí. Al sur de este recinto se han localizado los restos de un gran palacio saadí de patio central, edificado sobre otro más antiguo de época almohade. La prospección arqueológica origen de la presente investigación ha documentado el proceso de expansión del Agdal hacia el norte, que acabó transformando lo que era una finca aislada (una almunia) en un apéndice de la kasba. La prospección arqueológica de la llanura de Tasltante, inmediata al Agdal, ha permitido definir un modelo de finca y un patrón de implantación al que pertenece también esta finca real. Esta información arqueológica y el análisis exhaustivo de las fuentes cronísticas han hecho posible el primer intento de reconstrucción del Agdal y del paisaje periurbano, con anterioridad a la restauración alauí de la capitalidad imperial en Marrakech en el siglo XVIII.
\end{abstract}

Palabras clave: Agdal, Menara; almunia; jattara; jardines islámicos; arquitectura palatina; arquitectura almohade; arquitectura saadí; arquitectura alauí.

\begin{abstract}
The Agdal is a royal country estate located to the South of Marrakech and annexed to the kasba, founded in the Almohad period. The current enclosure is an area of 340 ha and consists mainly of orchards farmed uninterruptedly for centuries. Over 40 preserved buildings and numerous archaeological remains have been catalogued in its interior. Among these remains, the enclosure of the Dar al-Hana has been identified with the residential area of the Almohad and Saadian periods. In the southern area of this complex, the remains of a large central court Saadian palace, built on a previous Almohad one, have been identified. The enlargement of the Agdal northwards, which converted an isolated country estate (an almunia) into an appendix of the kasba, has been also recorded. The archeological prospection of the Tasltante plain, close to the Agdal, has allowed defining a model of country state and a settlement pattern, which is also followed by this royal property. The archaeological information and the analysis of the written sources have made possible to reconstruct the Agdal and the peri-urban landscape previous to the Alaouite restoration of the imperial capital status to Marrakech in the eighteenth century.
\end{abstract}

Keywords: Agdal; Menara; Islamic country estates; khattara; Islamic gardens; palatine architecture; Almohad architecture; Saadian architecture; Alaouite architecture.

Recibido: 20/08/2013. Aceptado: 07/11/2013.

Cómo citar este artículo / Citation

Navarro Palazón, J., Garrido Carretero, F., Torres Carbonell, J. M. y Triki, H. 2013: “Agua, arquitectura y poder en una capital del Islam: la finca real del Agdal de Marrakech (ss. XII-XX)", Arqueología de la Arquitectura, 10: e007. doi: http://dx.doi.org/10.3989/arq.arqt.2013.014

\section{Copyright}

(c) 2013 CSIC. Este es un artículo de acceso abierto distribuido bajo los términos de la licencia Creative Commons Attribution-Non Commercial (by-nc) Spain 3.0. 


\section{I NTRODUCCI ÓN ${ }^{1}$}

Reciben el nombre de Agdal $^{2}$ las fincas y huertos de propiedad real anejos a las kasbas de las ciudades imperiales de Marrakech, Rabat, Fez y Mequínez. El topónimo es el mismo término con el que se denominan en Marruecos las áreas reservadas para pastos comunes, cuyo acceso está estrictamente regulado según las estaciones; el apelativo “agdal” o “aguedal” que reciben está cargado de una fuerte connotación de prohibición simbólica, como señaló Mezzine (1998: 69) al estudiar el derecho consuetudinario ('urf) de las zonas rurales del Atlas marroquí. Es probablemente este componente el que explica que el término se aplicara también a los espacios privativos del sultán, situados extramuros y perfectamente delimitados, estuvieran cultivados o no. En las fuentes escritas marroquíes de los siglos XIX y XX que recogen el término, éste no va acompañado de otro que lo califique o matice. Fueron los observadores occidentales, especialmente franceses, los que desde finales del siglo XIX acuñaron la expresión "jardins de 1'Agdal" para referirse a él. La denominación hizo fortuna aunque los mismos que la utilizaban eran, a veces, conscientes de sus límites; por eso emplearon también otras como parc (parque) o verger (vergel, huerto). Para un observador de lengua española, el Agdal de Marrakech es más una gran huerta que cualquier otra $\operatorname{cosa}^{3}$; por este motivo en las páginas que siguen nos referiremos a él como "finca" o "huerta", tanto en singular como en plural.

El Agdal está situado al sur de la ciudad de Marrakech, como anexo de la kasba, a la que está estrechamente vinculado (Fig. 1). Es propiedad del majzén (Estado) desde su fundación en el siglo XII, pero las fuentes escritas no la recogen con este nombre hasta finales del siglo XVIII o principios del XIX, ya bajo la dinastía alauí. En época almohade se la conocía como la Buhayra y en la saadí como Rawd al-Masarra (El Parque de la Alegría). Sus huertas se han mantenido cultivadas ininterrumpidamente, sirviendo a la vez de espacios de recreo. Desde 1985 integra la lista del Patrimonio Mundial de la UNESCO como parte del conjunto histórico de la medina de Marrakech. Cuenta con una muralla de tapia de unos

Todos los planos y levantamientos que acompañan al texto son inéditos y han sido elaborados por el equipo responsable de la prospección. Las restituciones infográficas son fruto de los levantamientos realizados en campo.

2 Nota sobre transcripción de términos árabes: los topónimos se transcriben siguiendo el uso marroquí más habitual; para los términos técnicos y las citas de textos se ha elegido la opción más próxima posible a la fonética de la lengua española, evitando el uso de signos diacríticos y la indicación de las vocales largas.

3 Puede establecerse un claro paralelo entre el Agdal y las conocidas "Huertas del Rey" que abundan en la toponimia de la península ibérica, a menudo herencia de las grandes fincas palatinas de época islámica.
9 km de perímetro que protege una amplísima extensión de huertos y un conjunto de edificaciones de recreo, estructuras hidráulicas e instalaciones industriales de interés patrimonial (Figs. 2 y 3). Este vasto recinto incluye en $\mathrm{su}$ interior otro de $1,5 \mathrm{~km}$ de perímetro que constituye el núcleo palatino de Dar al-Hana, compuesto por una alberca rodeada de huertos y flanqueada por los restos de un antiguo palacio situado en su frente meridional. A finales del siglo XIX y principios del XX, periodo de su máxima expansión, el Agdal llegó a tener una extensión de 535 ha y su muralla se prolongó hacia el sur hasta alcanzar un perímetro de $11 \mathrm{~km}$ que incluía en su interior lo que se conoce como Agdal Barrani (Agdal Exterior). Todo el conjunto se conocía con el nombre de Gran Agdal (Fig. 2). En la actualidad su superficie se reduce a unas 340 ha que se mantienen en plena producción, plantadas principalmente de olivos, cítricos y granados, cultivos documentados ya en época almohade. Su subdivisión en huertos separados por tapias parece remontarse, al menos, a época saadí, lo que no excluye que su actual fisonomía sea muy deudora de la restauración realizada por los soberanos alauíes en la primera mitad del siglo XIX.

No deja de sorprender que el Agdal, a pesar de su gran notoriedad, valor histórico y atractivo turístico, no hubiera sido objeto de un estudio en profundidad hasta la campaña de prospección arqueológica realizada en 2012 por la Escuela de Estudios Árabes de Granada, dependiente del CSIC. Un estudio de El Faïz (1996) ${ }^{4}$ había mostrado el enorme interés histórico, arquitectónico y paisajístico de la finca, y la publicación cuatro años después de una obra colectiva sobre el Agdal promovida por la Fundación Benetton (Luciani et al. 2000) sirvió para llamar de nuevo la atención sobre la necesidad de preservarlo.

Llegar a conocer en detalle una realidad que se extendió por más de 500 ha y cuya evolución abarca ocho siglos requería mucho más: era necesario hacer planos actualizados y precisos de la finca, elaborar un catálogo de su patrimonio, documentar gráficamente de manera pormenorizada sus elementos más notorios, llevar a cabo, en fin, una indagación sistemática sobre su estado actual y sobre su pasado. Resultaba imprescindible realizar una encuesta exhaustiva que describiera adecuadamente lo que había, aunando la exploración de las fuentes escritas

\footnotetext{
Este estudio fue vuelto a publicar con ligeras variantes en una edición bellamente ilustrada (El Faïz 2000a); un extracto de los pasajes específicos sobre el Agdal se publicó ese mismo año en italiano (El Faïz 2000b). En 2007 se publicó en inglés parte del mismo texto (El Faïz 2007). Dada la similitud existente entre los cuatro textos, en adelante se citará la publicación de 1996, origen de las otras tres.
} 


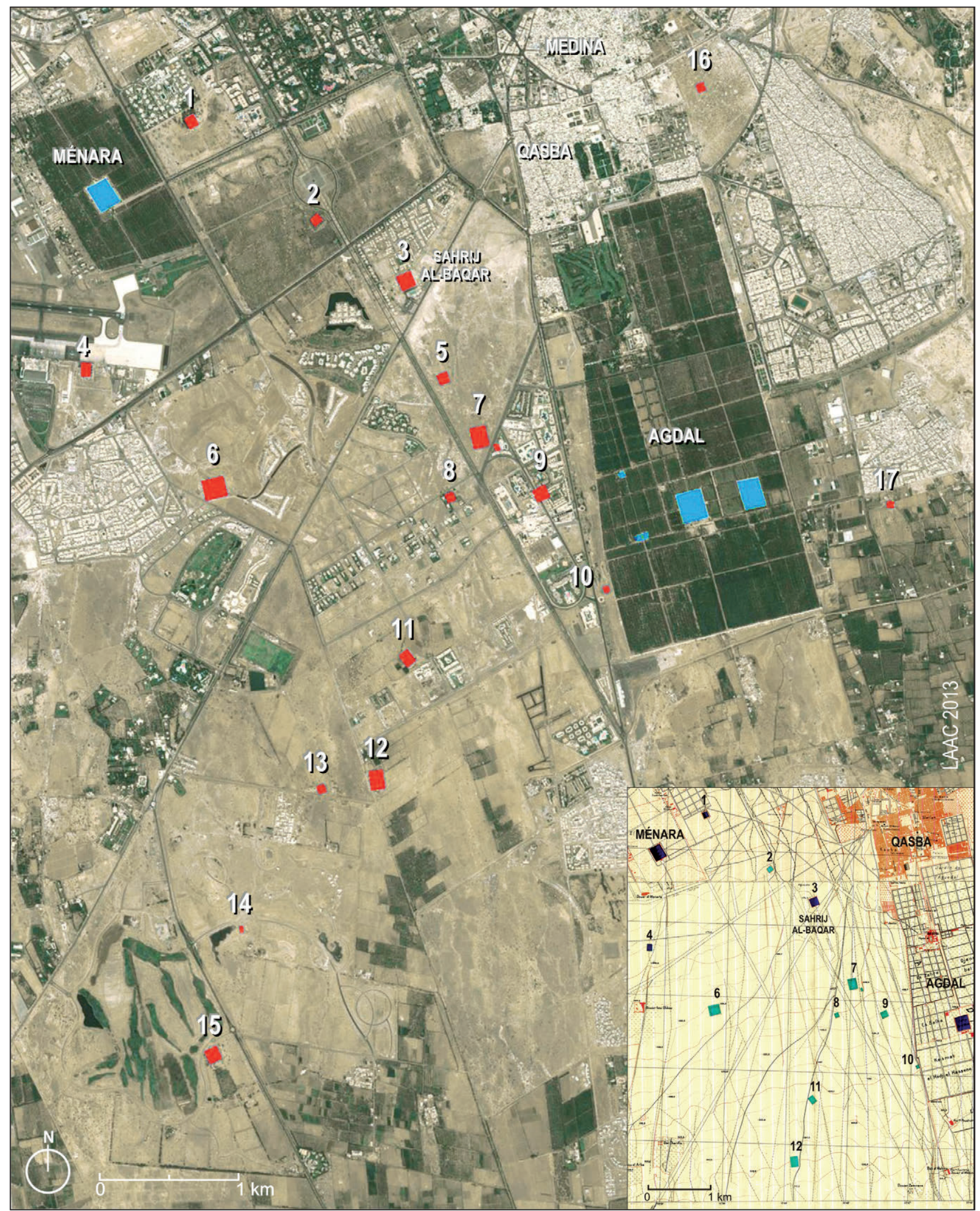

Fig.1. Vista aérea vertical de la zona sur de Marrakech y de la llanura de Tasltante. Se marcan en rojo las albercas abandonadas. La mayor parte de ellas ya lo estaban en el primer tercio del siglo XX, como muestra el Plano Topográfico de Marrakech de 1935-1950 (inserto). Las albercas 8 y 9 desaparecieron a mediados de la década de 2000 y la 4 fue parcialmente demolida en las mismas fechas. La 6 fue destruida a principios de la década de 2010 y la 13 se hallaba en curso de demolición en mayo de 2013 


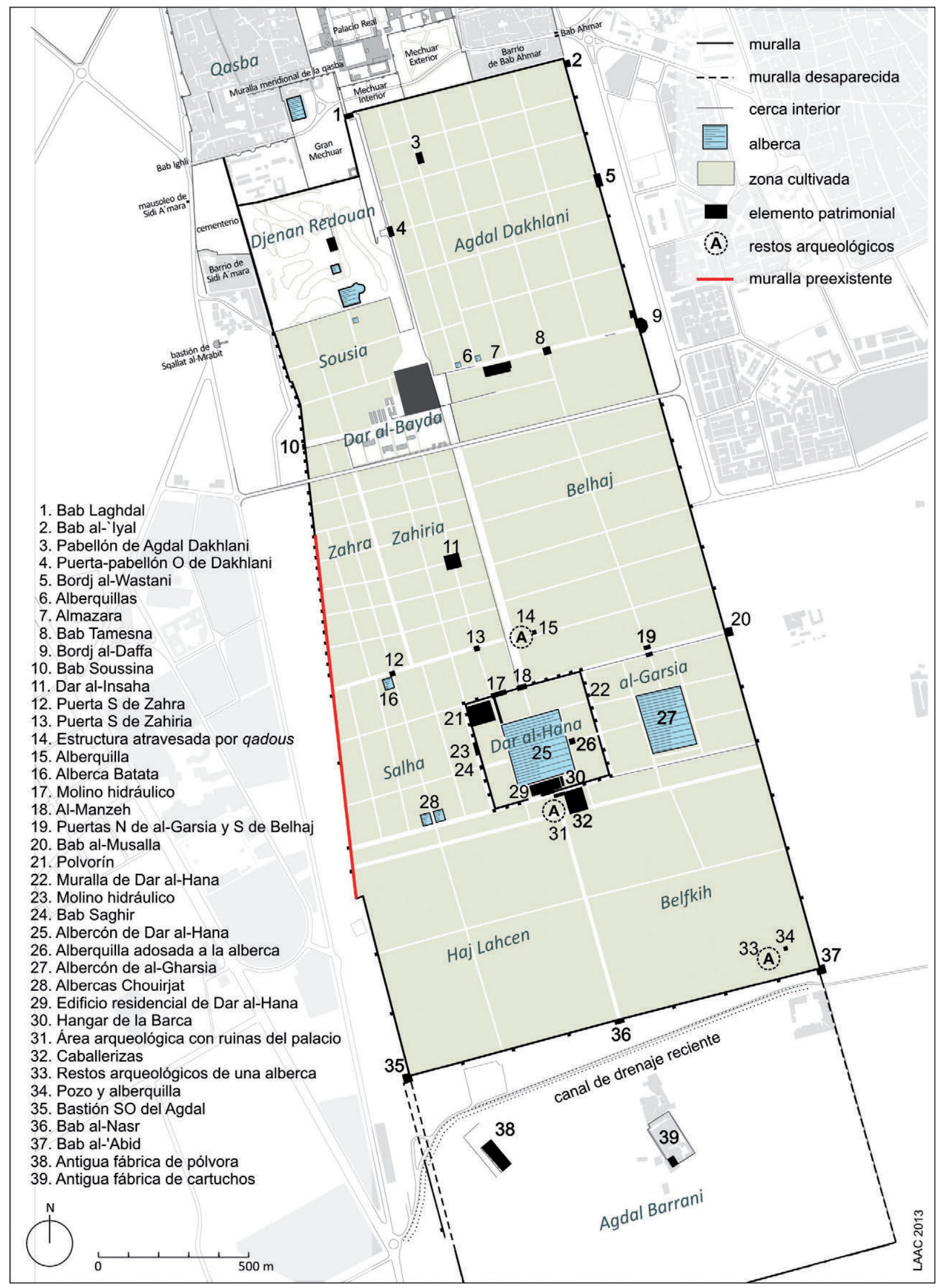

Fig. 2. Agdal. Croquis general del estado actual de la finca con indicación de las estructuras arquitectónicas y arqueológicas catalogadas. El tamaño de los elementos patrimoniales localizados se ha aumentado por claridad 


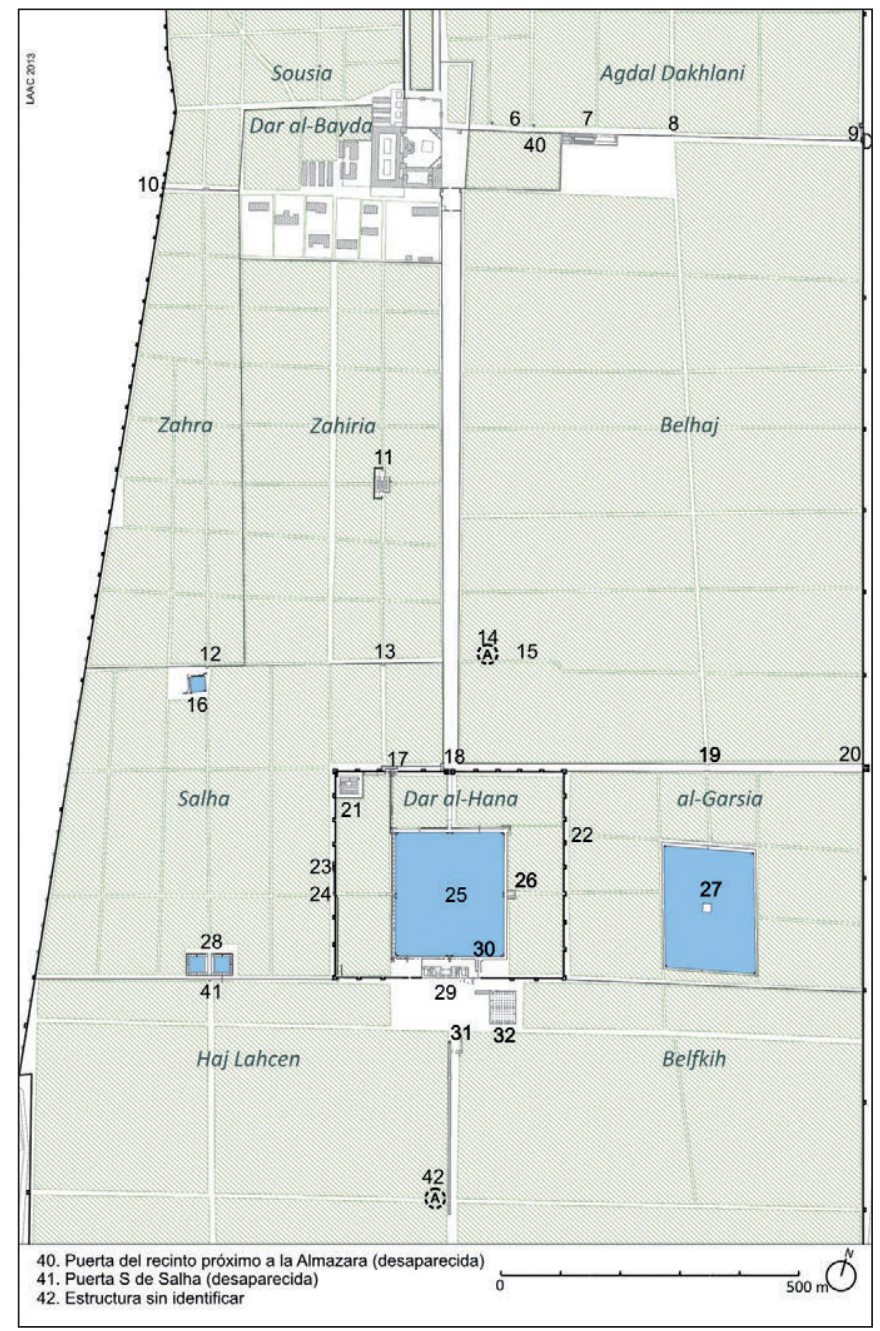

Fig. 3. Agdal. Parte central de la finca representada según el estado en que se hallaba en 1917, a partir de una fotografía aérea del ejército francés. La numeración de los elementos de interés se corresponde con la de la Fig. 2. Las puertas señaladas con los números 40 y 41 no se conservan

y arqueológicas con el análisis comparativo de otras realidades similares.

La prospección realizada en 2012 permitió inventariar y documentar gráficamente, por primera vez, unos 400 elementos de interés arquitectónico y arqueológico, entre los que destacan unos 40 edificios que conservan sus alzados (Figs. 2 y 3), así como describir la red hidráulica de la finca. Se ha llevado a cabo un estudio detallado de las fuentes árabes disponibles y revisado la información que facilitan los textos en lenguas occidentales, especialmente las descripciones de viajeros de los siglos XVI al XIX. Todo ello se ha contrastado, por primera vez, con la información proporcionada por la prospección arqueológica y ha permitido proponer una hipótesis de la evolución histórica del Agdal desde época almohade hasta el siglo XX (Figs. 4 y 5).

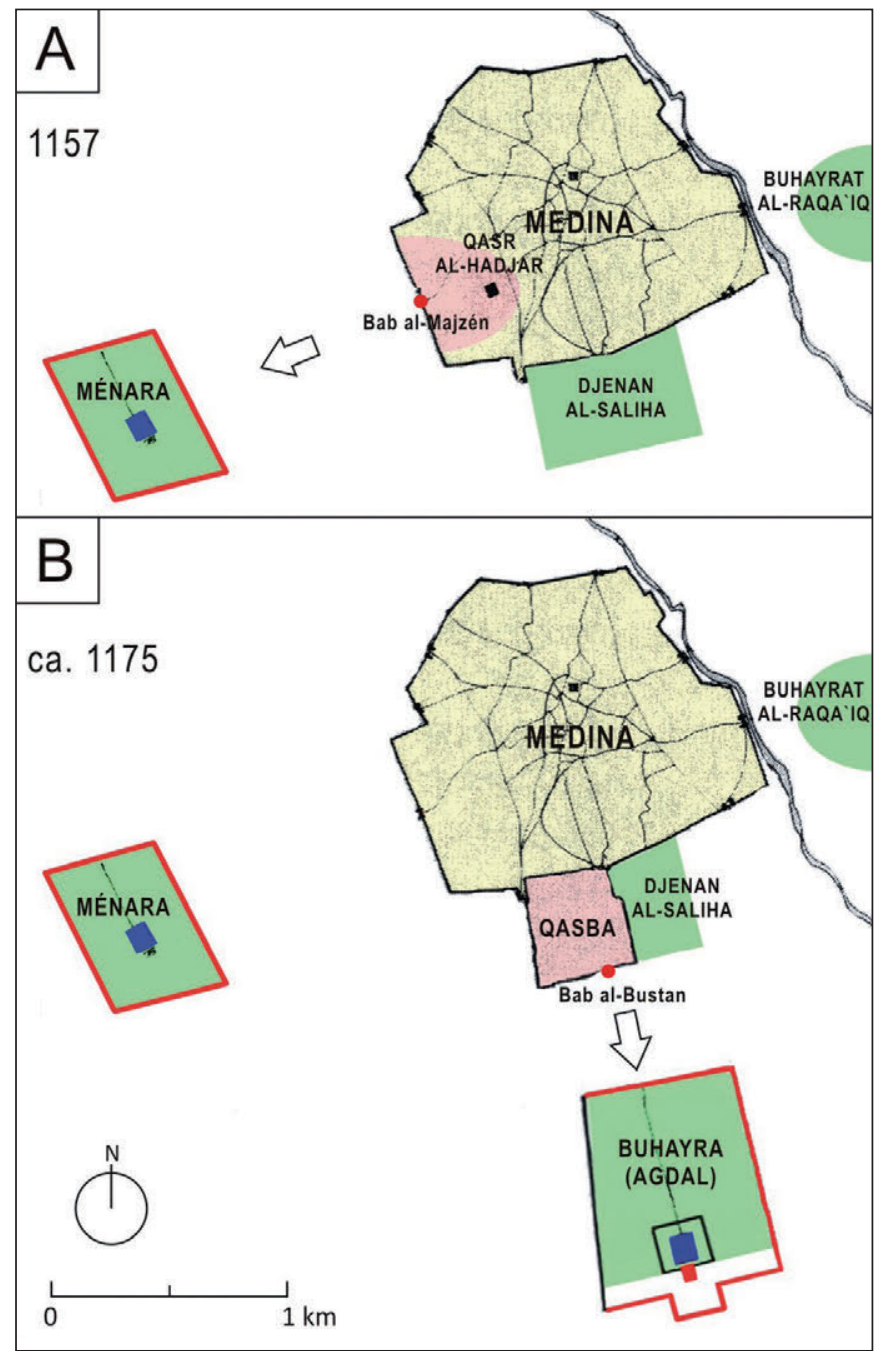

Fig. 4. Las almunias majzén de Marrakech en el siglo XII y su relación con los centros de poder

\section{2. ÉPOCA ALMOHADE (1130-1269)}

Los primeros trabajos hidráulicos de Marrakech fueron obra de los almorávides, fundadores de la ciudad en 1070. Es necesario remontarse brevemente a esta época para entender el contexto de las actuaciones almohades posteriores. 'Ali Ibn Yusuf (1106-1143), el segundo emir almorávide, aprovisionó de agua la residencia palatina de Qasr al-Hadjar y la medina mediante jattara/ $\mathrm{s}^{5}$ (y fue él el que emprendió la tarea de traer las aguas a la ciudad, aunque finalmente los almohades acabaron los trabajos (Al-Idrisi 1968: 68-69, 79; Triki 1995: 95-

El término jattara se utiliza en Marrakech para designar una galería drenante. Este sistema de captación de aguas subterráneas recibe el nombre de qanat en muchas zonas del próximo oriente. 


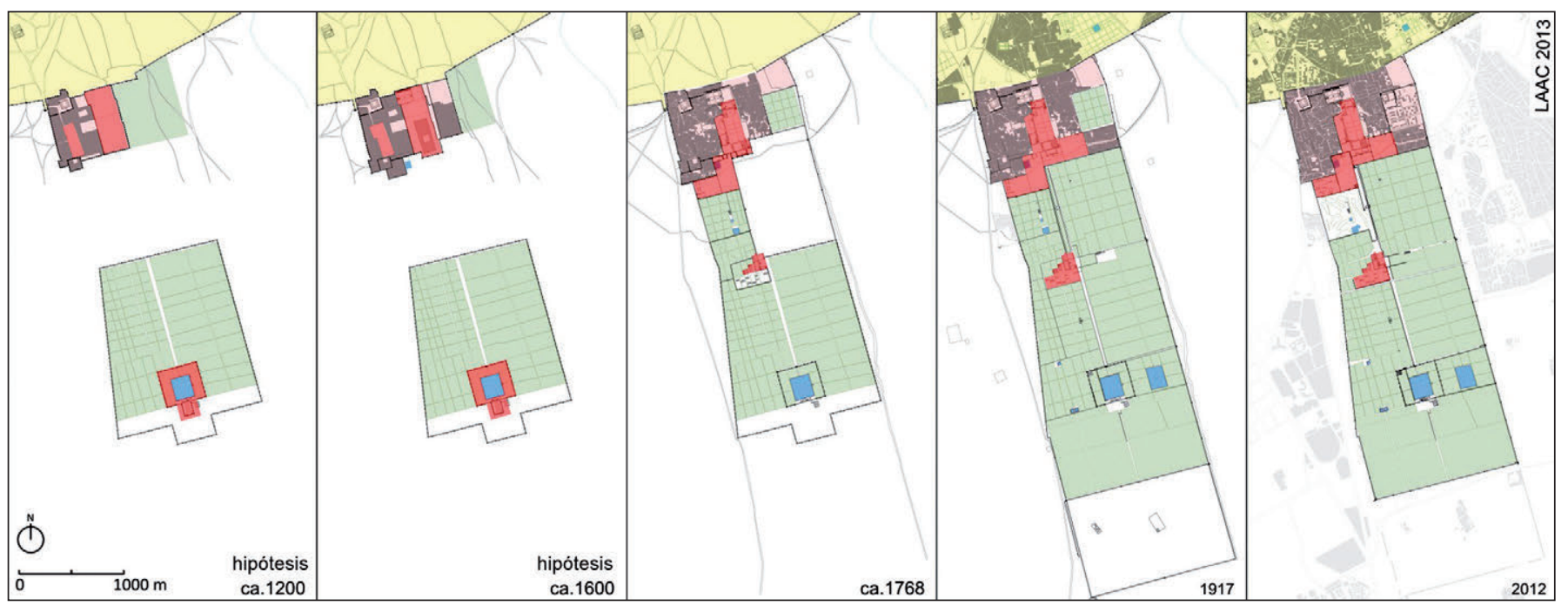

Fig. 5. Buhayra - Masarra - Agdal. Hipótesis de evolución

97) ${ }^{6}$. En la periferia de la medina abundaban las grandes fincas de regadío (Triki 1995: 96); la más famosa era la Buhayra al-Raqa'iq, situada al este de la ciudad (Fig. 4), donde tuvo lugar en 1130 la célebre batalla entre almorávides y almohades que terminó con la derrota de estos últimos. La conquista definitiva de Marrakech no se producirá hasta 1147. La descripción de los acontecimientos bélicos que hicieran Al-Baydaq (Lévi-Provençal 1928: 78-79 y 127-128), Ibn al-Qattan (1990: 159-160) y el autor anónimo del Kitab al-Ansab (Levi-Provençal 1928: 28 y 41) permite saber que esta buhayra era una finca cercada, provista de una puerta fortificada dotada de una torre (burdj), que se regaba mediante acequias (sawaqi) alimentadas por jettaras ('uyun), y que había silos de grano (murus) en su interior. Esta descripción nos da una idea de los elementos básicos que componían las buhayra/s almorávides y almohades; falta solamente la mención a una gran balsa de agua, que debemos suponer existió.

Será bajo la dinastía almohade cuando se generalicen los grandes proyectos hidráulicos. 'Abd al-Mu'min Ibn 'Ali (1130-1163) construyó en 1157 la gran buhayra de la Menara (Fig. 4). El hecho fue registrado por dos fuentes contemporáneas.

La primera nos revela el nombre con el que se conoció originalmente la finca. Según el testimonio de Al-Baydaq, personaje que formó parte de la corte almohade, el califa hizo plantar una buhayra llamada Shuntululya hacia 1157-1558:

\footnotetext{
6 Al-Idrisi terminó su obra a mediados de enero de 1154, aunque se sabe que hizo algunas adiciones posteriores (Al-Idrisi 1968: 4).
}

“En 550 [1155-1156], el califa ['Abd al-Mu’min] visitó la tumba del Mahdi [en Tinmal], después fue a Salé, donde permaneció dos años. Volvió después a Marrakech e hizo plantar [garasa] la buhayra que está en Shuntululya” (LéviProvençal 1928: 125 [texto árabe], 199-200 [trad. francesa]).

La segunda fuente es el Kitab al-istibsar, que nos informa de su ubicación:

"['Abd al-Mu'min] hizo plantar [garasa] una inmensa finca [buhayra 'adima] al Oeste de la ciudad, hacia el Nfis, de un perímetro de seis millas. Construyó dentro y fuera de ella [fi-ha wa jaridji-ha] dos albercas enormes [sahridjayn 'adimayn]" (Saad Zagloul 1985: 209-210).

Como se ve, las dos fuentes utilizan el término buhayra para referirse a una finca regada. El término se utilizaba en el área de Marrakech para designar una gran balsa de acumulación y por extensión el terreno regado gracias a ella ${ }^{7}$. Las precisiones espaciales y toponímicas que ofrecen estos dos textos permiten descartar que se estén refiriendo al Agdal fundacional, dado que este último estaba situado al

Según Deverdun una buhayra era "un immense verger clos doté d'un grand bassin (sahridj) destiné à assurer une abondante provision d'eau pour l'irrigation des arbres fruitiers au milieu desquels des cultures intercalaires de légumes ou de légumineuses trouvaient place" (Deverdun 1959: 194). El mismo autor afirmaba que esto es lo que se llama en Marrakech un "aguedal", nombre que no aparece en las fuentes cronísticas hasta época alauí. Por extensión, el término se utiliza actualmente en el sentido de vergel. Las menciones a las fincas peri-urbanas de los califas almohades recogidas en el Kitab al-istibsar y el Mann bi-l-imama de Ibn Sahib al-Salà, dos de las fuentes fundamentales para el periodo, se refieren a ellas como buhayra, y a las balsas en torno a las que se organizaban como birka o sahridj. 
sur de la medina (Fig. 4), no al oeste, lo que apunta claramente a que se trata de la Menara, como señaló Deverdun (1959: 194-197).

La Menara se aprovisionaba de agua mediante jattara/s. El sitio donde se construyó se hallaba en la llanura situada fuera de la Puerta del Estado (Bab alMajzén), que debía su nombre a que constituía el acceso a Qasr al-Hadjar (Fig. 4.A), el alcázar almorávide que fue también residencia del primer sultán almohade ${ }^{8}$. La finca constituía así una proyección exterior del área palatina de la época, algo que emulará su sucesor Abu Ya' qub Yusuf (1163-1184) fundando su almunia de la Buhayra frente a la ciudad palatina (kasba) que él fundó9 (Fig. 4.B).

Según el Kitab al-istibsar (Saad Zagloul 1985: 210) este monarca puso en explotación fincas con albercas de proporciones nunca vistas hasta entonces, y una de ellas fue el Agdal fundacional. Según Ibn Sahib al-Salà (1969: 173), alto dignatario de la corte de Abu Ya'qub Yusuf, la huerta más importante de Marrakech en esta época se llamó simplemente la Buhayra. Se la puede identificar con el primitivo Agdal gracias a un autor de mediados del siglo XIV, Al-'Umari, que se refiere a ella con ese mismo nombre y da su localización ${ }^{10}$. Cuando enumera las puertas de la kasba, Al-'Umari cita en primer lugar la Bab al-Bustan (Puerta del Jardín), que comunicaba el palacio con una gran finca extramuros situada al sur de la ciudad palatina (Fig. 4.B):

"[La kasba] tiene tres puertas que le son exclusivas: [la primera es] la Puerta del Vergel [Bab al-Bustan], que es privativa de los familiares del sultán; da acceso a un jardín [bustan] llamado la Buhayra; éste, que tiene 12 millas de longitud ${ }^{11}$, contiene construcciones magníficas, edificios inmensos y la alberca que no tiene comparación. Al-'Uqayli afirma que tiene 380 brazas [ba' $]^{12}$ de largo y

\footnotetext{
8 Las ruinas de Qasr al-Hadjar o Dar al-Hadjar se conocen gracias a las excavaciones arqueológicas realizadas en las inmediaciones de la mezquita Koutoubia en época del Protectorado. El primer oratorio almohade se construyó sobre parte de este palacio almorávide (Meunié et al. 1952 y 1957).

$9 \quad$ Fue este califa el que en 1163 trasladó la residencia palatina desde el Qasr al-Hadjar hasta su nueva localización al sur de la ciudad, en un lugar llamado Al-Saliha donde existía una gran huerta extramuros de época almorávide. Allí fundó una ciudad palatina que conocemos hoy día como la kasba de Marrakech (Ibn Idhari 1985: 174, 186, 230; Huici 1953: t. I 97-98, 122, 207).

10 Al-'Umari utiliza para Marrakech fuentes que se remontan siglo y medio atrás, hasta el año 1160 (Gaudefroy-Demombynes 1927: 179 n.1).

11 La milla equivale a $1995 \mathrm{~m}$. Las medidas que da Al-'Umari son imposibles.

12 La braza equivale a cuatro codos. Se acepta generalmente que el codo rashshashi utilizado en el Magreb y Al-Andalus equivalía a 54,04 cm (Hinz 2013). Pero el codo almohade utilizado en Marrakech equivalía a $64 \mathrm{~cm}$, según se ha podido comprobar a partir de las medidas de las mezquitas de la Kutubiya y de Tinmal proporcionadas por Al-'Umari (Wilbaux 2001: 180). Las dimensiones que da Al'Umari para la alberca de Dar al-Hana generarían un cuadrado de 243,2 m de lado, lo que no coincide con la realidad que hoy día vemos (208x183 m).
}

que sobre uno de sus bordes hay cuatrocientos naranjos, separados bien por un limonero, bien por una flor" (Al'Umari: 1988: 86; Gaudefroy-Demombynes 1927: 181).

Ésta es la única descripción que existe de la Buhayra almohade, pero en ella vemos ya todos los elementos y características que mencionarán autores posteriores: finca de tamaño excepcional, alberca sin parangón, plantíos de naranjos y limoneros perfectamente ordenados y edificios asombrosos.

De la misma manera que hiciera su predecesor 'Abd al-Mu 'min al crear la Menara fuera de la ciudad, siguiendo un eje este-oeste en el que se articulaban la finca y el alcázar califal, también Abu Ya'qub Yusuf proyectó su gran buhayra fuera de la nueva ciudad palatina de la que era promotor, la kasba, siguiendo en este caso un eje norte-sur completamente diferente al anterior (Fig. 4).

\section{3. ÉPOCA SAADÍ (1557-1659)}

No sabemos de ninguna fuente que mencione la Buhayra (el Agdal) en época meriní (1258-1456). El traslado de la capitalidad a Fez en este periodo provocó la decadencia y ruina parcial de Marrakech. A mediados del siglo XIV, sin embargo, muchos de los palacios y dependencias de la kasba estaban en uso y la red hidráulica funcionaba todavía (Ibn Marzuq 1981: 70-71, 156, 137). No puede descartarse pues que la Buhayra continuara existiendo, siquiera como explotación agrícola, dada la tenacidad con la que el majzén protegía sus propiedades. A principios del siglo XVI, León el Africano afirma del jardín asociado al palacio existente en el interior de la kasba que "tan hermoso antes, es hoy muladar de la ciudad” (León el Africano 2004: 171), sin hacer mención alguna a la famosa Buhayra almohade.

Tras el paréntesis meriní, bajo la dinastía saadí Marrakech recupera la capitalidad del imperio, lo que traerá una reactivación de la vida urbana reflejada en la construcción y restauración de palacios y en la recuperación de la red hidráulica. También tiene lugar la revivificación de las grandes fincas del majzén, particularmente del Agdal, que en este periodo era conocido como Rawd al-Masarra o simplemente la Masarra. Los textos de la época, mucho más abundantes y prolijos que los anteriores, describen una finca muy extensa compartimentada en huertos más pequeños, presidida por una alberca imponente a la que se asoma un gran edificio que es atravesado por la acequia que la alimenta. Con esta información es posible reconstruir la finca 
con cierta precisión e incluso conocer qué sultán hizo en ella las obras más importantes. No tenemos noticia alguna de la Masarra para el periodo de gobierno del sultán 'Abd Allah al-Galib (1557-1574). El estado en el que se encontraba la finca durante el gobierno de su sucesor 'Abd al-Malik I (1574-1578) se conoce en cambio gracias al testimonio del embajador inglés Edmund Hogan, que relata cómo fue recibido por el sultán en 1577 "en su jardín", tumbado en una cama de seda (Hogan 1918: 245). En otro jardín adyacente, al que se desplazan después, había una gran alberca con su barca en la que ambos navegan; menciona también que allí había una "banqueting house" que en la arquitectura Tudor, con la que el embajador inglés estaba familiarizado, era un edificio destinado a recepciones y banquetes al que se llegaba desde la residencia principal a través de jardines ${ }^{13}$. El equivalente saadí de este tipo de estructura era un pabellón de recreo. También es de destacar en el testimonio de Hogan que el sultán le mostrara "sus caballos y otros objetos de valor que tenía por su casa", lo que indica la existencia en aquel lugar de un edificio residencial y unas caballerizas (Fig. 27).

El sucesor de 'Abd al-Malik I, Ahmad al-Mansur (1578-1603), fue el gran constructor de la dinastía. Entre sus obras destaca el palacio del Badi', iniciado en 1578, apenas llegado al trono. Pudo inaugurarlo escasamente cinco años después, en 1593. También ejecutó otros muchos proyectos dentro de la kasba, edificó la rauda real conocida como tumbas saadíes y levantó la mezquita de Bab Doukkala y sus anexos (Deverdun 1959: 384ss.).

La Masarra de este periodo se conoce gracias a los anales de la dinastía saadí redactados por 'Abd-al-Aziz ibn Muhammad al-Fishtali (1549-1621), visir de AlMansur e historiógrafo oficial. El autor la describe en los siguientes términos ${ }^{14}$ :

"Este parque $[$ rawd $]$ de al-Masarra $[. .$.$] tiene la anchura$ de las murallas de la kasba y de Al-Saliha. Se distingue por su gran extensión y despliega un manto de verdura hasta el horizonte lejano; es tan grande que los mejores caballos de carreras serían puestos a prueba. La ordenación perfectamente simétrica de los cuadros de cultivo [hada iq] hace sucederse a las viñas, los granados, y las palmeras, en parejas o en grupos de especies de plantas, dispuestas unas frente a otras como si se miraran mutuamente. Hay huertos

\footnotetext{
13 Este tipo de edificios, al no tener carácter de residencia permanente, no contenía dormitorios ni cocinas.

14 La versión castellana que se ofrece aquí está basada en la traducción francesa realizada por Hamid Triki en el marco de la presente investigación.
}

[djannat] separados a lo largo y ancho por avenidas bordeadas de plantas aromáticas y árboles: mirtos, limoneros, saúcos [jabur], macizos de rosas, nisrin [¿rrosas de Jericó o narcisos?], jazmines, y un bosque de innumerables olivos cuyo producto cubre las necesidades de la región. Cuando se llega a la Gran Alberca [al-birka al-'udmà], parecida a un mar ondulante, situada en la parte más alta [de la finca de la Masarra], se descubre un panorama que maravilla la vista a causa de su inmensidad y de su anchura. [La alberca] es tan grande que podría contener una arena en la que los caballos corrieran a lo largo y a lo ancho [...] [Tiene] fuentes de surtidor central [jussas] $]^{15}$ integradas en la construcción, adosadas a sus muros al este y al oeste, bellas y enormes, cuya agua vierte en una conducción de corriente muy fuerte. [La alberca] está rodeada de plantas de múltiples variedades cuyas hojas son perennes y permanecen verdes siempre. Por lo que respecta al Gran Palacio [al-biniya al-'udmà], el encanto que produce su visión es proverbial. Se eleva al borde de la gran alberca y es atravesado por el canal [nahr] que vierte en ella, comparable en eso al océano en el que ondean las olas” (Al-Fishtali 1964: 178-179) ${ }^{16}$.

La kasba, según Al-Fishtali, se comunicaba con la Masarra mediante una puerta que se abría en un gran pórtico o galería (bahu) de la Gran Qubba (al-qubba al-'udmà) situada en el extremo sur del Jardín del Canal (al-bustan al-nahr), el actual jardín del palacio alauí que hay en el interior de la kasba. Este acceso estaba dominado por un gran baluarte (bordj) (Al-Fishtali 1964: 179-180). El autor describe cómo se veía la Masarra desde allí:

"La vista sigue el camino, bordeado a izquierda y derecha por plantas que le dan sombra, hasta el edificio dominante erigido sobre la gran alberca [al-biniya al-munifa almathila 'alà al-birka al-'udmà] en la parte más alta de la Masarra [fi a'là-l-Masarra]" (Al-Fishtali 1964: 177).

La descripción de Al-Fishtali, testigo privilegiado de lo que narra, es valiosísima por los detalles que ofrece sobre la disposición de la finca, dividida en huertos

\footnotetext{
En árabe marroquí una jussa, llamada fisqiya en Oriente, es una pila de mármol o material similar en la que el agua mana de un surtidor central.

16 La descripción que hace Al-Fishtali de los palacios de la kasba y de la Masarra no ha sido nunca objeto de análisis detallado. Véase Mouline (2009: 139-148) para una síntesis útil en la que lamentablemente se deslizan errores importantes, como confundir la localización del Jardín del Canal (Bustan alNahr), situado dentro del palacio de la kasba, con la de la Masarra, situada extramuros (Mouline 2009: figura de la p. 145 y p. 146).
} 
yuxtapuestos (djannat, hada iq) separados por avenidas bordeadas de plantas y flores. El autor diferencia claramente dos zonas de cultivo: la primera dedicada a frutales y a especies delicadas que necesitan más agua y son más propias de un jardín; la segunda un gran área de monocultivo del olivo. Esta misma distribución ha llegado en buena parte hasta nuestros días. Es de destacar que la extensión dedicada al cultivo del olivo debía de ser muy grande, dado que la producción obtenida en la Masarra cubría "las necesidades de la región".

La información que proporciona Al-Fishtali sobre las enormes dimensiones de un palacio situado junto a la alberca, también excepcional por su extensión, es en todo coincidente con la realidad arqueológica descubierta en Dar al-Hana (Figs. 6 a 8), punto sobre el que volveremos más adelante.

Al Ifrani, autor de la primera mitad del siglo XVIII, atribuye a al-Mansur la revivificación de la Masarra, citando el Rawdat al-As de Al-Maqqari (1578-1632): “AlMansur había concebido tres cosas admirables por su for- ma y de una maravillosa belleza: el Badi', la Masarra y la Mushtaha [un jardín interior de la kasba]". Pero Al-Ifrani sabía que la Masarra había sido originalmente obra de los almohades y por eso afirma a continuación que lo que hizo Al-Mansur en la finca fue, más que crearla, restaurar "los lugares de la Masarra [máalim al-Masarra] después de que hubiera caído en ruina [ba'da indirasa-ha]"(AlIfrani 1998: 112, Houdas 1889: t. II, 191).

El aspecto impresionante que presentaba la Masarra saadí nos fue transmitido por Al-Maqqari al narrar una reunión de amigos, todos dignatarios de la corte de Al-Mansur, que tuvo lugar en marzo de 1601, en pleno Ramadán, al borde de la alberca de Dar al-Hana. En medio de un debate sobre los jardines más bellos del mundo decía:

"Para mí [...] la Masarra supera a todos los jardines [...] las constelaciones mismas desearían pasearse en sus praderas $[. .$.$] bañarse en su alberca es mucho más agradable$ que hacerlo en el Nilo o en el Genil [de Granada]" (AlMaqqari 1983: 25-26).

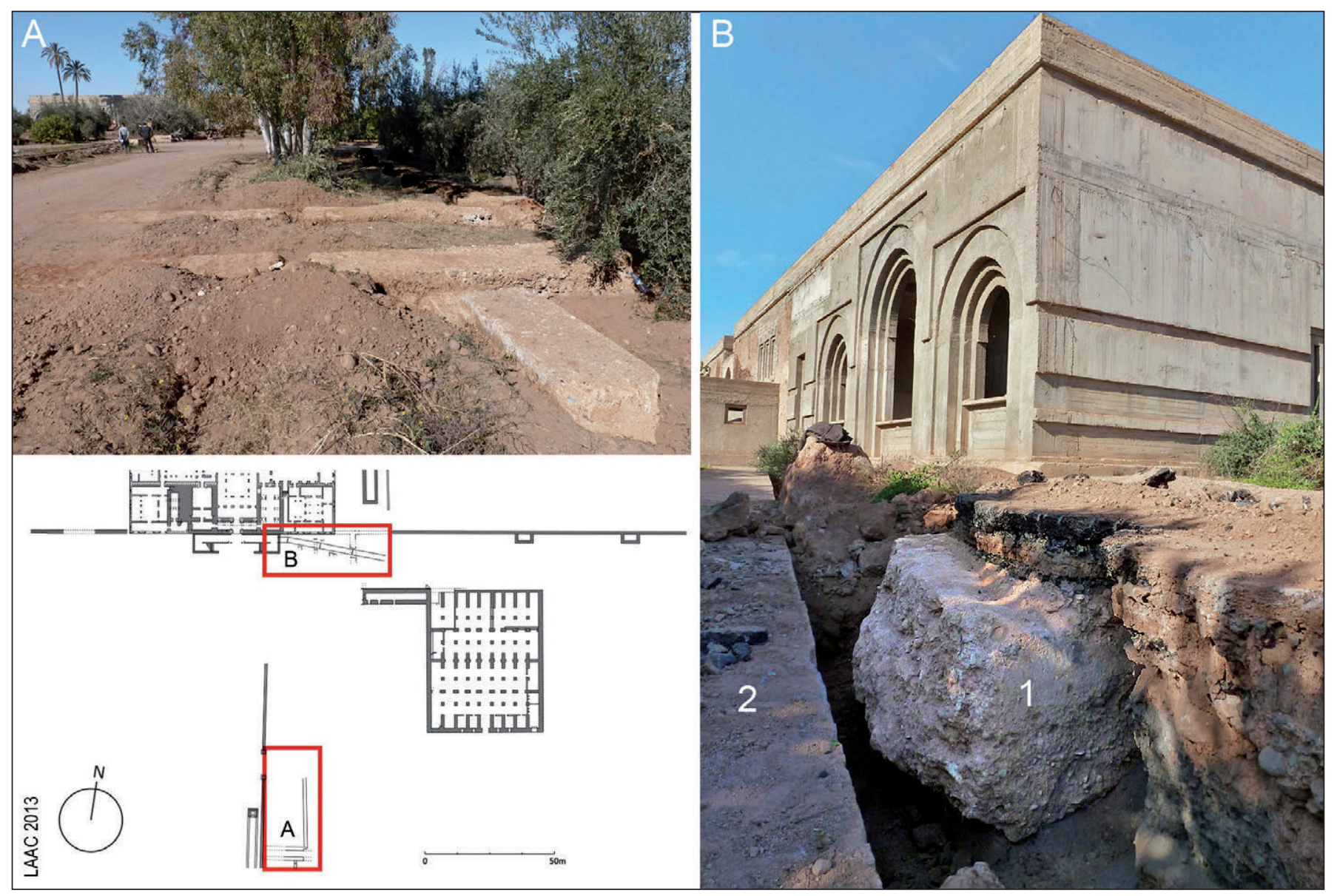

Fig. 6. Dar al-Hana. Restos arqueológicos situados en las inmediaciones del edificio residencial. (A) Estructuras en superficie en las proximidades de las albercas de decantación. (B) Estructuras arqueológicas (1) seccionadas por la construcción de un pasadizo subterráneo de hormigón (2); al fondo el edificio saadí reconstruido por Paccard 


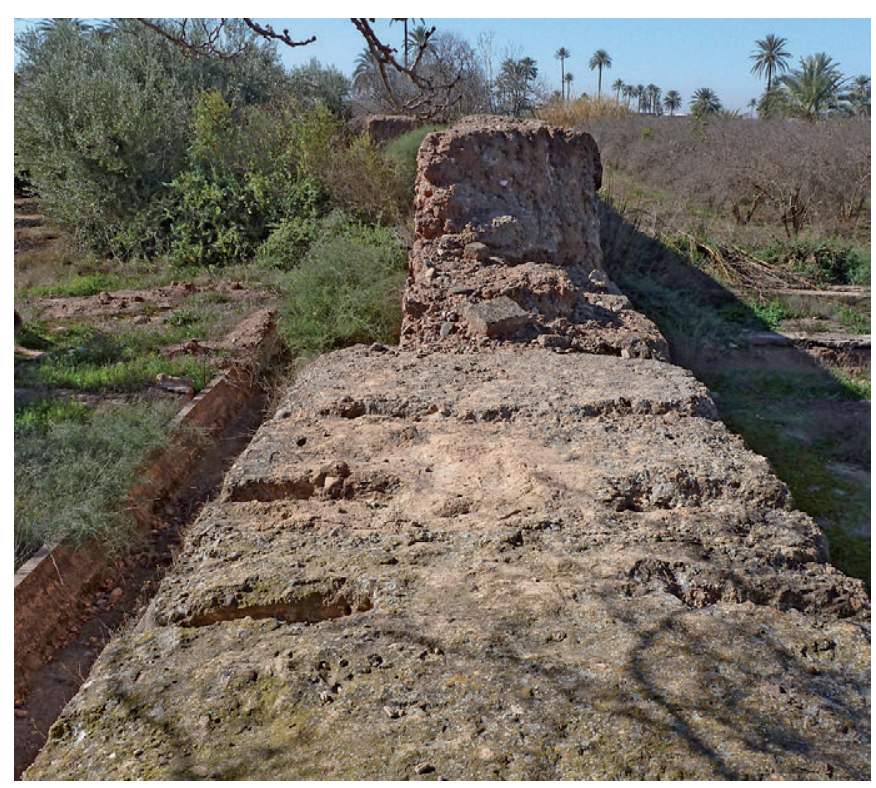

Fig. 7. Dar al-Hana. Muralla meridional, mitad occidental. Vista desde el este de dos tramos de diferente grosor. En primer término, una tapia hormigonada que probablemente pertenezca al proyecto almohade; al fondo, una tapia de menor grosor y menor carga de cal, probablemente perteneciente a la reconstrucción saadí

Contamos con dos testimonios europeos contemporáneos de Al-Fishtali y de Al-Maqqari que también la describen. Uno es el del cautivo portugués Antonio de Saldanha y otro el del francés Thomas Le Gendre. Ambos fueron testigos oculares.

El primero describe una "huerta cercada de muros" de más de una legua de circuito en la que había una alberca de 500 por 400 pasos que podía llenarse en dos días y vaciarse en otros dos, y que se aprovisionaba de agua mediante un gran canal llamado "Rio del Rey" (la acequia Tassoultant) que Al-Mansur "mando traer de los Montes Atlas" (Saldanha 1997: 81) ${ }^{17}$. Sorprendentemente no hace comentario alguno del gran palacio que había en la finca.

El segundo menciona la existencia de un jardín llamado la Pequeña Masarra (Dar al-Hana) desde el que se accedía a la gran finca que lo albergaba, la Masarra (Le Gendre 1911: 726-727). La suma de ambos recintos constituiría la gran finca heredera de la Buhayra almohade. Le Gendre especifica que el agua que la atraviesa termina llegando al Palacio del Badi', y afirma que los ciudadanos de Marrakech podían acceder a estos jardines, tradición que hoy día se mantiene. Al igual que De

\footnotetext{
Esta acequia es en realidad la construida por los almohades a mediados del siglo XII, cuyo uso recuperó Al-Mansur. La confusión de De Saldanha puede deberse también al hecho de que en esta época se efectuó la traída de aguas de la acequia El-Bachia, que confluía con las aguas de la Tassoultant al sur de Marrakech (véase apartado 6.1).
}

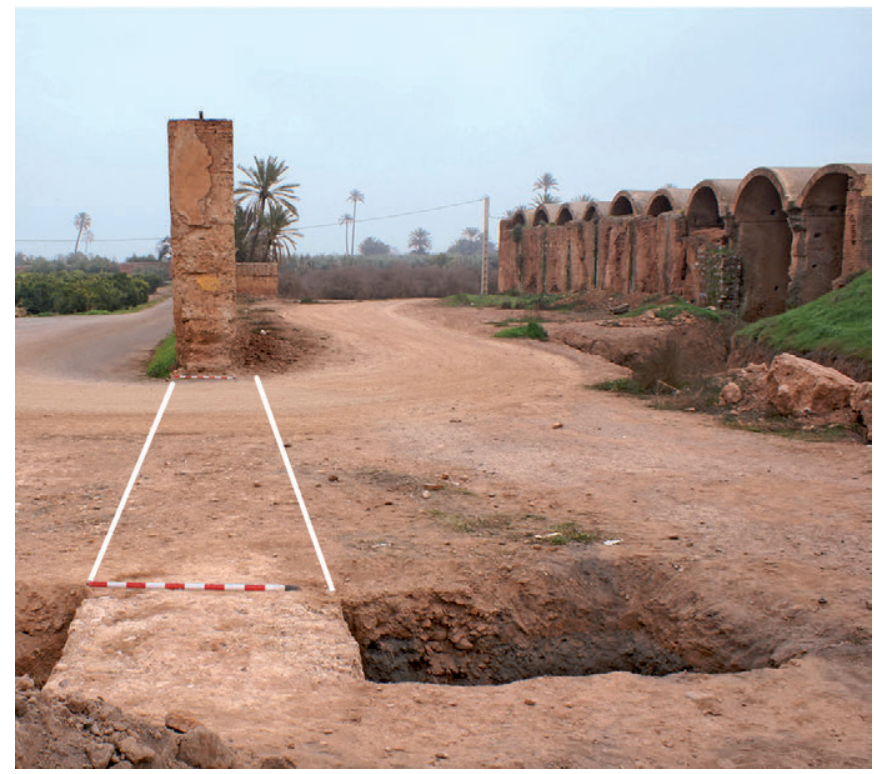

Fig. 8. Dar al-Hana. Muralla meridional, mitad oriental. Vista desde el oeste. La estructura inferior es más gruesa y pertenece probablemente al proyecto fundacional almohade. El alzado del fondo pertenecería a la reconstrucción saadí

Saldanha, no dice nada del gran palacio que mencionara Al-Fishtali.

En 1641, el holandés Adrien Matham realiza una vista panorámica de Marrakech para la que escribe un texto explicativo (Matham 1913: 635). La Masarra se hallaba según él "a una media hora de la ciudad". Afirma que hay 36.000 mil olivos, 15.000 limoneros y otros tantos naranjos y palmeras. Si damos credibilidad a las cifras que ofrece, bastante superiores a las registradas por la administración del Protectorado para la primera mitad del siglo XIX, deberíamos imaginar una finca de dimensiones similares a las del actual Agdal ${ }^{18}$.

\section{4. ÉPOCA ALAUÍ (1669-FI NALES S. XIX)}

Los alauíes toman Marrakech en 1669. El estado en el que se hallaba la Masarra saadí a poco de su advenimiento puede saberse gracias a dos testimonios de viajeros occidentales.

El primero es la relación que hace Antonio da Silva Pereira de su embajada a Marruecos en 1677. Afirma que tiene casi legua y media de largo y que está atravesada por un camino completamente limpio de piedras (Da Silva 1864: 107). Su descripción coincide en lo esencial con las de Le Gendre y Matham, hechas

\footnotetext{
18 En 1916 el número de olivos de la finca era de 29.227, el de naranjos 9.851 y el de granados y otros frutales 11.717; para 1940 las cifras han descendido ligeramente: 29.000, 9.800 y 10.000 respectivamente (El Faïz 1996: 30, 35).
} 
sesenta y cuarenta años antes, respectivamente. Al igual que ellos, no menciona la existencia de un palacio en la Masarra, aunque es agasajado en la alberca, donde se le ofrece una comida amenizada por una orquesta (nûba).

El segundo testimonio es de Germain Mouette, fechado en 1684. Según este cautivo francés la finca tenía un circuito de dos leguas y en ella había avenidas bordeadas de flores y cipreses, donde se podían ver "viveros llenos de peces", en una clara referencia a las albercas (Mouette 1924: 193-194). Destaca la disposición ordenada de la finca, algo que hará también, medio siglo después, Thomas Pellow, cautivo en Marruecos entre 1720 y 1736. A este último le llaman la atención el orden, la variedad y el buen estado de las plantaciones, o lo bien cuidados que estaban los árboles frutales, especialmente los naranjos (Pellow 1890: 193-194) ${ }^{19}$.

El nombramiento en 1746 de Muhammad Ibn 'AbdAllah, el futuro Muhammad III (1757-1790), como virrey (jalifa) de Marrakech, tras el juramento de obediencia prestado por sus habitantes a su padre el sultán 'AbdAllah (1728-1757), supuso un gran acontecimiento para la ciudad. Como virrey inició la reconstrucción de la kasba, cuyo estado era tan deplorable que a su llegada hubo de instalarse en tiendas en su jardín. Tras su acceso al trono en 1757 continuó estas obras y ejecutó otras muchas que llegaron a valerle el calificativo de bienhechor de Marrakech (Deverdun 1959: 479ss.). Desafortunadamente los cronistas nos informan de todo esto de manera desordenada e imprecisa, algo particularmente de lamentar porque los proyectos que llevó a cabo en la kasba y su entorno, incluido el Agdal, determinaron la evolución urbana de esta parte de la ciudad durante el siglo siguiente. La construcción de los mechuares al sur de la kasba, en sustitución del antiguo espacio abierto (Asarag) ${ }^{20}$ almohade y saadí situado intramuros, proyectó la ciudad palatina hacia el exterior de las murallas. No resulta casual que construyera, en los espacios del Agdal más próximos a los nuevos recintos protocolarios exteriores de la kasba, el núcleo original de la residencia de recreo de Dar al-Bayda y la huerta de Djenan Redouan.

Una vista de las murallas meridionales de la kasba recogida por Georg Höst, danés que residió en Marruecos entre 1760 y 1768 , permite saber hasta dónde habían avanzado los trabajos de construcción de los mechuares y

\footnotetext{
19 Morsy (1983) hizo una traducción al francés de la obra de Pellow, acompañada de una valiosa introducción.

20 Sobre la Asarag de la kasba en época almohade y saadí véase Deverdun (1959: 222-224 y 387-388). Entre los Seksawa, el asarag era "leur forum, siège des réunions et des danses”, según lo describió Berque (1978: 32).
}

de Djenan Redouan en esa década (Höst 1781: lám. VIII). En este grabado se representa, de izquierda a derecha, la huerta de Djenan Redouan, el Gran Mechuar, la muralla del Dar al-Majzén, la muralla de la Mellah y la huerta de Djenan al-Afiya (Fig. 9.A). En la década de 1760 no existían todavía los mechuares interior y exterior ni el barrio de Bab Ahmar, construcciones posteriores de este mismo sultán. El punto de vista del artista estuvo situado al sur del barrio de Bab Ahmar, en lo que actualmente es el sector Dakhlani del Agdal. Aunque desconocemos los detalles del proceso de creación de los mechuares (Deverdun 1959: 481, 497), la vista de Höst permite reconstruir en qué fechas tuvo lugar la primera fase de restauración alauí del Agdal, circunscrita a la construcción de Dar alBayda y de Djenan Redouan.

Sabemos que la antigua Masarra se salvó del designio destructor de Ismail gracias a las descripciones que hicieron varios viajeros occidentales. Las más interesantes son las hechas por los miembros de una embajada francesa de $1767^{21}$. El diario oficial redactado por el diplomático Louis Chénier menciona lacónicamente la existencia de "un viejo palacio" en el jardín donde acampó la comitiva (Chénier 1943: 4-5) Pero los testimonios más prolijos pertenecen a otros dos componentes de esa misma embajada.

El Duque Des Cars, entonces un joven oficial, narra que el lugar de acampada, situado a media legua de la ciudad, era la huerta de un "viejo palacio imperial arrasado". Estaba "cercada de muros, aunque con numerosas brechas". El palacio arruinado que contempla es el "gran edificio" que describiera Al-Fishtali más de siglo y medio antes, rodeado por el complejo amurallado de Dar al-Hana. Menciona también un curso de agua que atraviesa la finca de parte a parte y en ella encuentra limoneros, granados, albaricoqueros y melocotoneros. A pesar de que el palacio se hallaba en ruinas, la finca estaba lo suficientemente cuidada como para ser digna de albergar huéspedes ilustres, cuya satisfacción era cuestión de estado. Muchos años después, al redactar sus memorias, recordará haber visto desde el lugar de acampada "una cantidad considerable de pabellones construidos con elegancia, casi todos al borde de algún lago destinado a los paseos vespertinos del Emperador y de las Reinas, que venían a respirar el

\footnotetext{
21 La comitiva de la embajada procedía de Safi y se acercó a Marrakech por el noroeste. Una vez en las afueras bordeó las murallas occidentales de la medina y la kasba para acceder al Agdal a través de Bab Ighli, pasando por el Gran Méchouar. Allí fueron saludados con tres salvas de cañón. En la esquina sureste del Gran Mechuar existe todavía un edificio que era utilizado como almacén de guerra de las piezas de artillería del sultán.
} 


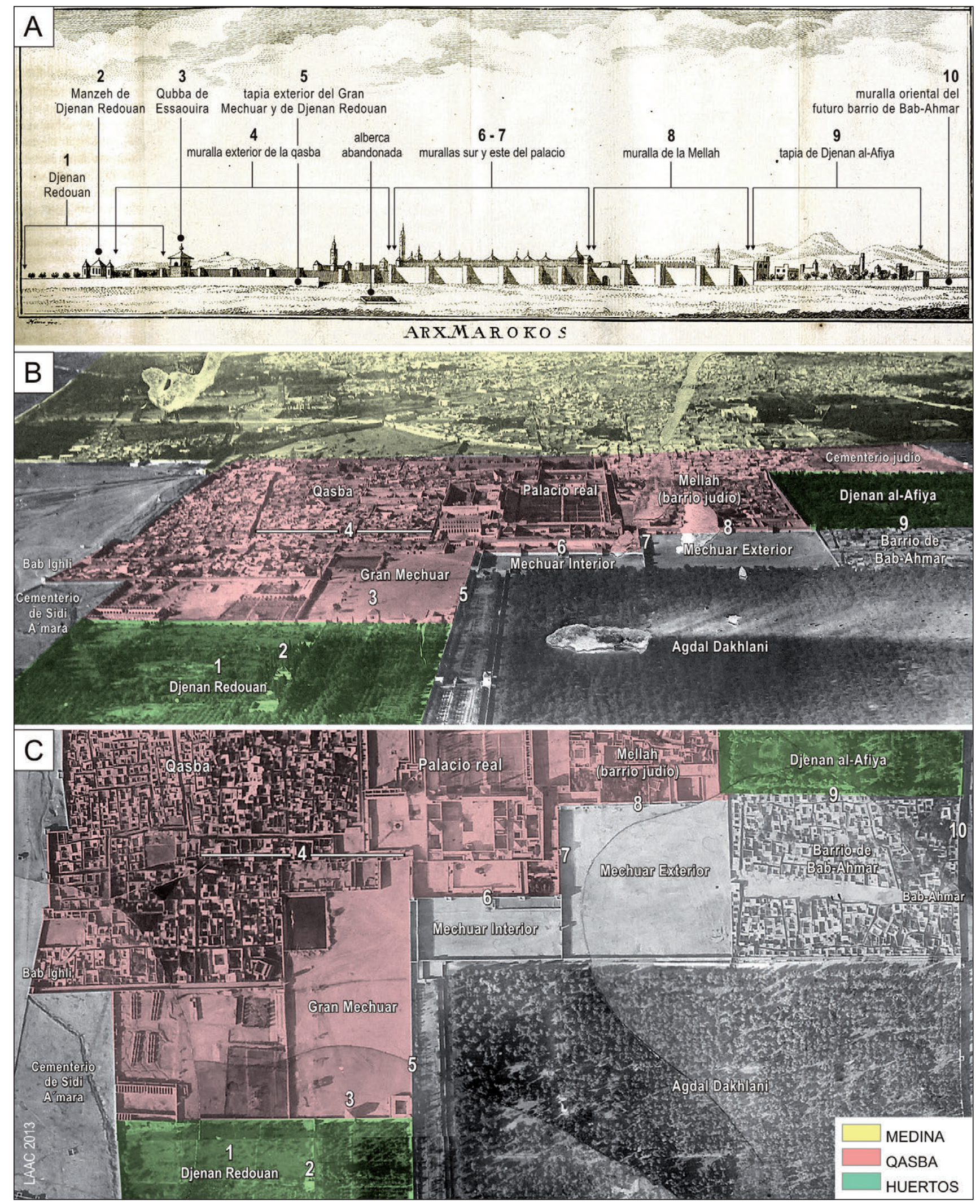

Fig. 9. La kasba y los mechuares hacia 1760. (A) Vista del frente sur de la kasba según un grabado Höst (1781). Ya se habían construido, de izquierda a derecha, Djenan Redouan (1), el Gran Mechuar (5), Djenan al-Afiya (9) y un primer palacio en Dar al-Bayda (situado al sur de Djenan Redouan, no visible en la imagen). Todas estas obras fueron promovidas por Muhammad III (1757-1790), que durante su reinado construirá también los mechuares interior y exterior y el barrio de Bab Ahmar. (B) Interpretación del grabado de Höst sobre una fotografía aérea de 1917. (C) Interpretación del grabado sobre una fotografía aérea vertical de la misma fecha 
fresco, a pasearse sobre el agua en góndolas" (Des Cars 1890: vol. I, 47).

El segundo testigo ocular es Bidé de Maurville, un cautivo liberado a raíz de las negociaciones realizadas por la embajada, que quedó impresionado por lo que vio:

\begin{abstract}
"las ruinas del palacio de uno de los antiguos reyes de este Imperio, que todavía dan claramente a entender hasta qué punto estaba infinitamente por encima de todos los edificios actuales de este país, y podía, creo yo, ir parejo con lo que hubo entonces de más bello en su género en toda esta parte" (Bidé de Maurville 1775: 345).
\end{abstract}

Esta última descripción, aunque carente de detalles, es relevante porque establece una comparación entre los palacios contemporáneos que vio el autor y el palacio saadí del Agdal, en la que resulta claramente favorecido este ultimo. Curiosamente, ni él ni el Duque Des Cars mencionan la gran alberca de Dar al-Hana, a pesar de que los restos del palacio se encontraban inmediatos a ella (como lo están hoy). Es probable que para entonces no contuviera agua, ya que sabemos de su restauración cincuenta años después.

Muhammad III construyó un primer palacio en Dar al-Bayda y el huerto de Djenan Redouan a mediados del siglo XVIII, pero serán los sultanes 'Abd al-Rahman (1822-1859) y Muhammad IV (1859-1873) los que restauren la gran finca del Agdal, que Muhammad extenderá hacia el sur creando el Agdal Barrani. Hassan I (1873-1894) continuará esta política haciendo diversos intentos por instalar actividades industriales de interés para el majzén.

Muhammad Ibn Ahmad Akansus (m. 1877), secretario de la cancillería e historiógrafo oficial de 'Abd alRahman y de Muhammad IV, escribió una obra laudatoria que permite conocer cómo se ejecutó este proyecto restaurador desde el punto de vista de su promotor, el majzén alauí (Akansus 1918: t. I, 9-10, 22-23). 'Abd al-Rahman recuperó primero el derecho de soberanía sobre la acequia Tassoultant, que traía el agua del rio Ourika desde época almohade. En tiempos de Muhammad III (m. 1790) los Mesfioua se habían apropiado de ella y Suleyman (m. 1822) se vio obligado a negociar con ellos concediéndoles el uso del agua a cambio de 1.000 meticales anuales ${ }^{22}$. Abd al-Rahman (m. 1859) “recuperó por la fuerza la acequia del Sultán” de manos

\footnotetext{
22 El metical (mitqal) equivalía a 10 onzas ('uqiya) o 10 dirhems de peso legal (un dírhem contiene 2,93 gramos de plata).
}

de los Mesfioua ${ }^{23}$. Para la restauración de la finca trajo campesinos expertos de otras zonas del país. Restauró la alberca de Dar al-Hana, llena de limos y ocupada por un poblado (douar), y reparó las demás albercas del Agdal. Las plantaciones "estaban expuestas a la sequía durante el verano"; hasta entonces habría sido prácticamente imposible regar durante el estiaje. Akansus no especifica sin embargo las fechas en que se ejecutaron las obras. Según el historiador Ahmad ibn Jalid al-Nasiri (m. 1897) los primeros trabajos de restauración del Agdal tuvieron lugar entre 1824 y 1834 (Fumey 1907: 119) ${ }^{24}$.

Aunque Akansus se detiene en la vinculación de la Gran Alberca (al-Birka al-Udmà) con el Pequeño Mar (al-Bahr al-Sagir) de los almohades, evocando los paseos en barca de los antiguos soberanos, no menciona que existiera allí ningún edificio residencial construido por 'Abd al-Rahman o Muhammad IV, algo que hubiera hecho sin lugar a dudas si tal cosa hubiera ocurrido. Es evidente que para los alauíes Dar al-Hana había dejado de tener interés como residencia, una vez que Muhammad III construyó Dar al-Bayda en la segunda mitad del siglo XVIII. A lo largo del siglo XIX se harán obras de ampliación y mejora en el nuevo palacio con el fin de cubrir todas las necesidades residenciales que los monarcas alauitas tenían en el Agdal. Djenan Redouan, obra también de Muhammad III a linde del Gran Mechuar, será el lugar donde en ocasiones señaladas los sultanes ofrezcan convites que duraban días a los altos dignatarios y jefes tribales (Fumey 1907: 264-265). En estas celebraciones el monarca se instalaba en la Qubba de Essaouira, abierta al norte y al sur, para observar los alardes que tenían lugar en el Gran Mechuar y disfrutar de la vista sobre el jardín. Los mechuares, por su parte, serán el escenario de recepciones multitudinarias y desfiles en los que participan miles de personas agrupadas según su rango y afiliación. En estas ocasiones, el público asistente tiene a sus espaldas los muros del Dar

\footnotetext{
23 La solución parece haber sido solamente temporal, a juzgar por una revuelta de los Mesfioua de 1859, no recogida por las crónicas oficiales. Fue desencadenada por la imposición del majzén, al menos desde 1852, de cerrar periódicamente, entre abril y septiembre, todas las acequias situadas en el rio Ourika por encima de la acequia estatal de Tassoultant, con objeto de aumentar el débito de esta última. Los incidentes terminaron con el arresto del líder de los Mesfioua y otros miembros de la tribu, que intentaron evadirse; la guardia mató a veinticinco de ellos e hirió a cuarenta y cinco. Las cabezas de los muertos fueron colgadas en la plaza de Jmaa al-Fna. El episodio fue analizado por Pascon (1977: 170-172) a partir de los archivos familiares de un caid de los Ourika.

${ }^{24}$ Al-Nasiri explica así su estimación de fechas: “Comme nous n'avons pas trouvé dans toute cette période rien qui nous permette d'établir les dates, nous avons rangé les faits dans l'ordre que nous ont inspiré la réflexion et l'examen" (Fumey 1907: 119).
} 


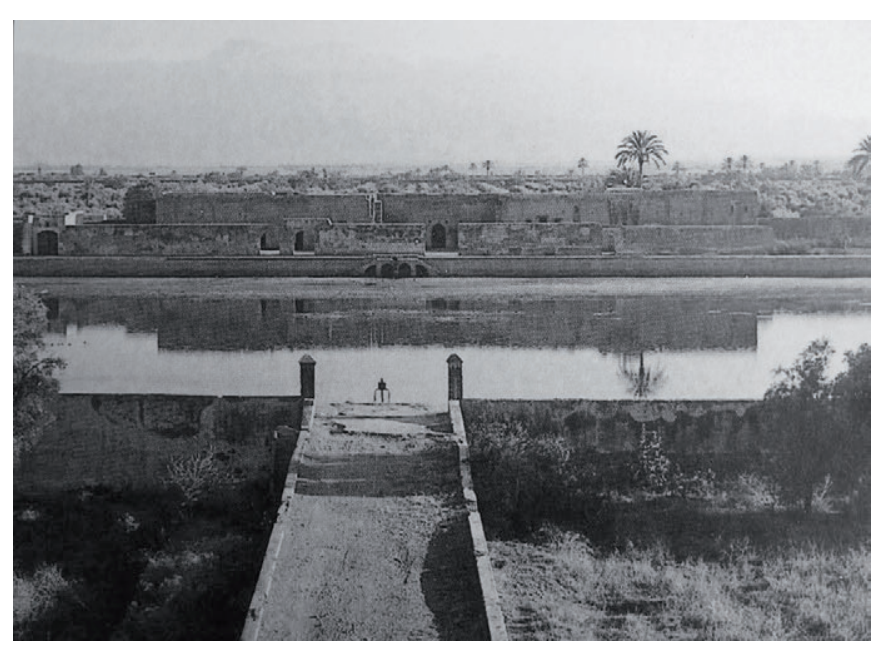

Fig. 10. Dar al-Hana. Vista del conjunto hacia el sur tomada desde la cubierta de Al-Manzeh. Fotografía: El Faïz (2000a: 21)

al-Majzén, residencia del sultán, y enfrente la muralla del Agdal.

Casi un siglo de esfuerzos por parte de tres sultanes había conseguido hacer del Agdal una plantación rentable de olivos y frutales, a la que se dotó de instalaciones agropecuarias e industriales. Aún así el edificio residencial de Dar al-Hana mostraba a principios del siglo XX un estado de abandono que indica la escasa atención que le depararon los alauíes (Figs. 10 y 11) ¿Qué percepción tenían los contemporáneos de estas obras? Más allá del innegable valor económico y propagandístico de la restauración de la finca y de la puesta en cultivo de nuevas parcelas, afloraba siempre una insatisfecha aspiración a la gloria. El testimonio de Al-Nasiri cuando compara el Agdal alauí con las grandes obras de los antiguos así lo demuestra:

\footnotetext{
"Los quioscos persas [al-mutanazahat al-kusruiya], las qubba/s de los césares [al-qubab al-qaysariya], los pabellones de los omeyas [al-maqa'id al marwaniya] que se elevan en el interior [del bustan o parque del Agdal] son tales que inmovilizan la mirada y desafían toda descripción: así son Dar al-Hana, Dar al-Bayda, Al-Salha, Al-Zahra, etc.” (AlNasiri 2001-2005: t. VIII, 20; Fumey 1907: 118).
}

Lo exagerado de la afirmación no hace sino poner en evidencia el carácter más bien modesto de los proyectos residenciales alauíes en el Agdal. El mismo Al-Nasiri afirmó, refiriéndose al sultán Muhammad IV, que los tiempos en los que le había tocado vivir no le favorecieron, porque "sus aspiraciones valían más que su época" (Al-Nasiri 2001-2005, t. VIII: 141; Fumey 1907: 274).

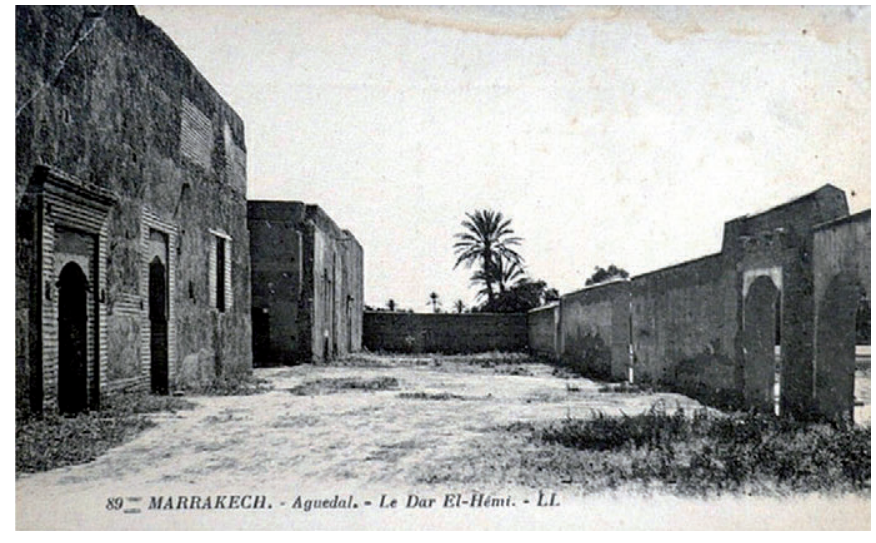

Fig. 11. Dar al-Hana. Edificio residencial. Tarjeta postal de principios del siglo XX que muestra una vista del patio que se extendía entre el cuerpo del edificio y la alberca. Se ve el estado en que se encontraban sus muros, que presentan pérdidas de la costra de la tapia, grietas y reparaciones. Todos los elementos visibles en la postal desaparecieron tras las obras de remodelación del edificio llevadas a cabo en la década de 1980

Las construcciones de nueva planta, la restauración de las antiguas y las ampliaciones de la finca son las obras que hicieron los alauíes para conformar el Agdal que ha llegado hasta nuestros días. Este Agdal es en lo esencial el que se cultiva hoy y el que aprecian sus escasos visitantes, pero representa apenas una cuarta parte de su historia, la más reciente.

\section{LA COMPARTI MENTACI ÓN DE LA FI NCA}

La configuración del espacio interior del Agdal muestra una ordenación rigurosamente geométrica organizada en torno a un eje director, orientado aproximadamente de norte a sur y coincidente con la pendiente del terreno (Fig. 12). Este eje queda marcado por el camino central que une Dar al-Hana con la kasba, y se prolonga hacia el sur entre las parcelas de Haj Lahcen y Belfkih. Su linealidad se resiente a la altura de Dar al-Bayda generando un pequeño quiebro en ángulo de $90^{\circ}$ que se explica más adelante. A partir de él se organiza una trama ortogonal que divide la superficie en parcelas, y éstas a su vez en cuadros de cultivo cuadrangulares cuyos límites vienen marcados por la red de caminos, en cuyos linderos se plantan hileras de olivos. Tan sólo en algunas parcelas del frente occidental esta red pierde ligeramente su ortogonalidad para adaptarse a la desviación de la muralla exterior, que no es paralela a la dirección del eje principal.

Las orientaciones definidas por esta trama no sólo comprometen la ordenación general de las parcelas, sino que son respetadas por los trazados de todos sus elementos. 
Tanto es así que la presencia de alguna construcción que no cumpla estos principios es considerada una anomalía necesitada de explicación.

Este carácter marcadamente ortogonal tiene sentido tanto desde el punto de vista técnico de la gestión de una explotación agrícola asentada en el llano como de la consecución de un proyecto urbanístico y arquitectónico coherente y bien acordado.

A pesar de las modificaciones sufridas a lo largo de su historia, la organización espacial general parece haber cambiado muy poco. Así, las trazas del proyecto fundacional almohade y del acometido durante la restauración saadí habrían quedado fosilizadas en el sector central de la finca, marcando la pauta que habrían de seguir las posteriores ampliaciones hacia el norte y hacia el sur (Fig. 5).

Desde la restauración alauí a mediados del siglo XIX la finca quedó dividida en once parcelas, cuya superficie variaba entre 13 y 74 ha, que necesitaban de una cierta gestión coordinada debido a que dependían de una red hidráulica compartida ${ }^{25}$. Cada una de ellas estaba protegida por tapias de tierra y separada de las otras por los caminos que les daban acceso (Fig. 38). La mayoría de estos cercados han desaparecido debido a la escasa durabilidad de este tipo de fábrica y a su inadecuación a la gestión contemporánea de la finca, en la que los animales de labor han sido sustituidos por maquinaria agrícola y transporte mecanizado. En cambio, la mayor parte de las antiguas puertas de acceso a las parcelas, a pesar de haber perdido su función, se han conservado debido a la mayor solidez de su fábrica y al hecho de haber recibido cierta atención ornamental. Se trata por lo general de pequeños y sencillos edículos de planta cuadrada o rectangular, con acceso directo y situados a eje con los principales caminos internos. La uniformidad en su diseño, técnicas y acabados indica que la restauración alauí afectó a todas las parcelas.

Se sabe por las fuentes que desde época almohade existió un gran eje norte-sur que llegaba a la puerta septentrional del recinto de Dar al-Hana, el actual pabellón de al-Manzeh construido en el siglo XIX ${ }^{26}$. Este trayecto ascendente lo era tanto en sentido estricto como figurado, ya que el camino tenía su culmen al llegar a Dar al-Hana. Con independencia de la capacidad que tiene este eje a la hora de estructurar toda la superficie de la finca, parece evidente que sirvió también para señalar cuál era el espacio neurálgico del Agdal, la parte que explicaba

\footnotetext{
25 Se excluye de este recuento la parcela del Agdal Barrani que no fue colonizada con los mismos criterios que el resto del Agdal.

26 Un estudio de este edificio como parte de una instalación industrial para la fabricación de pólvora puede verse en Navarro et al., en prensa).
}

y justificaba la totalidad. Dado que este eje compositivo también ha sido y es el camino principal de la finca, parece razonable pensar que como vía de circulación no podía finalizar allí, pues la puerta principal del Agdal se encontraba al otro lado de Dar al-Hana, en el extremo meridional del recinto. Planteada la hipótesis de cuál fue el tramo de arteria principal del Agdal hasta llegar al frente septentrional de Dar al-Hana, es necesario reflexionar sobre lo que sucedía con este camino una vez llegado a este punto. No hay duda que en el lugar que hoy ocupa el pabellón septentrional de Dar al-Hana hubo una puerta que permitía acceder al recinto palatino cuando la autoridad de turno venía de la kasba. Dado que este acceso tendría un carácter más privado, es necesario considerar que el camino debió de continuar hacia el sur bordeando Dar al-Hana hasta llegar a la puerta meridional del palacio. Este segundo trayecto debió de iniciarse en el lugar en el que hoy día hay un acceso del siglo XIX, al oeste del pabellón de al-Manzeh (Figs. 2.18 y 3.18). Desde allí el camino continuaría bordeando la muralla de Dar al Hana por sus frentes septentrional y occidental. Adosados a estos dos tramos de la muralla se instalaron en el siglo XIX dos molinos y el complejo industrial del polvorín (Figs. 2 y 3). Aunque estas actividades se introdujeron cuando Dar al-Hana dejó de funcionar como núcleo palatino, ello no impediría que allí hubiera un camino importante cuya finalidad fuera poner en contacto el eje norte-sur con la puerta meridional de la antigua finca, que debió de formar parte del edificio palatino cuyas ruinas se han localizado al sur del recinto de Dar al Hana.

El camino que bordea por el norte la parcela de AlGarsia y une la Puerta de la Musalla con la puerta del polvorín y con el pabellón septentrional de Dar al-Hana es a todas luces una abertura decimonónica. Se hizo para crear un acceso de nueva planta al complejo industrial del polvorín que evitara circulaciones indeseables por el interior de la finca (Navarro et al., en prensa).

A la hora de estudiar la organización interna del Agdal se ha creído oportuno dividirlo en tres sectores: septentrional, meridional y central. Esta subdivisión no es arbitraria; cada uno de ellos tiene una historia propia que puede explicar ciertas peculiaridades.

\subsection{Sector septentrional}

Este sector engloba las actuales parcelas de Sousia, Djenan Redouan y Dakhlani (Fig. 12). Coincide, en su mayor parte, con la ampliación hacia el norte de la antigua Masarra saadí, iniciada por Muhammad III (1757-1790) y culminada por 'Abd al-Rahman (1822-1859). La creación 
del complejo palatino de Dar al-Bayda ${ }^{27}$ es un elemento distorsionador que conviene individualizar. En el análisis se ha desgajado de Sousia con el fin de explicar su fundación en la parcela en la que probablemente tuvo su origen, Zahiria.

Sousia. Limita al norte con Djenan Redouan, y al sur con las parcelas de Zahra y Dar al-Bayda, con las que compartía tapias. Una tercera tapia la separa por el este del camino central del Agdal. Su frente oeste queda definido por la muralla exterior de la finca. Tiene una superficie de 11,5 ha. El sector noroccidental está actualmente plantado de olivos. Esta parcela se introduce por su sector suroccidental dentro del área que puede considerarse el Agdal fundacional, es decir se trata de un fragmento de parcela que en origen perteneció a Zahra.

Djenan Redouan. Creado a mediados del siglo XVIII, se ubica en el extremo noroccidental de la finca, protegido por tapias de tierra y comunicado mediante cinco puertas, una de ellas situada en la Qubba de Essaouira (Fig. 12). Sus límites son los siguientes: al norte, el Gran Mechuar; al este, el camino entre tapias de Dar al-Bayda; al sur, la parcela de Sousia y al oeste la muralla exterior de la finca. Todo el espacio interior sufrió una remodelación íntegra a finales del siglo XX para construir un campo de golf. Albergaba dos albercas, de las que sólo se conserva en uso la meridional, desfigurada por el campo de golf, así como un pequeño complejo residencial formado por dos pabellones de recreo articulados a través de un patio. La Qubba de Essaouira se sitúa en el muro septentrional de la parcela y se proyecta sobre el Gran Mechuar, abriéndose a ambos lados (Fig. 9). La parcela estuvo plantada de cítricos, que convivirían con jardines de especies ornamentales en las proximidades de los pabellones.

Dakhlani. Esta parcela se ubica en el extremo nororiental del Agdal. Fue plantada por 'Abd al-Rahman hacia $1830 \mathrm{y}$ desde entonces se ha venido destinando al cultivo exclusivo del olivar tal y como sucede en toda la mitad oriental de la finca. Tiene una superficie aproximada de 65 ha. Limita al norte con los mechuares interior y exterior y con el barrio de Bab Ahmar (Figs. 2 y 12), al oeste y al sur con las tapias del camino central del Agdal y de la parcela contigua de Belhaj, respectivamente, y al este por la muralla exterior del Agdal. Contó con cuatro accesos en su perímetro. En la zona septentrional existe

27 La primera noticia de trabajos en el palacio en esta zona data del reinado de Muhammad III, a mediados del siglo XVIII. Fue ampliado por Hassan I en el último cuarto del siglo XIX. un pequeño pabellón de recreo, rodeado por una zona ajardinada con alberquillas.

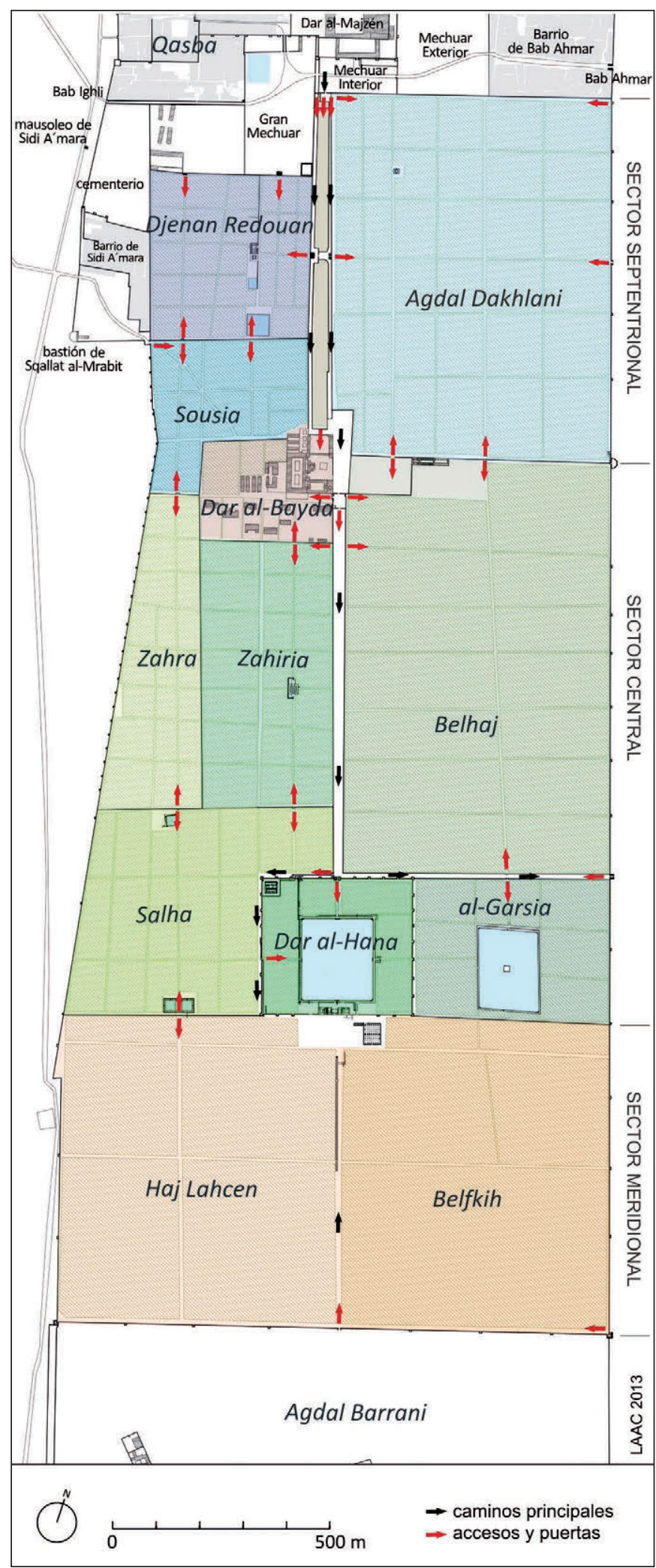

Figura 12: Agdal. Planta general con indicación de la parcelación y las circulaciones interiores a comienzos del siglo $\mathrm{XX}$ 


\subsection{Sector meridional}

Este sector engloba las actuales parcelas de Haj Lahcen y Belfkih, situadas en el extremo meridional de la finca. Cada una ocupa un área aproximada de 53,5 ha destinadas al cultivo de olivar. Son las únicas parcelas que no reciben aguas de jattara/s, lo que es un indicio más de que nunca formaron parte de las zonas regadas del Agdal fundacional; su puesta en funcionamiento como espacio agrícola está estrechamente relacionada con la recuperación alauí de la acequia Tassoultant (1824-1834).

Su similitud permite describirlas conjuntamente. Limitan por el norte con las parcelas de Salha, Dar alHana y Al-Garsia. Sus frentes este, sur y oeste quedan recorridos por la muralla exterior del actual Agdal. Están separadas entre sí por el camino que enlaza Dar al-Hana con la puerta Bab al-Nasr, que se abre en el frente sur de la muralla. Tanto ésta como la puerta de la esquina suroriental, Bab al-'Abid, deben considerarse accesos a la finca, no a estas parcelas en particular (Figs. 2.36 y 2.37 ).

Las dos parcelas se organizan internamente de la misma manera, con unos ejes orientados de este a oeste que generan tres bandas de anchura desigual que decrecen de sur a norte. Estas irregularidades resultan extrañas en un espacio de nueva colonización, lo que induce a pensar que existieron restos de una organización anterior lo suficientemente importantes como para condicionar el nuevo diseño.

Entre las dos bandas mayores hay un camino importante en el que se han localizado los restos de una estructura rectangular, bien visible en la fotografía aérea de 1917. Estaba situada dentro de la parcela de Haj Lahcen, en las inmediaciones del camino principal que la separa de Belfkih (Fig. 2.42). En la prospección de 2012 no se pudo localizar, lo que impide hacer una propuesta de identificación o averiguar qué relación pudo tener con el cierre meridional del palacio.

La banda más septentrional, inmediata a las parcelas Salha y Al-Garsia, es la más pequeña y tiene un ancho aproximado de $75 \mathrm{~m}$; sus cuadros de cultivo presentan una forma muy alargada este-oeste y una superficie media de 1,8 ha, sensiblemente menor a todas las demás de este sector. En la parte central, en las inmediaciones del edificio residencial de Dar al-Hana, se ubica el gran edificio de caballerizas (Figs. 2.32, 19 y 27), así como una importante zona arqueológica de aproximadamente 1 ha de superficie (Fig. 6). Estas singularidades y su disposición ocupando todo el frente sur de lo que fue el Agdal fundacional hace pensar que su configuración actual es deudora del gran complejo constructivo que hubo en torno a las ruinas del palacio de Dar al-Hana.

\subsection{El sector central}

El sector central de la finca engloba las actuales parcelas de Al-Garsia, Belhaj, Zahra, Zahiria, Salha y Dar al-Hana (Figs. 2, 3 y 12). Se corresponde, aproximadamente, con la superficie ocupada por el Agdal almohade y saadí (Fig. 5). Es muy probable que, en gran medida, tanto su organización parcelaria como su especialización productiva, en función de la mayor o menor necesidad de riego de sus cultivos, sean realidades cuyo origen se remonte al Agdal fundacional o, como mínimo, a la restauración saadí. Por este motivo conviene observar detenidamente los criterios que se han seguido en la organización parcelaria y en la especialización de sus cultivos poniendo todo ello en relación con la red hidráulica. La fotografía aérea de 1917 puede ser muy útil para este fin, dado que se trata de la imagen más antigua que tenemos de la totalidad de la finca. Un dato que se obtiene al observarla es que no ha habido cambios significativos desde entonces. Otro es la clara diferencia que hay entre su mitad oriental y la occidental: en la primera hay tres parcelas de menor tamaño dedicadas al cultivo de frutales (Fig. 13), en la segunda hay dos, destinadas a olivar. En medio de estas dos realidades se situaban los jardines palatinos de Dar al-Hana, cercados por su propia muralla (Fig. 14). A partir de esta reflexión se puede argumentar que la restauración alaui acometida por 'Abd al-Rahman (1822-1857) hacia 1830 fue respetuosa con la mayor parte de los elementos esenciales de la organización espacial de la finca anterior.

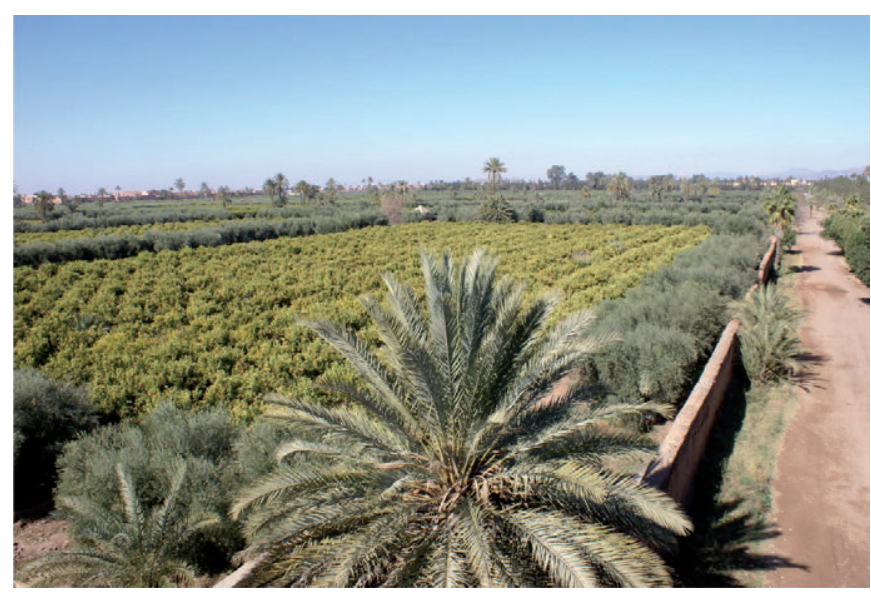

Fig. 13. Agdal. Vista del camino central, hacia el norte. A la izquierda, las parcelas de Salha y Zahiría y la tapia de tierra que las delimita por el este. Puede observarse la organización en grandes cuadros de cultivo delimitados por hileras de olivos que sirven de cortavientos 


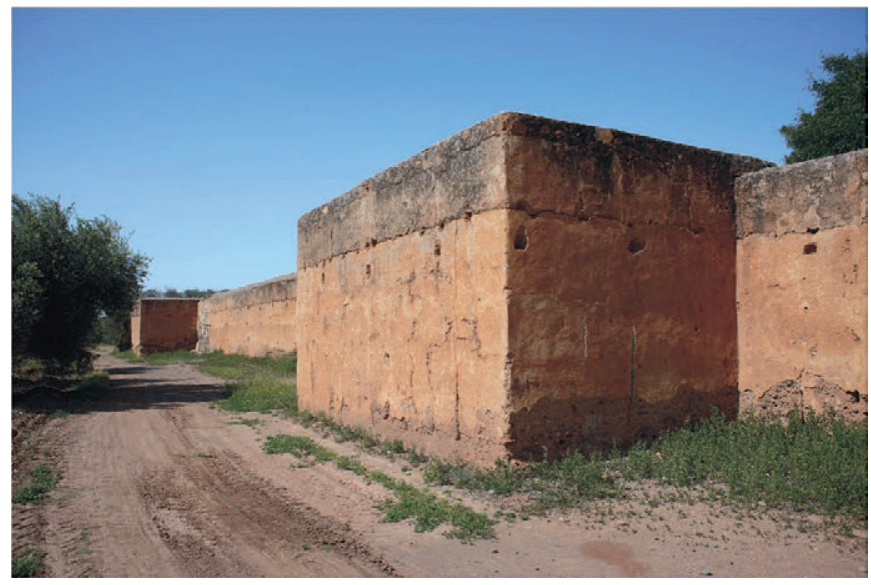

Fig. 14. Dar al-Hana. Vista del frente oriental de la muralla

Al-Garsia. Alberga en su interior el albercón del mismo nombre. Con anterioridad a su construcción en el siglo XIX es muy posible que existiera allí una alberca más pequeña, tal y como sucede en la parcela opuesta de Salha. Queda delimitada al oeste por el recinto amurallado de Dar al-Hana y al este por el frente oriental de la muralla exterior. Al norte y al sur está cerrada por tapias de tierra. Cuenta con una puerta de acceso centrada en su frente septentrional. Tiene una superficie aproximada de 18 ha dedicada al olivar. Este cultivo puede observarse ya en la fotografía aérea de 1917, aunque en ese momento se detecta una distribución irregular de los árboles, dejando grandes zonas vacías que más tarde han vuelto a replantarse. Al comparar esta parcela con Salha, situada al otro lado de Dar al-Hana se constata la notable asimetría que hay entre ellas, lo que resulta extraño en un diseño regular y simétrico como el que se observa en todos los elementos antiguos identificados en el Agdal. La configuración actual de Al-Garsia es fruto de las reformas del siglo XIX, y su límite norte, tal como lo conocemos hoy, se diseñó cuando fue necesario crear un acceso propio para el complejo del polvorín, la Puerta de la Musalla. En su origen la parcela debió de ser igual que la de Salha.

Belhaj. Es la mayor parcela del Agdal, con una superficie de 74 ha. Queda delimitada al este por la muralla exterior de la finca. Los frentes meridional y occidental contaron con tapias de tierra, hoy desaparecidas, que la aislaban de los dos caminos más importantes del Agdal: el central que discurre de norte a sur y el que une la puerta de Dar al Hana con la de la Musalla. Contaba con una tercera tapia en el norte, que compartía con la parcela contigua de Dakhlani. Tuvo cuatro accesos. Se ha destinado tradicionalmente a olivar, cultivo atestiguado ya en las fotografías históricas.
En su extremo septentrional hay una antigua almazara que se describe más abajo y que en la fotografía de 1917 aparece en ruinas (Fig. 15). Hay motivos para pensar que se trata de una obra de época saadí. Su emplazamiento en el límite septentrional del Agdal fundacional responde a toda una lógica del diseño en el que se pretende evitar la entrada al interior de la finca de todos aquellos que no trabajan en ella.

Un potente muro de hormigón de cal de una veintena de metros de longitud y $1,80 \mathrm{~m}$ de grosor se pudo localizar, visible en superficie, en el ángulo suroeste de la parcela (Fig. 2.14). Su presencia ha alterado la regular organización interna de sus huertos, generando en esta zona un ancho de huerto mayor que viene a coincidir con el camino que separa las parcelas de Salha y Zahiria. La estructura en cuestión está atravesada por bovedillas (qadus) destinadas a permitir el paso del agua de una acequia procedente de la alberca de Dar al-Hana ${ }^{28}$. Aunque no se puede descartar que se trate de un muro de contención destinado a salvar el desnivel existente, con una cota más baja en el lado norte de dicha estructura, es más probable que se trate del cierre meridional de una antigua alberca, que al quedar abandonada fue parcialmente demolida y colmatada ${ }^{29}$. La identificación

\footnotetext{
28 Éste es el sistema empleado en varios puntos de las murallas del Agdal para hacer entrar o salir el agua del recinto.

29 En la fotografía de 1917 se observa una calva en el lugar, que podría explicarse por la proximidad del pavimento del vaso en el subsuelo.
}

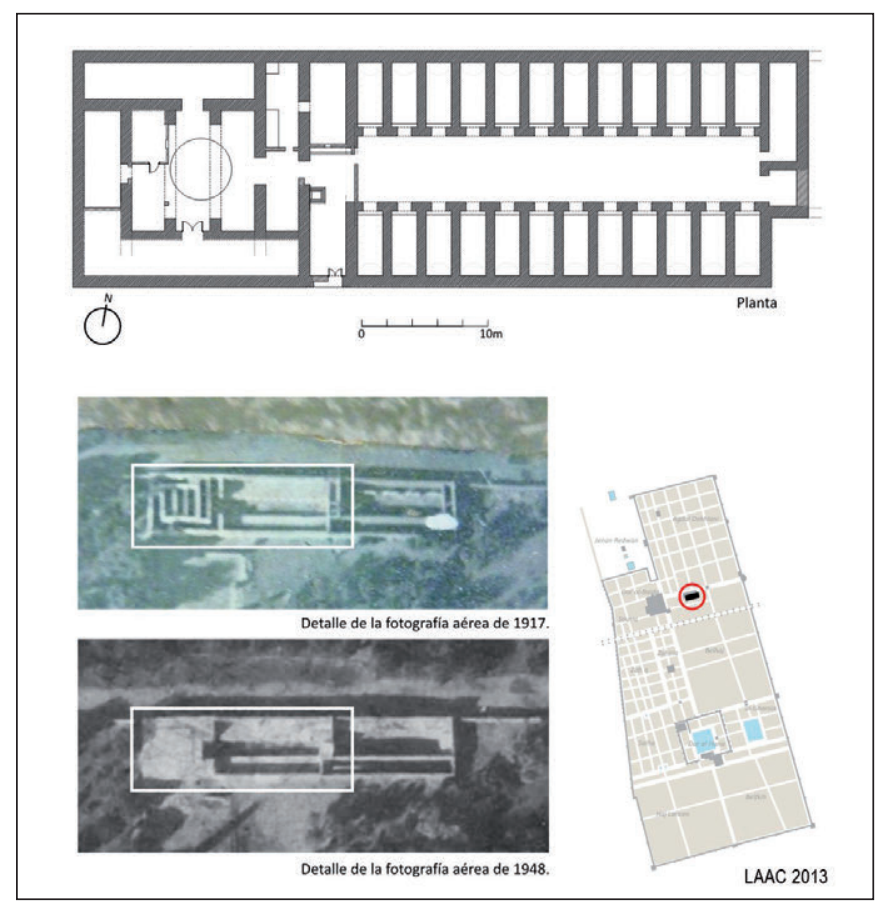

Fig. 15. Agdal. Sector Belhaj. Almazara 
de estos restos como pertenecientes a una alberca obliga a reflexionar sobre su integración dentro de la red hidráulica del Agdal. Dado que estas albercas menores estuvieron alimentadas por jattara/s, difícilmente podría llegarle una de ellas si se interpone, como ocurre, el recinto de Dar al-Hana en su trayectoria natural. La existencia de este obstáculo insalvable permite sugerir que los restos de la alberca pertenecieron a una almunia anterior al proyecto almohade que conocemos. De lo que existen menos dudas es que dicho muro señala una división parcelaria desaparecida, la que hubo entre la primitiva parcela de Al-Garsia y la de Belhaj antes de que en el siglo XIX se abriera el camino de acceso al complejo industrial, que iba desde la Puerta de la Musalla hasta el pabellón norte de Dar al-Hana (Fig. 12). Dicho de otro modo, el límite meridional de la parcela Belhaj debió de estar originalmente a la misma altura que están hoy los de Zahiria y Zahra.

Zahra y Zahiria. Tienen una organización interior sensiblemente diferente a la del resto. Están subdivididas en cuadros de cultivo de menor superficie que, a juzgar por las fotografías históricas, se dedicaban a cultivos de hortalizas, frutales, cereales y leguminosas, limitando la presencia del olivo a las alineaciones que definían los linderos. Hoy se encuentran plantadas de mandarinos. En origen debieron de formar una sola parcela pero sus límites septentrionales fueron alterados por la implantación de Dar al-Bayda en el siglo XVIII.

Zahra tenía a comienzos del siglo XX una superficie de 15,7 ha pero la construcción de la carretera que la atraviesa segregó 1,7 ha de su extremo septentrional, que hoy se percibe formando parte de la vecina Sousia (Fig. 12). Queda delimitada al oeste por la muralla del Agdal. Los frentes norte, este y sur estuvieron cerrados por tapias que no se han conservado. Contó con dos puertas enfrentadas en los lados norte y sur.

Zahiria tiene una superficie 22,6 ha. Estaba cerrada en sus cuatro frentes por una tapia que la separaba de Dar al-Bayda, del camino central del Agdal y de las parcelas vecinas de Zahra y Salha. Su organización interior está condicionada por la presencia de una acequia que la recorre de sur a norte y la subdivide en dos mitades. La oriental se abre al exterior mediante dos puertas situadas en sus extremos norte y sur; ambos accesos estaban unidos por un camino que conducía a un pabellón de recreo rodeado de un jardín rehundido, la Dar al-Nzaha o Pabellón del Picnic, conocido también como "Pabellón de los Periodistas" (Fig. 16).

La actual conformación de Zahiria es el resultado de una importante mutilación de la parcela sufrida en su

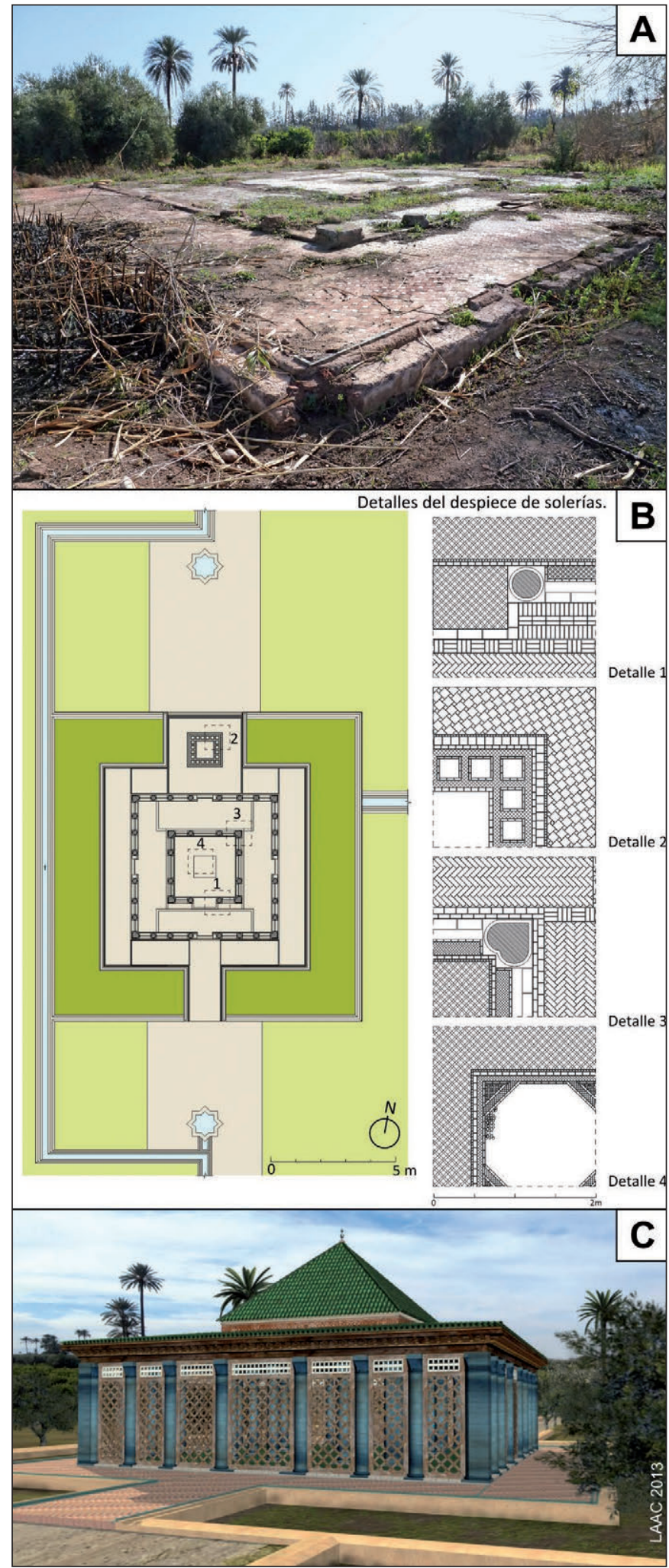

Fig. 16. Agdal. Sector Zahiria. Dar al-Nzaha o Pabellón del Picnic. (A) Fotografía del estado actual. (B). Levantamiento de la planta con detalle de sus pavimentos. (C) Reconstrucción hipotética. La información obtenida en la toma de datos en campo ha sido completada con el análisis de las fotografías históricas, que nos permiten conocer el aspecto del pabellón antes de su destrucción por un incendio en los años 30 del siglo XX 
frente septentrional en el momento en el que se funda Dar al-Bayda dentro del recinto del primitivo Agdal en el siglo XVIII. Este antiguo límite septentrional de la finca estaría en la actual línea de división parcelaria que hay entre Belhaj y Dakhlani, quedando ésta última parcela fuera de ese perímetro. La expansión de Dar alBayda hacia el norte pudo llevarse a cabo demoliendo el primitivo frente de muralla septentrional, creando así los huertos de Sousia, y entre éstos y el Gran Mechuar se fundó Djenan Redouan. La implantación de Dar alBayda explica también que la actual parcela de Zahra no llegue más al norte, hasta el límite histórico del Agdal fundacional (Fig. 12).

Salha. Tiene una superficie de 26,8 ha. Queda confinada al oeste por la muralla del Agdal y al este por la de Dar al-Hana y el camino central del Agdal, del que la separa una tapia (Fig. 13). Otras dos tapias la limitan por el sur y el norte. Su acceso desde el camino central se hacía a través de una puerta adosada al pabellón de al-Manzeh de Dar al-Hana (Figs. 2.18 y 3.18). Una segunda la comunicaba con Zahra y una tercera se abría en la tapia meridional, ambas sobre el camino que era el eje principal de la parcela.

En el extremo meridional y flanqueando el camino que se acaba de mencionar se construyeron las dos albercas Chouirjat, en las que se hizo un esfuerzo ornamental al rodearlas de parterres y canalillos (Fig. 2.28). Son probablemente una innovación de época alauí, contemporánea de la otra reforma que fue la construcción de la gran alberca de Al-Garsia. Los gestores de la restauración, al ampliar las zonas de cultivo, se vieron obligados a aumentar la capacidad de almacenaje de agua de los reservorios, para lo que fue necesario sustituir las pequeñas albercas pre-existentes por una más grande en Al-Garsia y por dos gemelas en Salha.

Otra alberca de Salha es Batata, que se sitúa en el extremo opuesto a las Chouirjat, al borde del mismo camino (Fig. 2.16). Aunque pertenece a Salha por estar dentro de su perímetro, funcionalmente forma parte de Zahra pues fue diseñada para regar las tierras que hay más abajo.

Su compartimentación interior es muy similar a la de Djenan Redouan, Sousia, Zahra y Zahiria, con una subdivisión en cuadros relativamente pequeños, dedicados al cultivo de frutales, que en el pasado se combinaban con hortalizas y cereales.

Del análisis de la subdivisión parcelaria de la finca se puede concluir que existen dos tipos de parcelas diferenciables en función del tamaño de sus bancales y del tipo de cultivo. Las situadas en la zona occidental, con la excepción de Haj Lahcen, forman una banda homogénea caracterizada por una subdivisión en bancales de menor superficie, donde se concentraban los cultivos con una elevada demanda de agua, como se discute en el apartado siguiente. Por eso se las dotó de su propio abastecimiento mediante dos jattara/s reguladas por las albercas Chouirjat y Batata (Fig. 17, jattara/s 6 y 7). Las parcelas orientales y meridionales, dedicadas al olivar, con sus grandes cuadros de cultivo, se riegan con la acequia Tassoultant, bien directamente, bien a través de las albercas de Dar al-Hana y Al-Garsia.

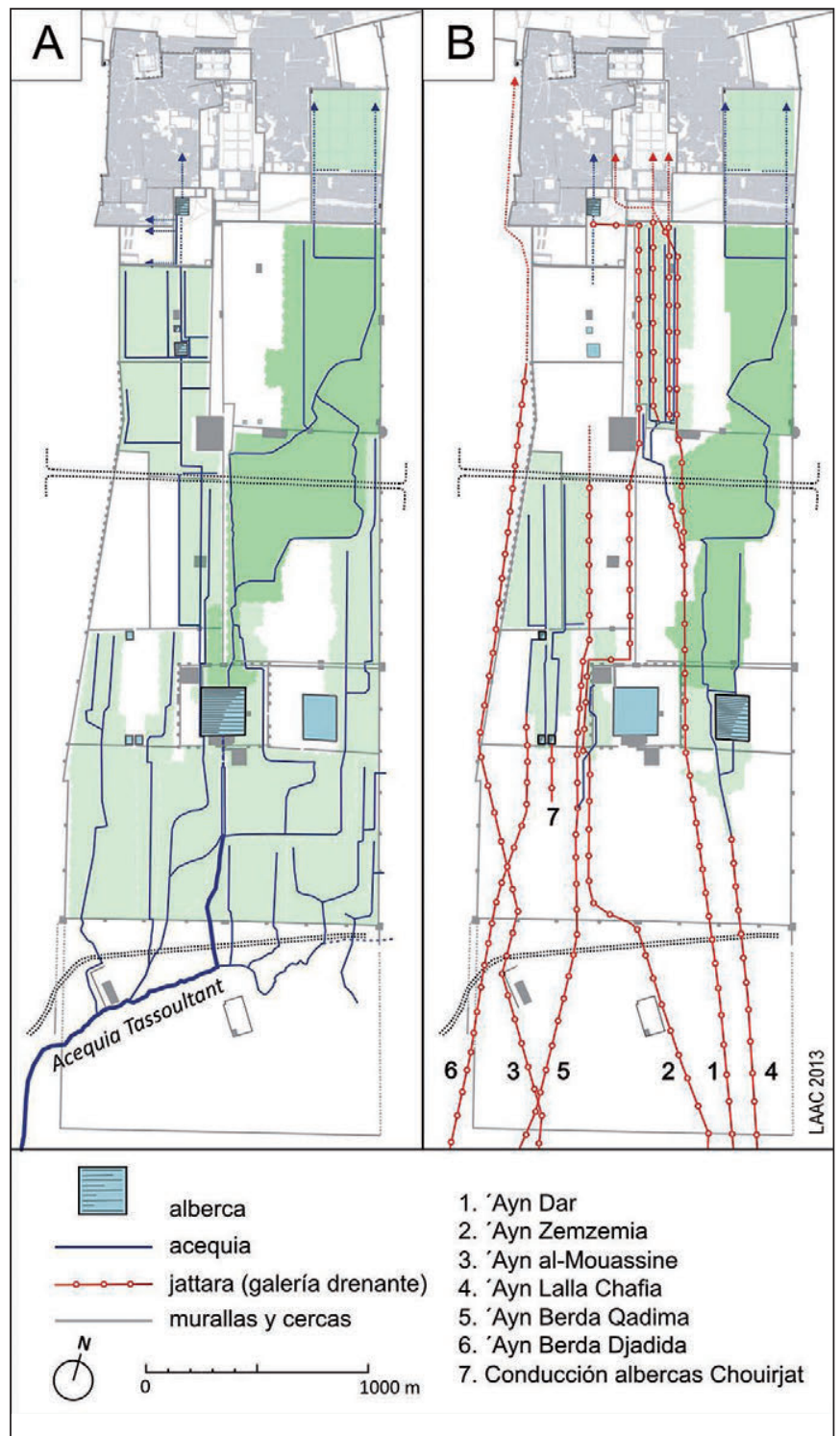

Figura 17: Agdal. Red hidraúlica. (A) Recorrido de la acequia Tassoultant. (B) Recorridos de las siete jattara/s del Agdal. 'Ayn Dar (1) y 'Ayn Zemzemia (2) lo atravesaban camino de la kasba. 'Ayn al-Mouassine (3) quedó parcialmente dentro del perímetro amurallado tras la ampliación del Agdal hacia el sur. Las demás jattara/s regaban sectores de la finca. Tramadas en verde intenso, las áreas regadas exclusivamente con las albercas de Dar al-Hana y Al-Garsia 


\section{LA HI DRÁULI CA DEL AGDAL}

La severidad del medio natural del Haouz hace que tanto el desarrollo de la agricultura como el de la vida urbana estén estrechamente ligados a la obtención y movilización de recursos hídricos. Desde el momento de la fundación de Marrakech, su supervivencia dependió de la implementación de sistemas eficientes de captación, transporte y almacenamiento de agua.

Las jattara/s eran la fuente de agua potable de la medina. Tres de ellas pertenecían al majzén y estaban destinadas al servicio del palacio real y la kasba ('Ayn Dar, 'Ayn Zemzemia y 'Ayn Sidi Mimoun). Otras tres eran bienes habices ${ }^{30}$ ('Ayn Mouassine, 'Ayn Qubba y 'Ayn Baraka). Éstas últimas proporcionaban 4/5 partes del volumen total de agua que entraba en la ciudad y aprovisionaban 70 mezquitas, 61 salas de abluciones, 86 fuentes públicas, 23 hammam/s, 75 casas y 10 jardines (Luccioni 1982: 108).

La situación no cambió sustancialmente hasta la llegada de los sistemas de bombeo y distribución modernos. Hacia 1970 había censadas 567 jattara/s de las que 500 aún funcionaban ${ }^{31}$. Tenían un débito total de $5.059 \mathrm{l} / \mathrm{s}$ (poco más de $5 \mathrm{~m}^{3} / \mathrm{s}$ ) y atendían el $14 \%$ de la superficie regada del Haouz: 20.520 hectáreas frente a las 75.586 que se regaban con acequias. Otro $15 \%$ de la superficie se regaba mediante sistemas mixtos de acequias y jattara/s (El Faïz y Ruf 2006, 2010). Las jattara/s drenaban más del $60 \%$ del agua acumulada en la capa freática. Las 37 más importantes del Haouz tenían entre 1940 y 1970 un débito conjunto de 1525 1/s. En 1986, 16 de ellas estaban secas y otras 5 estaban obstruidas o se habían hundido. El débito de las 16 que seguían en funcionamiento era solamente de $295 \mathrm{l} / \mathrm{s}$, poco más del $19 \%$ del débito que proporcionaban las jattara/s unos años antes (Benbiba 1987: 42). La explicación de esta disminución en los débitos radica por una parte en la disolución de las solidaridades entre linajes, lo que dificulta las operaciones de mantenimiento, y por otra en la bajada del nivel piezométrico de la capa freática del Haouz, que descendió un 50\% entre 1975 y 1985 (Benbiba 1987: 41). En la actualidad las jattara/s que todavía subsisten se hallan mayoritariamente en el medio rural, como el caso del área de Tamesloht.

El aprovisionamiento de agua del Agdal se realizaba mediante una combinación de aportes, tanto subterráneos como superficiales, regulados por balsas entre

\footnotetext{
30 Habus, sing. habis, donación religiosa inalienable.

31 Según Benbiba (1987: 41) en 1970 existían 650 jattara/s, 150 de ellas abandonadas.
}

las que destaca la gran alberca de Dar al-Hana. Este sistema tuvo su origen en época almohade y sobrevivió hasta una época relativamente reciente. A pesar de la gran importancia que tuvieron las jattara/s como parte del sistema de abastecimiento del Agdal, éstas quedaron obsoletas a partir del último cuarto del siglo XX una vez que se generalizó el uso de procedimientos modernos de captación y transporte, especialmente los grandes proyectos hidráulicos de derivación de aguas superficiales.

El Agdal no podía sobrevivir al estiaje si, además del aporte continuo pero relativamente débil de las jattara/s, no disponía también de un suministro adicional que sólo se podía conseguir recurriendo a una derivación del río de Aghmat, $40 \mathrm{~km}$ al sureste de Marrakech, en tierras de los Ourika. Las áreas de donde se podía derivar el agua estaban ocupadas desde antiguo por comunidades que regaban según un orden estricto, sancionado por la costumbre y el derecho ('urf). Los regantes instalados en la parte alta del cauce tienen prioridad respecto a los situados en la parte baja. No había sitio para extraños. La injerencia del majzén en este reparto local de derechos era vista siempre como una confiscación, una ruptura del orden social campesino, cuyas implicaciones políticas marcaron la historia del Haouz (Pascon 1970: 5-7; Pascon 1977: 95-98; Ennaji y Herzenni 1987; Madani 2005 y 2012: 109-114).

La puesta en funcionamiento del Canal de Rocade a mediados de la década de 1980 supuso un cambio radical en el sistema de aprovisionamiento y distribución de agua en el Agdal. Este canal es una conducción de $120 \mathrm{~km}$ procedente de las presas de Sidi Driss y Hassan I, al Este del Haouz. Para llevar sus aguas a la finca se construyó una red de canalizaciones que penetran en el Agdal por su esquina sureste y salvan los obstáculos en su camino mediante sifones. Esta traída de aguas asegura el aprovisionamiento durante el estiaje y se regula mediante las dos grandes albercas del Agdal. Supuso el abandono definitivo del sistema de jattara/s pero convive con las traídas tradicionales de aguas superficiales. Se describe a continuación el sistema tradicional de abastecimiento de agua del Agdal, diferenciando las aguas superficiales de las subterráneas.

\subsection{Las acequias majzén}

A mediados del siglo XII el majzén almohade construyó la acequia Tassoultant captando sus aguas del Ourika por encima de la localidad de Aghmat, a $40 \mathrm{~km}$ al sureste de Marrakech. Esta captación vino a ocupar el séptimo puesto en la secuencia de ocho acequias importantes que se derivaban del rio en tierras del grupo tribal de los 
Ourika $^{32}$. Dio su nombre a la llanura de Tasltante, al sur de la ciudad, hasta la que llevaba el agua.

En época saadí se realizó una segunda captación lejana de aguas, la acequia El-Bachia, derivada del rio Rhirhaia. Su excavación se hizo con un doble objetivo: por una parte permitir el riego de un área cultivable situada en la margen derecha del Rhirhaia y por otra aumentar el caudal de la acequia Tassoultant, con la que confluía.

Tras recorrer la llanura y recibir el aporte suplementario de El-Bachia, la Tassoultant atravesaba el Agdal Barrani en dirección suroeste-noreste y penetraba en el Agdal propiamente dicho por el sur, a la izquierda de Bab al-Nasr (Fig. 17A). Esta conducción alimentaba la alberca de Dar al-Hana, a partir de la cual se regaba el sector del mismo nombre y una parte sustancial de los sectores Belhaj y Agdal Dakhlani. Unos $450 \mathrm{~m}$ antes de llegar a esta

32 El recorrido de la acequia Tassoultant fue modificado en época colonial para hacerla llegar más directamente a la llanura de Tasltante y alejarla en lo posible de las acequias tribales. Esta acequia se conoce con el nombre de Tassoultant Majzén y también con el de Rumia, que delata su origen (rumi tiene el significado de europeo por contraposición a baladi, del país. González 2002: 361). La nueva conducción atravesaba la acequia El-Bachia para después dirigirse a la llanura de Tasltante.

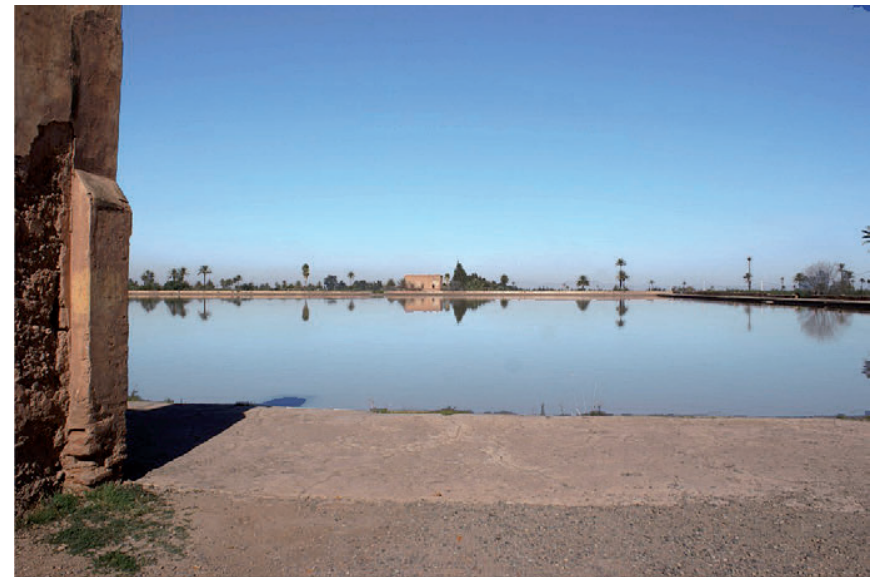

Fig. 18. Dar al-Hana. Alberca. Vista general hacia el norte. En primer plano a la izquierda, el muro oriental del hangar de la barca

alberca y durante un recorrido de aproximadamente 300 $\mathrm{m}$, la acequia se ensancha y se convierte en una sucesión escalonada de decantadores que permiten la precipitación de una parte de los lodos en suspensión. En el punto de arranque de este tramo de acequia, a unos $450 \mathrm{~m}$ al sur de la alberca, se derivaba un brazo secundario que partía en
Fig. 19. Dar al-Hana. Hipótesis de reconstrucción en la que se integran diferentes edificios y restos conservados. En la planta se muestran las construcciones que formaron parte del programa palatino almohade o saadí. Se han excluido las construcciones industriales posteriores, así como la ampliación del edificio residencial acontecida en el siglo $X X$

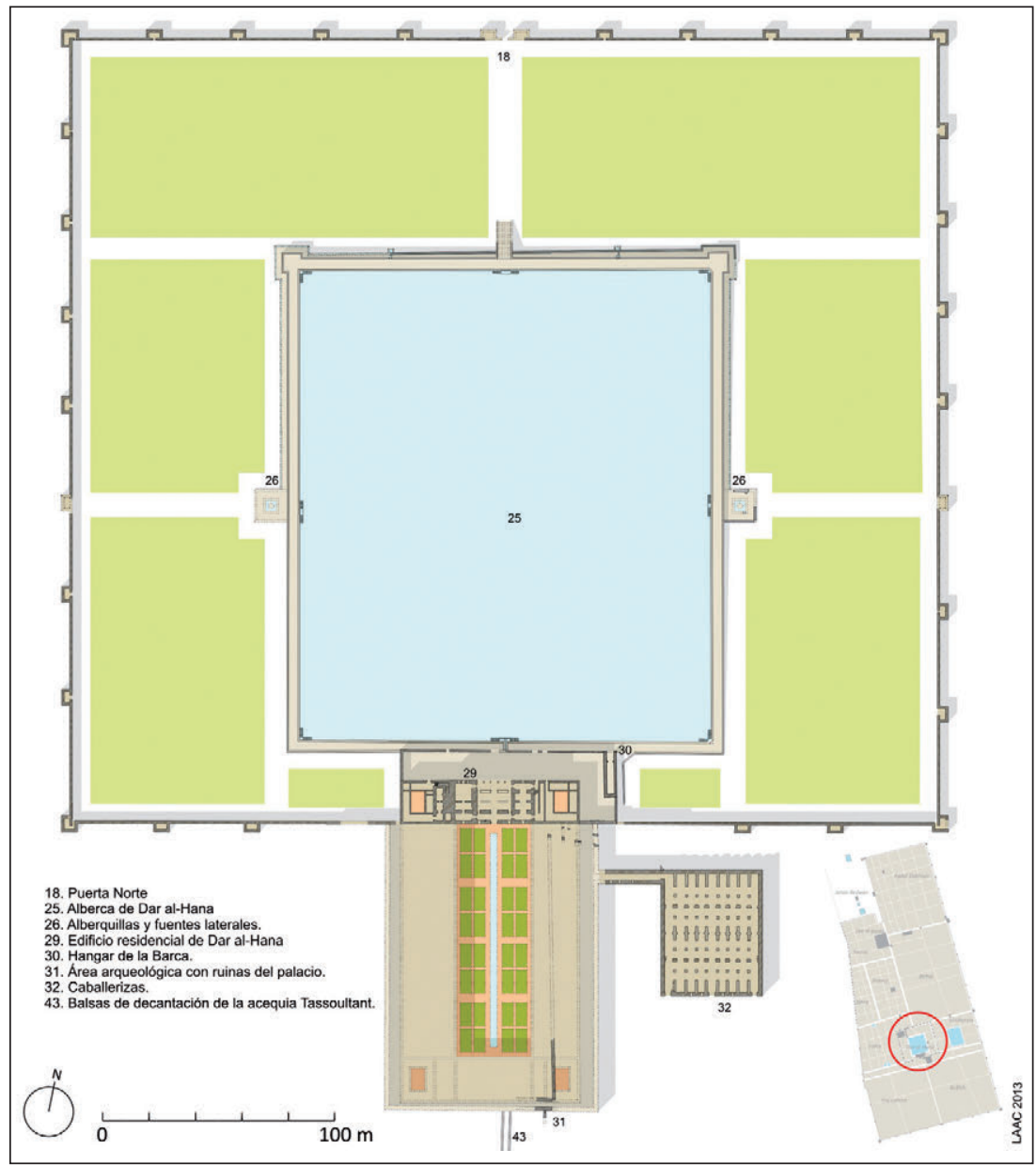


dirección este y que a su vez se dividía en otros dos que tomaban dirección norte, abrazando la alberca Al-Garsia. El brazo izquierdo, tras regar parte del sector Belfkih, se unía a la acequia de salida de la alberca de Dar al-Hana, lo que en caso necesario permitía suplementar su aporte de agua e incluso prescindir de la alberca para regar los plantíos situados pendiente abajo. El brazo derecho regaba una parte del sector Belhaj.

El agua de la Tassoultant permitía regar, además del Agdal, el palacio de Dar al-Bayda, la parte Sur de la kasba y el barrio de Berrima (Parroche 1925: 59) Regaba también el Djenan al-'Afiya. La acequia tenía un débito de 200 litros por segundo, aunque en 1913, debido a problemas de mantenimiento, no daba más que un hilo de agua. La alberca de Dar al-Hana es el destino final de la conducción (Figs. 18 y 19. véase apartado 10.3. para su descripción).

\subsection{Las aguas subterráneas: las jattara/s} Todas las jattara/s del Agdal conocidas históricamente han podido ser identificadas (Fig. 17.B). Las siete que llegaron a existir dejaron de funcionar en la década de 1980, si no antes. A mediados de la década de 2000 fueron seccionadas por la excavación de un gran canal de drenaje que atraviesa el Agdal Barrani de este a oeste, en paralelo al muro sur de la finca (Fig. 2). La reconstrucción de sus recorridos se ha hecho a partir de la información de Parroche (1925), de las fuentes gráficas y planimétricas ${ }^{34}$ y de los datos obtenidos durante los trabajos de prospección.

Había tres jattara/s que atravesaban el Agdal camino de la kasba o la medina, cuyas aguas iban destinadas exclusivamente a esos espacios. Son las siguientes:

'Ayn Dar. Aprovisionaba la kasba y Dar al-Bayda (Luccioni 1982: 108). Es la jattara XXIII de las descritas por Parroche (1925: 51). Era una jattara majzén muy antigua con un débito abundante. Su destino era el Dar al-Majzén (palacio real), de donde le viene el nombre. El abastecimiento de Dar al-Bayda fue una innovación realizada para atender las necesidades del palacio construido a mediados del siglo XVIII.

\footnotetext{
33 En la actualidad es imposible reconstruir estos circuitos. Lo impide la urbanización contemporánea de la kasba y del barrio de Berrima. Dar al-Bayda, por su parte, tiene el acceso estrictamente regulado y solo se han podido identificar los restos de las conducciones que se dirigían hacia ella, visibles al norte del sector Zahiria y al noroeste del sector Belhaj.

34 El estudio de Braun (1974) sobre las jattara/s del Haouz y las consideraciones que hace Wilbaux (2001: 140-154) en su obra sobre el urbanismo de la ciudad son los únicos análisis contemporáneos de las jattara/s de Marrakech. Ambos deben mucho a las descripciones que hiciera Parroche (1925).
}

'Ayn Zemzemiya. Abastecía la kasba y Dar alBayda (Parroche 1925: 69-73 y lámina II; Luccioni 1982: 108). Su débito era muy abundante y se aumentaba mediante aportaciones de las acequias Tassoultant y El-Bachia, ya dentro del Agdal. Como en el caso de la 'Ayn Dar, su uso para abastecer Dar al-Bayda es una innovación del siglo XVIII.

'Ayn al-Mouassine. Esta jattara quedó parcialmente dentro de los límites del Agdal tras la ampliación de éste hacia el sur a mediados del siglo XIX. Atraviesa el SO del Agdal camino de la medina, en la que entraba por Bab al-Robb. Es la jattara XXI de Parroche (1925: 50). Su trazado dentro del Agdal, que solo se podría haber detectado por sus pozos de aireación, no se localizó durante la prospección de 2012. Podría ser muy antigua ya que alimentaba unas cuarenta fuentes de la parte oeste de la medina, una parte de la kasba y parte del Mellah, pero probablemente es contemporánea de la mezquita Mouassine que le da nombre, construida por el tercer monarca saadí, 'Abd-Allah, entre 1562-63 y 1572-73. El hecho de que se ciña al exterior del extremo sur de la muralla occidental más antigua del Agdal, presumiblemente de época almohade, indica que es posterior a la muralla.

Había cuatro jattara/s destinadas a aprovisionar diferentes sectores del Agdal. Eran las siguientes:

'Ayn Lalla Chafia y la alberca Al-Garsia. Esta jattara era la única conducción de este tipo que abastecía la mitad oriental del Agdal. Es probable que esto se explique por ser esta zona la destinada tradicionalmente al cultivo del olivar, mucho menos necesitado de agua que los cítricos y frutales. No puede descartarse que formara parte del diseño fundacional de la finca. Era conocida también con el nombre de 'Ayn Miloudia. Parroche la llama "jattara del Agdal" y afirma que su débito es poco abundante (1925: 52). Se conservan numerosos restos superficiales de ella en el sector Belfkih, resultado de la demolición reciente de sus estructuras.

La alberca Al-Garsia, en la que vertía, tiene forma de paralelogramo romboide con dos pares de ángulos de 95 y 85 grados. Mide 204 por $151,6 \mathrm{~m}\left(30.804 \mathrm{~m}^{2}\right)$ y tiene una profundidad de $2,5 \mathrm{~m}$. Puede embalsar unos 75.000 $\mathrm{m}^{3} \mathrm{y}$ tiene una isleta central de 15 por $15 \mathrm{~m}$. A partir de ella era factible regar una parte de los sectores Belhaj y Agdal Dakhlani, como complemento al riego que se realizaba desde la alberca de Dar al-Hana. A juzgar por las descripciones de la Masarra saadí que hacen a finales de siglo XVI y principios del XVII Al-Fishtali y varios 
viajeros europeos, en las que se menciona una sola alberca, no existía en esta época, al menos con esas grandes dimensiones. Tampoco aparece en el plano elaborado por el teniente Washington (1831: 123-155; mapa fuera de texto), como señaló Deverdun (1959: 528). Todo apunta a que es una obra del siglo XIX, época en la que se replanta el Agdal. El Faïz (1996: 6-7) la considera obra almohade con una argumentación poco convincente.

Las tres jattara/s que se comentan a continuación abastecían exclusivamente parcelas de la mitad occidental del Agdal. Su mayor número en este sector hay que relacionarlo con que esta es la zona tradicionalmente destinada a cultivos que necesitan una mayor cantidad de agua. Las jattara/s en cuestión son las siguientes:

'Ayn Berda Qadima. Parroche la llama "jattara de la parte Oeste del Agdal" y afirma que tiene un débito abundante (1925: 49-50). Parece haber aprovisionado principalmente Dar al-Bayda, aunque también abastecía una conducción de qadous que alimentaba la kasba de agua potable. Las construcciones más antiguas de Dar al-Bayda, destino aparente de 'Ayn Berda Qadima, datan de mediados del siglo XVIII.

'Ayn Berda Djadida y la alberca Batata. Esta jattara no es mencionada por Parroche, lo que induce a pensar que fue excavada con posterioridad a su estudio, publicado en 1925. Su nombre quiere decir Berda Nueva, lo que podría indicar que se trata del desdoblamiento de la Berda Qadima (Berda Vieja). Vertía en la alberca Batata para regar el sector Zahra. La alberca mide 24,5 $\mathrm{m}$ de lado. Tiene una superficie de $600,25 \mathrm{~m}^{2}$ y una profundidad actual de $1,20 \mathrm{~m}$, pudiendo embalsar unos $720 \mathrm{~m}^{3}$. Su capacidad era originalmente la mitad, ya que su vaso se recreció $60 \mathrm{~cm}$ en época reciente. Desde esta alberca el agua podía derivarse, como aporte suplementario, hacia el sector regado por la jattara de las albercas Chouirjat. La alberca Batata fue diseñada para regar, al menos, el sector Zahra.

Las albercas Chouirjat. Se trata de dos albercas dispuestas simétricamente y separados por un camino que les sirve de eje. Miden 25,5 por $25 \mathrm{~m}$ de lado, tienen una superficie de $637,50 \mathrm{~m}^{2}$ y una profundidad de 1,10 $\mathrm{m}$; cada una puede embalsar unos $700 \mathrm{~m}^{3}$. Ambas eran abastecidas por una conducción subterránea procedente de una jattara cuyo recorrido no se pudo localizar durante la prospección. Actualmente riegan parte de los sectores Salha y Zahiria, ambos incluidos dentro del perímetro del Agdal fundacional. La presencia de dos albercas juntas parece una innovación alauí y cabe pensar que en el diseño original de la finca solo se contempló una de ellas alimentada por la misma jattara que aprovisiona las actuales. Su emplazamiento en la cabecera del sector Salha era el adecuado para regar la totalidad o parte del sector occidental de la finca fundacional.

\section{EL MODELO DE FI NCA Y SU I MPLANTACI ÓN TERRITORI AL}

La investigación sobre el Agdal demandaba desde el principio su identificación tipológica, ya que una cosa es reconocer su evidente singularidad y otra bien distinta considerarlo excepcional. Lejos de ser un apéndice exquisito y anómalo de la kasba, el Agdal fue durante la mayor parte de su historia un elemento periurbano separado y autónomo. No fue hasta la segunda mitad del siglo XVIII cuando se produjo su anexión. A la hora de identificar el modelo de finca al que perteneció fue de mucha utilidad la prospección arqueológica de la llanura de Tasltante, al suroeste de Marrakech, donde se localizaron los restos arqueológicos de 17 grandes albercas de riego (Fig. 1). Todas se hallan abandonadas y no han sido hasta ahora objeto de atención por parte de la comunidad científica. Están en inminente riesgo de desaparición debido a los grandes proyectos urbanísticos que se están llevando a cabo en la zona.

Las fuentes cronísticas permiten entender la razón de la presencia de estas albercas. Una de ellas, de finales del siglo XII, afirma que Marrakech era la ciudad del Magreb donde había más "vergeles [basatin] y jardines [jannat] que reciben el nombre de baha ir [pl. de buhayra] por lo grandes que son" (Saad-Zagloul 1985: 209-210).

Este testimonio temprano, generado en la época del esplendor almohade de Marrakech, puede ser la referencia con la que medir la salud de la ciudad en los siglos venideros, pues muchos de los observadores que dejarán relatos de su paso por ella hacen mención a las fincas y jardines situados extramuros, bien para describir su belleza, bien para lamentar su desaparición.

Al-'Umari señalaba, refiriéndose a los almohades, que fuera de la Bab al-Sadat (Puerta de los Señores), situada en la muralla occidental de la kasba, estaban "las tumbas de sus grandes personajes [maqabir akabirihum] y las fincas de los dignatarios [djana in al-a'yan]" (Al-'Umari 1988: 87; Gaudefroy-Demombynes 1927: $184)^{35}$. El área señalada por este geógrafo del siglo XIV es justamente el extremo norte de la zona donde se han

\footnotetext{
Deverdun (1959: 226) ya comentó la relación existente entre la información de Al-'Umari y las albercas abandonadas de la llanura de Tasltante.
} 
localizado los restos de las albercas (Fig. 1). Ésta y otras informaciones suyas permiten imaginar un entorno de la medina ocupado por fincas organizadas en torno a grandes balsas ${ }^{36}$.

La supervivencia de estas fincas periurbanas dependía de la existencia de ciertas condiciones de seguridad, que sólo podían ser garantizadas por el majzén. Cuando León el Africano visita Marrakech a principios del siglo XVI afirma que "en los campos de fuera no puede la gente disponer de un palmo de terreno a causa de los árabes", pues la ciudad había envejecido antes de tiempo debido "a las guerras y a los cambios de amo" (León el Africano 2004: 166, 171).

Para principios del siglo XVII sabemos que el paisaje periurbano de Marrakech era muy próspero:

\begin{abstract}
"Fuera de la ciudad, en los alrededores, por el campo, hay gran número de jardines y vergeles con toda suerte de frutos y viñas, con aguas, y una pequeña residencia para ir a recrearse; tienen allí algunos esclavos para trabajar" (Mocquet 1909: 401).
\end{abstract}

El panorama floreciente descrito por Mocquet se explica por la presencia de un poder fuerte como el del majzén saadí. Pero la amenaza de la desintegración estaba siempre presente. Será Thomas Le Gendre, comerciante francés que visitó Marrakech entre 1618 y 1625 , quien nos informe de que pocos años después de la visita de Mocquet todo ha cambiado a peor:

\begin{abstract}
“Los propios moros no tienen posesiones ni jardines más allá de un tiro de mosquete de las murallas de sus ciudades, porque no los disfrutarían, los árabes les robarían todo de noche; lo que es la causa de que estas gentes no cultiven, y no se sirvan de la bondad de su país" (Le Gendre 1911: 717, 721).
\end{abstract}

La similitud de esta última descripción con la que hiciera poco más de un siglo antes León el Africano resulta aleccionadora sobre el carácter cíclico de las crisis que sufrió la ciudad de Marrakech, en este caso la acaecida tras la muerte de Ahmad al-Mansur (1603). A los problemas sucesorios que siguieron hay que añadir

\footnotetext{
36 Al exterior de la Puerta de Al-Saliha (que estuvo situada al sureste de la medina, entre la Puerta de Agmat y la kasba almohade) también había cementerios y jardines (maqabir wa basatin). Extramuros de Bab al-Robb se extendía la Gran Alberca (al-Sahridj al-Kabir), conocida después como Sahridj al-Baqar o Alberca de las Vacas, y más allá de la Puerta de Nfis había otra alberca en la que los niños aprendían a nadar (Al-'Umari 1988: 88-89; Gaudefroy-Demombynes 1927: 184-190).
}

el impacto de las grandes epidemias de peste (el propio Al-Mansur murió de ella) y las hambrunas que se sucedieron en la primera mitad del siglo XVII y que indudablemente contribuyeron a la despoblación de muchas áreas de la ciudad y sus alrededores (Rosenberger y Triki 1973 y 1974).

Testimonios de viajeros y cronistas de la segunda mitad del siglo XVIII y principios del siglo XIX hablan de un pasado esplendor de la ciudad todavía reconocible.

Un cautivo francés afirmaba en la década de 1770 que la única zona susceptible de cultivo y soportable a la vista eran las proximidades de la kasba (el "Palacio del Rey"), lo demás era de una fealdad inimaginable (Bidé de Maurville 1775: 346).

Otro francés, un diplomático que visitó Marrakech entre 1767 y 1784, afirma que la llanura estuvo "dividida en un número infinito de huertos cercados", plantados de olivos "que han sobrevivido a la barbarie de los hombres”. Estos huertos habían albergado en otro tiempo las "casas de campo de los particulares y sus plantaciones", regadas por "más de seis mil fuentes". Todo eso había desaparecido y solo quedaban ruinas, pues las "ricas propiedades fueron devastadas en las revoluciones que precedieron y caracterizaron el reino de Moulay Ismail [1672-1727]" (Chénier 1787: t. 3, 49).

En la primera mitad del siglo XIX los alauíes intentarán regularizar parte de sus fuentes de ingresos mediante una doble política: revivificar las antiguas plantaciones reales y colonizar nuevas tierras. Desde 1824, el sultán 'Abd al-Rahman (1822-1859), con la colaboración de su hijo el príncipe heredero, el futuro Muhammad IV, emprendió en el Haouz cinco grandes proyectos agrícolas: $1^{\circ}$, la replantación del Agdal; $2^{\circ}$, la revivificación de la jattara de Bou 'Okkaz y la restauración de su alberca, al suroeste de Marrakech; $3^{\circ}$, la replantación de la Menara; $4^{\circ}$, la excavación de la acequia Targa, derivada del Nfis; $5^{\circ}$, la construcción del canal de Tassaout, en el Haouz Oriental (Akansus 1918: vol. I, 9-10, 23-25).

La Menara, edificada en 1157 por el primer califa almohade 'Abd al-Mu'min Ibn 'Ali, es el único ejemplo vivo de finca peri-urbana medieval del entorno de Marrakech que ha conservado su coherencia tipológica hasta nuestros días. El Kitab al-hulal al mawshiya, una fuente anónima del siglo XIV, hace la siguiente descripción:

"El califa 'Abd al-Mu’min plantó fuera de Marrakech un jardín [bustan] de tres millas de largo y una anchura aproximada; en él había toda clase de frutas apetecibles y llevó 
a él el agua desde Agmat y perforó muchos manantiales [istanbata 'uyun ${ }^{\text {an }}$ kathirat $^{\text {an }}$. Dice Ibn al-Yasa': «No salí yo de Marrakech el año 543 -1148- sin que este huerto, que plantó, produjese por la venta del aceite y de las frutas 30.000 dinares muminíes, a pesar de la baratura de la fruta»" (Zamama y Zakkar 1979: 145-146; Huici 1951: 174) ${ }^{37}$.

La Menara precedió por pocos años a la buhayra que dio origen al actual Agdal, como se discute en el apartado 2. La singularidad tanto de una como de la otra reside más en su tamaño y en su promotor (el majzén almohade) que en cualquier otra característica. A pesar de ser una finca de recreo bien conocida, todavía no ha sido objeto de análisis arqueológico y arquitectónico. Su estudio pormenorizado permitiría obtener elementos de comparación tanto para la comprensión de las etapas más antiguas del Agdal como para la caracterización de otras fincas hoy desaparecidas, que sólo pueden detectarse por los restos arqueológicos de sus albercas.

A partir de la información arqueológica y del análisis de las fuentes escritas podemos concluir que en el entorno de Marrakech existió un modelo de finca periurbana con una serie de características comunes:

1. Emplazamiento extramuros. Todas estuvieron situadas fuera de las murallas de la ciudad, sin alejarse de ella más de 7 u $8 \mathrm{~km}$, lo que permitía llegar a ellas sin hacer grandes desplazamientos. Cabe recordar que estas propiedades han de entenderse indisolublemente ligadas a la vida urbana. De hecho, la localización ideal de este tipo de explotaciones era la llanura de Tasltante, prácticamente a vista de la kasba (Fig. 1).

2. Red hidráulica. La existencia de estas fincas dependía de las posibilidades que tenían sus propietarios para crear un sistema propio de captación de agua destinada a la agricultura y al consumo humano. Para ello se recurría a drenar el acuífero con jattara/s; solamente las propiedades majzén disponían del uso de las grandes acequias estatales.

3. Alberca. En todas las fincas se construyó una alberca de grandes dimensiones reguladora tanto del débito de las jattara/s como del riego de los espacios cultivados. La alberca, además de ser una pieza clave para la explotación agrícola, se convierte en el elemento central en torno al cual gira la composición general

\footnotetext{
37 Como señaló Huici, la fecha de 1148 que ofrece el texto para las cifras de producción es imposible, ya que el huerto fue creado en 1157. Sin embargo, no hay por qué dudar de ese montante, revelador de la importancia económica que tenían tanto el cultivo del olivo como el de los frutales.
}

de la finca. Su forma es la de un contenedor de planta cuadrada o rectangular, cuyo eje principal se orienta en sentido nor-noroeste, coincidente con la pendiente topográfica. El borde del vaso solía ser utilizado como andén de circulación perimetral. A partir de cierto tamaño incorporaban contrafuertes salientes para el refuerzo de sus esquinas.

4. Función productiva. Contaron siempre con un amplio espacio cultivado de regadío, preferentemente arbóreo. Dada la débil pluviometría de la zona, en estas fincas no existieron los cultivos de secano, pues hasta los olivos requerían de riego. En todas ellas la presencia del olivar parece que fue relevante. Según la extensión del área cultivada, la finca podía tener edificios de carácter productivo: almazaras, molinos, caballerizas, silos, etc.

5. Función residencial. La presencia de edificios residenciales en estas fincas parece que fue una constante. Sin duda eran necesarios para acoger a sus propietarios en los momentos de solaz y proporcionarles el necesario cobijo. Según la importancia de la finca, el número y monumentalidad de estos edificios iba en aumento. La expresión más sencilla de estas construcciones es un pequeño pabellón, en el que sus dueños podían residir temporalmente. Cuando había necesidad de permanecer más tiempo o se deseaba incrementar el carácter protocolario del edificio, aparecía el auténtico palacio y se multiplicaban las construcciones de recreo a modo de pabellones exentos.

6. Diseño regular. Tanto los espacios cultivados como el área residencial de la finca solían presentar un diseño basado en los principios de axialidad, ortogonalidad y simetría. Este tipo de ordenación, además de ser idóneo para la explotación óptima de esos espacios irrigados, producía un innegable deleite estético al visitante.

7. Cerca perimetral. Contaban siempre con una cerca o muralla rodeando todo el perímetro de la finca. $\mathrm{Su}$ presencia responde a requerimientos funcionales tanto como simbólicos y propagandísticos. Entre los primeros podemos citar la necesidad de garantizar un adecuado aislamiento y protección respecto al exterior, la defensa frente al robo, la generación de una pantalla cortavientos, etc. Entre los segundos, la construcción de un alto muro, que en ocasiones incorporaba torres almenadas y puertas de aparato, era una poderosa herramienta de escenificación del poder de su promotor.

8. Asociación con el majzén y con las élites urbanas. Esta forma de colonización del entorno de la ciudad fue promovida por el majzén y por las élites urbanas, 
instancias que tenían la capacidad técnica y los recursos financieros necesarios para enfrentarse con éxito tanto a un contexto geográfico hostil como a la movilización de los recursos humanos necesarios. Sin embargo, a diferencia de los perímetros de regadío gestionados por las comunidades campesinas del Haouz, sistemas ultraestables, fruto de órdenes agrarios viejos y perdurables, estas fincas periurbanas eran creaciones sofisticadas pero frágiles. Su dependencia de las fortunas cambiantes de sus promotores las hacía vulnerables a los episodios de crisis política y social. Esto es lo que explica los testimonios aparentemente contradictorios de viajeros y cronistas de distintas épocas que se discuten en los apartados 2 a 4. La historia de Marrakech estuvo siempre ligada a la fuerza y a la capacidad de imponerse de los poderes dinásticos de turno, y esta historia tuvo siempre su reflejo en el entorno inmediato de la ciudad.

\section{MURALLA EXTERIOR}

El Agdal cuenta con un perímetro amurallado de unos $9 \mathrm{~km}$, jalonado por torres. Una primera aproximación permite afirmar que se trata de una obra heterogénea en donde se refleja la compleja historia formativa de la finca. La información que proporcionan las fuentes escritas sobre esta muralla es prácticamente inexistente, y el análisis arqueológico es todavía preliminar debido a la gran extensión de la cerca, a las reparaciones sufridas recientemente y también a las limitaciones existentes para acceder a determinados sectores.

En la prospección de 2012 se catalogaron en la muralla unos ciento cincuenta elementos de interés, correspondientes a lienzos, torres, bastiones y puertas que hoy día están en pie; también se localizó un tramo de otra más antigua, completamente arrasada, situada bajo la primera. Este trabajo nos ha permitido conocer las principales características de la fábrica de la cerca, así como documentar ciertas discontinuidades estructurales y realizar el estudio formal de sus torres. Todo ello ha hecho posible la individualización de ciertos tramos del recinto en cada uno de sus cuatro frentes.

\subsection{Frente septentrional}

El cierre del lado norte del Agdal, más que una autentica muralla es una sucesión de tapias que separan la finca de los mechuares. En el lado oriental, el muro aísla el Agdal Dakhlani de los mechuares interior y exterior y del barrio de Bab Ahmar; en el occidental separa Djenan Redouan del Gran Mechuar y de otro gran recinto con funciones militares (Figs 2, 9 y 12). Las modificaciones contemporáneas en la disposición de los mechuares y la presencia de revestimientos recientes dificultan su adecuada documentación; no obstante, todo este frente es obra de Muhammad III (1757-1790). Gracias al grabado de Höst (Fig. 9) sabemos que hacia 1768 estaba ya construida la tapia oriental del Gran Mechuar y la que lo separa de Djenan Redouan. La del Agdal Daklani se construirá años después, en todo caso antes del final de su reinado.

\subsection{Frente occidental}

Se han identificado cuatro tramos que presentan rasgos morfológicos propios, coincidentes aproximadamente con el desarrollo de las parcelas que hay en sus inmediaciones. El último de ellos será analizado en el apartado dedicado al frente meridional. La descripción de cada tramo que se hace a continuación sigue un orden de norte a sur.

El primero es una tapia de tierra que separa Djenan Redouan del cementerio de Sidi A'mara y del barrio del mismo nombre (Figs. 2 y 12). El hecho de que este tramo sea una simple tapia se debe, probablemente, a que cuando se fundó Djenan Redouan ya existía el cementerio en el exterior ${ }^{38}$, lo que hacía innecesario las torres, que en el Agdal normalmente cumplen una función más simbólica que poliorcética.

El segundo tramo es también obra de tapia de tierra aunque está torreado. Se extiende por 1,2 km desde el norte de la parcela de Sousia hasta el sur de Zahra. Su mitad meridional transcurre apoyada sobre una antigua muralla amortizada que le sirve de cimiento y zócalo (Figs. 2 y 20). Lo que mejor caracteriza este tramo es la escasa distancia que hay entre sus torres, con una media de unos $32 \mathrm{~m}$. En su extremo septentrional se localizan dos irregularidades que debemos señalar. La primera es la inflexión que la muralla hace a la altura de la división parcelaria que hay entre Belhaj y Dakhlani, línea que venimos considerando el limite septentrional del Agdal fundacional (Fig. 3). La segunda se sitúa dos torres más al norte; allí observamos un quiebro cuyo diseño intencionado nos hace pensar en la posible presencia de un antiguo portillo. En este momento no tenemos información suficiente para hacer una propuesta cronológica que nos convenza. A lo único que nos atrevemos es a decir que esta fábrica no es almohade. Si nos atenemos

\footnotetext{
38 El cementerio está asociado al mausoleo de Sidi A'mara, obra de 'Abd al-Rahman (1822-1859) según una inscripción recogida por Deverdun (1959: 534, n.47).
} 


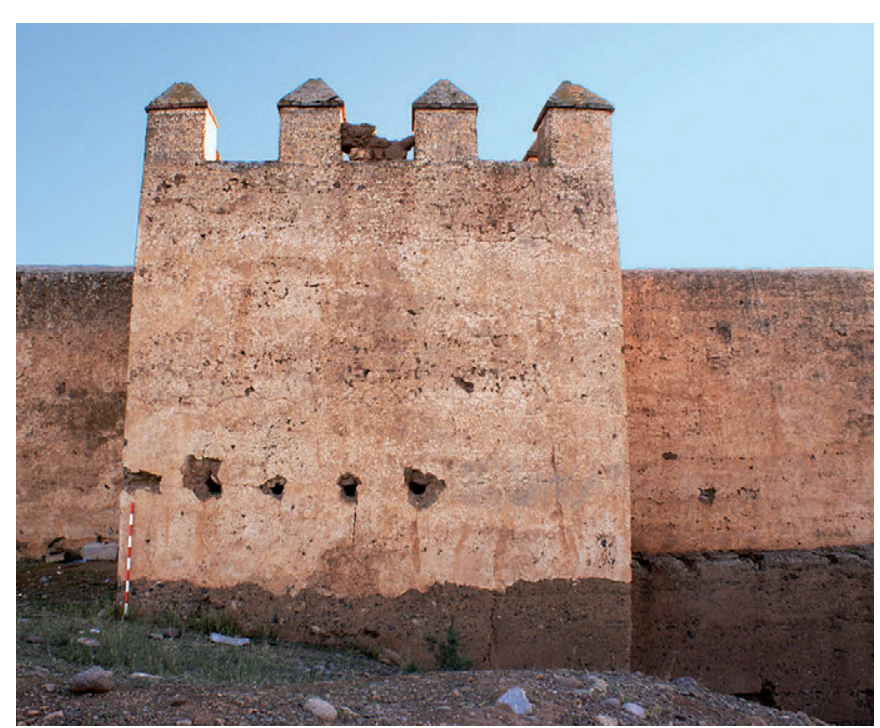

Fig. 20. Agdal. Muralla exterior. Frente occidental. Tramo anexo a la parcela Salha. La muralla y la torre actuales se asientan sobre los restos de otra preexistente, más oscura

solamente al ritmo en la implantación de las torres habría que concluir que tampoco es alauí por su densidad. Hay que señalar en todo caso que no se ha detectado una discontinuidad de fábrica entre este tramo y el siguiente, en el que las torres aparecen más distanciadas.

El tercer tramo coincide aproximadamente con la parcela Salha. Se diferencia del tramo anterior en el menor número de torres y en la mayor distancia que hay entre ellas, que oscila entre 215 y $281 \mathrm{~m}$. En los $500 \mathrm{~m}$ aproximados que mide este tramo de muralla no se reprodujeron las torres preexistentes y se reconstruyeron solamente dos, lo que nos hace sospechar que estamos ante una fábrica de época alauí (Figs. 2 y 21).

Las diferencias que existen entre los dos últimos tramos fueron explicadas por Deverdun (1959: 529) a partir de una tradición oral según la cual los Rehamna destruyeron la totalidad de la muralla oeste del Agdal en $1862^{39}$. Tras este acontecimiento fueron obligados a reconstruirla, obteniendo el favor de no tener que volver a levantar todas las torres destruidas. No se conoce ninguna fuente cronística que narre este acontecimiento. Es oportuno recordar que las destrucciones generales de murallas han sido siempre excepcionales, pues para inutilizar un recinto solamente era necesario abrirle brechas. Puede cuestionarse por tanto que tuviera lugar

\footnotetext{
39 Deverdun recogió esta información en 1949 del testimonio de un viejo albañil y del guardia de la Sqallat al-Mrabit, el bastión situado en el extremo suroeste del barrio de Sidi A'mara (Deverdun 1959: 529 n. 30)
}

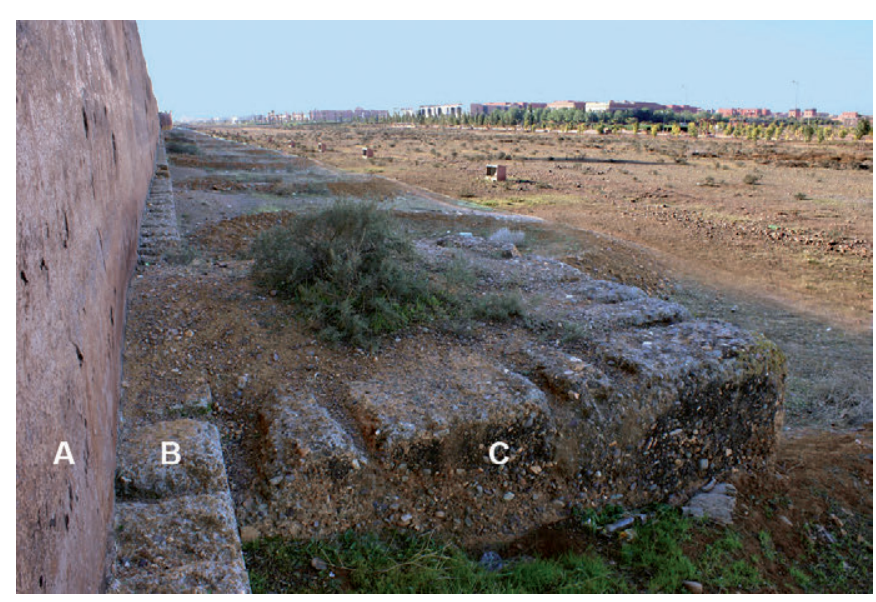

Fig. 21. Agdal. Muralla exterior. Frente occidental. Tramo anexo a la parcela de Salha. La actual muralla (A) se asienta sobre los restos de otra más antigua (B), cuya torre (C) no fue reconstruida

una demolición total del frente occidental tal y como la describen los testimonios orales que recogió Deverdun. Sea como fuere, no puede descartarse que la zona arrasada por los Rehamna afectara solamente al tercer tramo de la muralla.

Por otra parte, sabemos que Muhammad III (m. 1790) restauró las murallas de la kasba, lo que conllevó entre otras obras la refacción de todo su frente occidental. La observación de la cartografía detecta en este nuevo recinto alauí una baja densidad de torres y la existencia de separaciones irregulares entre ellas. Fotografías de principios del siglo XX permiten distinguir cómo la nueva muralla alauí no reprodujo todas las torres preexistentes del recinto de la kasba ${ }^{40}$, fenómeno análogo al que encontramos en el tercer tramo del frente occidental del Agdal. Así pues, en principio no era necesario que ocurriera un suceso extraordinario para que los alauíes reconstruyeran desde sus cimientos las antiguas murallas, y hay precedentes de que cuando lo hacían no siempre reproducían la secuencia de torres que encontraban.

Los restos visibles de la muralla preexistente sobre la que asienta parte de la cerca del segundo tramo y la totalidad del tercero, tienen $1,2 \mathrm{~km}$ de longitud y su fábrica es una tapia hormigonada. Fue demolida de manera controlada con el fin de servir de basamento sobre el que asentar la que subsiste (Figs. 20 y 21). Es seguramente obra almohade.

\footnotetext{
40 Actualmente no existen evidencias superficiales de esta refacción. La cota del terreno circundante ha sido elevada y ha enterrado los restos de la muralla anterior, visibles a principios del siglo XX.
} 


\subsection{Frente oriental}

Si exceptuamos el tramo anexo a la parcela Belfkih, ampliación bien fechada en el siglo XIX, el resto de este frente mide $2.360 \mathrm{~m}$ desde Bab al-'Iyal (Fig. 2.2) hasta el extremo sur de Al-Garsia. En contraste con el frente occidental es completamente rectilíneo y conecta con la muralla del barrio de Bab Ahmar en la puerta que le da acceso por el este (Figs. 2, 9 y 12). Es en esta puerta, obra del siglo XVIII, en donde parecen confluir dos alineaciones diferentes: la septentrional, generada por la cerca de Djenan al-Afiya, y la meridional, prolongación del primitivo frente oriental del Agdal almohade. A la luz de lo expuesto, la muralla anexa a la parcela Dakhlani y la del barrio de Bab Ahmar serian obra Muhammad III (m. 1790) y estarían ya construidas en 1768 , tal como indica el grabado de Höst (Fig. 9).

En este mismo frente de muralla e inmediata a la parcela Al-Garsia se yergue la Puerta de la Musalla (Fig. 2.20). La musalla, espacio abierto destinado a grandes celebraciones religiosas en las que participaba el califa, fue trasladada desde las inmediaciones de Bab al-Robb, donde se hallaba todavía a principios del siglo XVIII, hasta el exterior de la muralla oriental del Agdal en fecha que se desconoce (Deverdun 1959: 576).

Se trata de una puerta monumental de entrada recta alojada en una torre, ubicada en el frente oriental de la muralla exterior del Agdal (Fig. 2.20). Su construcción se atribuye a 'Abd al-Rahman (1822-59) (Deverdun 1956: 220; 1959: 528, n. 28). Durante la prospección de 2012 se pudo comprobar la superposición de dos enlucidos ornamentales en sus muros exteriores. El más superficial presenta el acabado prototípico de la reforma alauí de la segunda mitad del siglo XIX. El más antiguo es un encintado realizado directamente sobre la tapia con el fin de simular una obra de sillería.

Los bastiones de Bordj al-Wastani (Fig. 2.5) y Bordj al-Daffa (Fig. 2.9), situados entre Bab al-Musalla y Bab Igli, fueron por su parte adiciones de Hassan I (1873-1894) (Deverdun 1959: 537). Como en el frente occidental, también en el oriental existe una discontinuidad que indica hasta dónde llegó la muralla antes de que se ampliara el Agdal hacia el sur.

\subsection{Frente meridional}

Esta muralla cierra el Agdal por el sur. Su disposición en forma de "U" y su desarrollo a lo largo de $3 \mathrm{~km} \mathrm{le}$ permite cercar las parcelas de Haj Lahcen y Belfkih (Fig. 2). Las dos esquinas del gran recinto fueron dotadas de bastiones que permitían alojar piezas de artillería.
Desconocemos si esta ampliación del Agdal es obra de 'Abd al-Rahman (1822-1859) o de Muhammad IV (1859-1873). En todo caso es anterior a la ampliación del Agdal Barrani realizada por Hassan I (1873-1894) (Deverdun 1959: 537). La muralla de esta última ampliación tenía una longitud de 3,3 km. Cercaba el área en la que se construyó una fábrica de pólvora y otra de municiones (Fig. 2. 38 y 39). En la actualidad solamente se conservan fragmentos de este recinto, dado que no forma parte de la zona declarada Patrimonio Mundial de la UNESCO en 1985.

\section{Lí MITES DE LA FI NCA ALMOHADE Y SAADí}

Con anterioridad a la gran expansión alauí del Agdal, la finca tuvo un perímetro menor que el actual y estuvo físicamente separada de la kasba (Fig. 5). Ante la escasa información que proporciona el análisis de la muralla del Agdal para conocer los límites precisos de la finca almohade y saadí, es necesario recurrir a datos indirectos para sustentar la hipótesis de restitución que proponemos y que se representa gráficamente en las Figs. 4 y 5. Se enumeran a continuación los indicios que existen de los cuatro frentes que constituyeron la delimitación original de la finca:

Límite meridional. No tenemos ningún testimonio arqueológico seguro que pruebe la existencia de este límite en el lugar en el que lo proponemos. Los datos que ofrecemos son los siguientes: en la muralla preexistente que hay en el frente occidental, su extremo sur llega hasta un punto que podría indicar el lugar en donde estuvo el límite sur (Fig. 2); en la muralla que se conserva en pie en ese mismo frente, en su extremo meridional hay un quiebro que coincide con el extremo de la muralla preexistente; la división parcelaria que separa Salha, Dar al Hana y Al-Garsia de Haj Lahcen y Belfkih señala una línea recta que traspasa todo el Agdal de este a oeste; el emplazamiento de la alberca de Dar al-Hana y de las otras que hay en Salha y Al-Garsia conforma otra línea, coincidente con la anterior, que señala la zona más alta de la primitiva finca y por tanto el límite meridional de la zona irrigada fundacional.

Límite septentrional. Respecto a la existencia de restos arqueológicos sucede aquí algo similar a lo visto en el límite meridional. Los datos son los siguientes: un quiebro existente en el trazado de la muralla occidental a la altura de Dar al-Bayda (Fig. 3); la discontinuidad que se detecta en el trazado del camino principal, cuan- 
do éste llega al primitivo núcleo de Dar al-Bayda desde el sur (Fig. 12); la división parcelaria que hay entre Belhaj y Dakhlani y la ubicación de la almazara como instalación periférica; todos estos indicios señalan una línea que coincide con el quiebro visto en la muralla occidental (Fig. 3).

Límite occidental. El frente occidental original se encuentra con toda probabilidad subsumido en el actual, a pesar de su notoria falta de alineación al presentar un giro de 9 grados en sentido horario respecto a su homólogo del frente oriental. Desconocemos las razones de esta falta de simetría, que debió de responder a la existencia de un fuerte condicionante previo a la fundación de la finca. A pesar de ser este el único lado irregular y por lo tanto el menos idóneo para ser considerado parte del programa fundacional almohade, es el único que cuenta con información arqueológica para probar que su actual conformación es muy antigua. Si se acepta una cronología almohade para la muralla subyacente, estaríamos ante uno de los escasos testimonios materiales del Agdal fundacional.

Límite oriental. Para sustentar la hipótesis de que el actual frente oriental coincide con el fundacional no contamos con información arqueológica alguna. No se localizó en superficie ningún resto de una muralla preexistente similar a la vista en el frente occidental; no obstante mantiene una orientación ortogonal respecto al resto del conjunto que facilita su consideración como parte del proyecto fundacional.

Es probable que en época saadí la revivificación de la finca mantuviera en lo sustancial la organización espacial de la fase almohade anterior. Sabemos que la finca tenía en ese momento, en torno al año 1600, una anchura similar a la de las murallas de la kasba y del huerto de Al-Saliha, contiguo a ella, lo que supone el mismo ancho que tiene la finca en la actualidad, aproximadamente $1400 \mathrm{~m}$.

Fue bajo los alauíes cuando se produjo un gran cambio en la organización espacial de la finca, debido a dos fenómenos diferentes pero estrechamente relacionados. El primero fue la proyección de la kasba hacia el sur, con la creación de los mechuares que todavía existen. El segundo fue el desplazamiento del área residencial del Agdal de sur a norte, abandonando el complejo residencial de Dar al-Hana en favor del de Dar al-Bayda, cuyo primer núcleo se construye a mediados del siglo XVIII por Muhammad III. La creación por el mismo monarca del huerto de Djenan Redouan en el espacio que mediaba entre el Gran Mechouar y Dar al-Bayda terminó por poner en contacto dos realidades diseñadas en el siglo XII como entes separados: la kasba y el Agdal. Lo que había sido una finca aislada, satélite de la ciudad, se convertía así en un apéndice de la ciudad palatina (Figs. 4 y 5).

\section{EL NÚCLEO PALATI NO DE DAR AL-HANA. ANÁLISIS ARQUITECTÓNI CO}

Desde el momento en que iniciamos el estudio del Agdal, reconocimos que el recinto de Dar al-Hana fue el núcleo principal de la finca almohade debido a que en su interior se encontraba el área palatina por antonomasia. Allí es donde mejor se han conservado los elementos tipológicos y estructurales de la finca fundacional, aunque su materialidad es mayoritariamente saadí.

En el extremo sur de este recinto, presidiendo el conjunto, se emplazan los restos de un gran edificio residencial, que las crónicas llaman "palacio", al que rodean otras construcciones independientes. Todo el conjunto circunscrito por sus murallas debe ser considerado como espacio palatino. Cada uno de sus componentes tiene una formalización y función particulares, pero ninguno de ellos puede ser entendido si no es formando parte de la unidad mayor. Así, no es oportuno considerar al edificio meridional como palacio en sí mismo, sino tan sólo como el componente residencial más significativo de un conjunto áulico que se completa con los demás elementos.

Desde su fundación en época almohade, el recinto de Dar al-Hana fue siempre un espacio diferenciado dentro de una finca más extensa que las fuentes escritas describen unánimemente como inmensa. Un testimonio de 1625 diferencia estas dos realidades, llamando a Dar al-Hana "la Pequeña Masarra" y al resto del primitivo Agdal "la Masarra" (Le Gendre 1911: 726-727).

Lo que nos ha llegado del área palatina queda definido por un perímetro amurallado de planta rectangular, con unas dimensiones de $347 \mathrm{~m}$ de lado medido en la dirección norte-sur y $384 \mathrm{~m}$ en la este-oeste, por lo que su superficie alcanza 13,3 ha (Figs. 3 y 19). Su planta presenta una composición marcada por la axialidad en dirección norte-sur, formando un conjunto ordenado y de geometría perfectamente ortogonal. Alineados con este eje principal encontramos la antigua puerta septentrional sobre la que se construyó, en época alauí, el actual pabellón de acceso o al-Manzeh (Figs. 2.18, 3.18 y 19.18); la gran alberca (Fig. 3.25) y el edificio residencial presidiendo todo el complejo (Figs. 3.29 y 22). Rodeando estas edificaciones se disponen zonas cultivadas, además de otras construcciones de carácter subsidiario y edificios industriales. 
Podemos observar un especial protagonismo concentrado en la zona meridional. Aquí, además del edificio residencial que hoy podemos ver, encontramos un amplio campo de ruinas de indudable valor arqueológico que se extiende hacia el sur, ocupando una superficie aproximada de una hectárea. Se han localizado varios muros de hormigón de cal de gran grosor, enterrados a una profundidad superior a los dos metros, puestos al descubierto hace unos años por la excavación de una zanja ${ }^{41}$ (Fig. 6.B). Sorprendentemente, a unos cien metros al sur de estos muros se hallaron otros cubiertos simplemente por la maleza (Fig. 6.A). En las inmediaciones del recinto se conserva un gran edificio de caballerizas cuya función estaría indudablemente ligada al área palatina. Frente a éstos se extendería una explanada en la que se hacían alardes y escaramuzas, mencionada por una fuente del siglo XVII (Da Silva 1864: 108).

El complejo palatino que estos restos ponen en evidencia estaría compuesto por el palacio propiamente dicho pero también por las caballerizas y por un sofisticado sistema de puerta que además de dar acceso al palacio permitiría una entrada diferenciada al resto de la finca desde el sur. Desde esta puerta, un camino interior bordearía el recinto de Dar al-Hana por el oeste hasta salir al camino central del Agdal en el lugar que hoy ocupa la puerta que hay junto al-Manzeh, en su extremo norte.

\subsection{Muralla}

La muralla de Dar al-Hana cierra un perímetro de casi $1,5 \mathrm{~km}$, jalonada con 30 torres distribuidas a intervalos aproximadamente regulares (Figs. 14 y 19). Conserva la mayor parte de su trazado, a excepción de pequeños tramos desaparecidos al noroeste, sur y este. A modo general, podemos describir unas características comunes, con algunas particularidades que presentaremos más adelante. Se trata de una obra de tapia hormigonada de cal y grava, muy consistente. Su alzado visible ronda los $4 \mathrm{~m}$, con 5 hiladas de cajones, tanto en las torres como en los lienzos, aunque dependiendo del tramo se detectan algunas variaciones, como veremos. Las dimensiones de estos cajones son las siguientes: una altura de entre 0,76 y $0,80 \mathrm{~m}$, similares a las que venimos observando en la actual muralla exterior del Agdal; un espesor que oscila

\footnotetext{
41 La zanja fue excavada con maquinaria pesada en los años 80 para construir un pasadizo subterráneo de acceso al edificio residencial de Dar al-Hana, que en aquellos momentos estaba siendo rehecho. Se trata de una trinchera de $2 \mathrm{~m}$ de profundidad y unos 40 metros de longitud. Tras el desbroce y el examen de los cortes se identificaron un elevado número de estructuras arquitectónicas que habían sido seccionadas, algunas de ellas de gran porte (Fig. 6).
}

entre 1,05 y $1,10 \mathrm{~m}$ y una longitud variable, aunque es frecuente encontrar medidas entre 1,60 y 2,20 m.

Las torres se adosan a los lienzos por su cara exterior. Presentan planta rectangular, con unas dimensiones de $7 \mathrm{~m}$ en su lado mayor, paralelo a la muralla, y un ancho de $3,7 \mathrm{~m}$. Su superficie interior es de $15 \mathrm{~m}^{2}$ aproximadamente. En algunas de ellas se han conservado evidencias de las puertas de acceso, fundamentalmente en el tramo oeste. Éstas se disponen centradas en el eje de simetría. Presentan jambas y arcos rebajados de fábrica de ladrillo. Las torres de esquina tienen planta en " $L$ ", con unas dimensiones exteriores de $7 \mathrm{~m}$. Su superficie interior es de $19 \mathrm{~m}^{2}$.

Los frentes este y oeste muestran unas características similares, con una secuenciación de torres que varía entre 32 y $48 \mathrm{~m}$. Cabe señalar que las torres centrales de ambos paños han desaparecido, al emplazarse la Bab Saghir en mitad del frente occidental (Figs. 2.24 y 3.24), ocupando el lugar de la torre previa, y arrasarse la del frente oriental para dar acceso rodado al interior del recinto.

El frente norte es el tramo más modificado. Un gran número de sus estructuras han sido reutilizadas al adosarse, tanto en el exterior como en el interior, diversas construcciones del complejo industrial septentrional, que incluye, entre otros, un molino y un polvorín (Figs. 2.21 y 3.21) y, en época reciente, varias casetas e infraestructuras modernas. Presenta una secuencia de torres bastante regular, con separaciones de $30 \mathrm{~m}$, aunque desde las que flanquean al actual pabellón norte, alManzeh, hasta éste la distancia aumenta a $32 \mathrm{~m}$. La razón de esta variación en la secuencia puede estar en que este edificio ocupa el lugar de la antigua puerta norte del recinto, y su construcción supuso la demolición de ésta. Prueba de ello puede ser el grueso muro que aún se conserva en su flanco oriental, cuya presencia sólo se puede explicar considerándolo un vestigio del torreón oriental de la puerta. Si aplicamos el módulo de separación entre torres, este muro coincide exactamente con la ubicación que le correspondería, y podemos restituir el sistema de puerta formado por un vano centrado en el eje norte-sur del recinto flanqueado por dos torreones iguales a los conservados en el resto de este frente (Fig. 19.18).

En el frente sur se detectan varias peculiaridades. Presenta una altura variable: en la mayor parte de su tramo oriental se cuentan 3 hiladas, aunque en la zona central se observa un escalonamiento que llega hasta 7; en el tramo occidental, sin embargo la altura es de 4. Sus torres son ciegas, sin ningún vano de acceso a su interior. Se conservan 4 de ellas, en los extremos oriental y occidental, que 
mantienen una separación media de $35 \mathrm{~m}$, aunque desconocemos si existieron más en este frente.

En la parte central su trazado queda interrumpido por la presencia del edificio residencial. A ambos lados de éste se dan varias singularidades. En primer lugar, se observa un mayor espesor en la fábrica de la muralla. Esto se evidencia en alzado al oeste del edificio, donde un tramo es $23 \mathrm{~cm}$ más grueso, alcanzando 1,26 m (Fig. 7), y al este, donde el basamento de la muralla alcanza 1,40 m (Fig. 8).

La ausencia de torres en la parte central, rompiendo claramente la secuencia del resto del perímetro, es significativa. Está indicando la existencia de algún condicionante que impidió que el cierre del frente sur se realizase de manera sencilla siguiendo el mismo esquema general de los demás lienzos.

La mayor parte de la materialidad de la muralla es una obra cronológicamente homogénea, adscribible a época saadí, aunque en momentos posteriores se hayan realizado modificaciones puntuales en algunas partes de su alzado. En cuanto a los tramos de mayor grosor detectados en el frente meridional, se trata probablemente de la muralla fundacional almohade sobre la que se construyó la obra que actualmente se conserva en pie (Figs. 7 y 8).

\subsection{Residencia meridional}

Se trata sin duda del edificio más importante del recinto de Dar al-Hana, tanto por su función como por la envergadura de su arquitectura. Lo que hoy día vemos es una obra inacabada proyectada por el arquitecto André Paccard a finales del siglo XX (Figs. 6.B y 22.A). Tiene sótano, planta baja y entreplanta en algunas zonas. Su trazado actual muestra una composición axial, de organización tripartita, simétrica, con los dos cuerpos laterales mayores avanzados hacia la alberca. Se presenta en estado de estructura de hormigón armado (Fig. 6.B), sin acabados ni decoración, aunque en su interior se localizan numerosas estructuras de la antigua residencia consistentes en muros de carga, con fábrica tanto de ladrillo como de tapia, y restos de bóvedas (Fig. 22.B). Con independencia de la afección causada en el viejo palacio, el edificio de Paccard es muy deudor de aquél, tanto en su organización espacial como en su materialidad. Con la excepción de las cubiertas, abovedadas o adinteladas, la mayoría de las estructuras antiguas que se conservaban en pie se reutilizaron. La gran alteración compositiva que introdujo el proyecto de Paccard fue construir un frente avanzado hacia la alberca, en cuyo centro se dispuso un patio porticado que alteró negativamente la relación tradicional que mantenía el antiguo palacio saadí con aquélla.

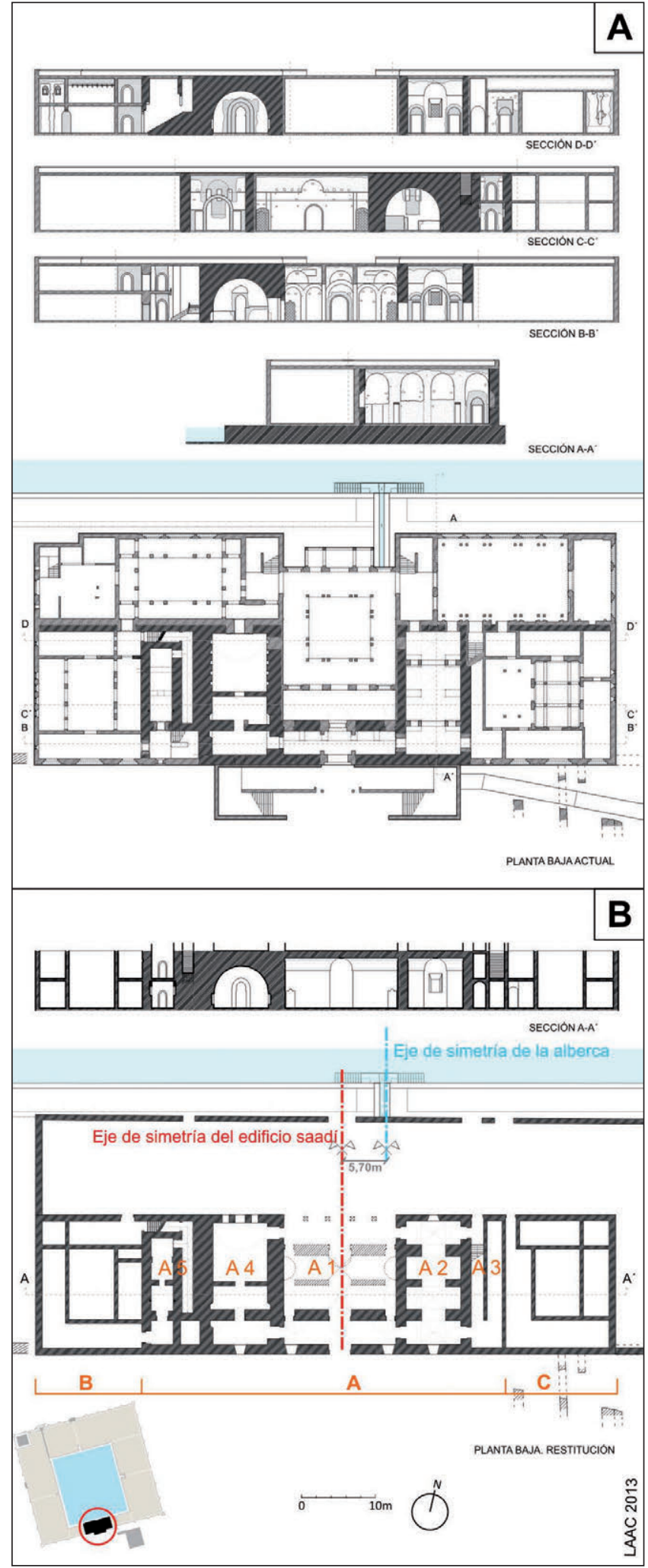

Fig. 22. Dar al-Hana. Edificio residencial meridional. (A) Levantamiento del estado actual del edificio reformado por el arquitecto A. Paccard. (B) Planta y sección hipotéticas, que pretenden reconstruir el edificio saadí eliminando las alteraciones contemporáneas. Los dibujos se elaboraron a partir del análisis de las estructuras arqueológicas que aún existen en el interior del edificio y de las fotografías históricas 
Los datos de que se dispone para plantear una hipotética reconstrucción de la antigua residencia provienen del estudio arqueológico-arquitectónico de sus estructuras y del análisis de la fotografía aérea de 1917. Se han consultado también otros documentos gráficos históricos, entre los que destacan diversas postales antiguas que han proporcionado una valiosa información adicional. En la fotografía de 1917 podemos observar cómo estaba, antes de que fuera demolido parcialmente, englobado dentro de un recinto de planta rectangular, con unas dimensiones de 95,3 por 32 m (Figs. 19 y 22.B), definido por tapias de cierre, que en el ángulo nororiental entestan contra una segunda construcción, el denominado hangar de la barca, sobre el que más tarde volveremos. Es notorio el hecho de que este recinto se encuentre alineado aproximadamente con el eje de simetría de la alberca, marcado por el canal que la alimenta desde el sur. La importancia de este eje es crucial en el discurso, dado que es el mismo que organiza todo el conjunto de Dar al-Hana; esta alineación, sin embargo, no es respetada por la implantación del edificio, que aparece desplazado 5,7 $\mathrm{m}$ hacia el oeste (Fig. 22.B).

El inmueble, tal y como se encontraba a comienzos del siglo XX, presentaba una planta de contorno rectangular con unas dimensiones de 79 por $19 \mathrm{~m}$, dispuesto paralelamente al borde sur de la alberca, y separado de ella por un espacio de 17,7 $\mathrm{m}$ de ancho (Figs. 10 y 11). En cuanto a su organización interna, observamos una disposición simétrica y tripartita con un complejo principal en su centro, flanqueado por dos secundarios. Se describen a continuación sus espacios interiores (Fig. 22.B).

Sector central (A). Es la parte más importante del edificio. Se caracteriza por presentar una fábrica muy

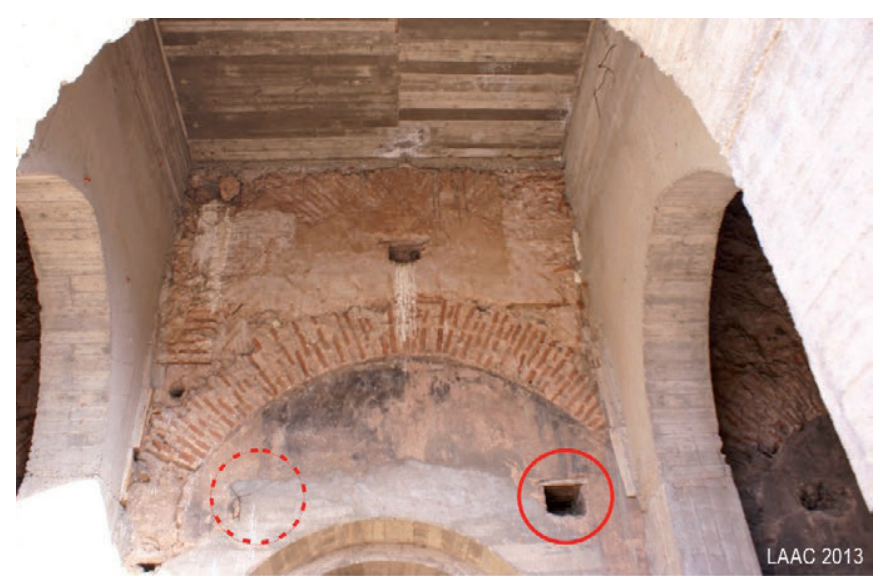

Fig. 23. Dar al-Hana. Edificio residencial. En la cara meridional del muro norte de la crujía de acceso se pueden observar los encastres para las gorroneras de una gran puerta de hojas batientes sólida de tapia de hormigón y por estar sus dependencias cubiertas con bóvedas de cañón construidas con ladrillo. Sus muros alcanzan un importante espesor, que va desde 1,3 a 2,5 m en los costados de las mayores bóvedas. Se divide en 5 cuerpos aproximadamente simétricos.

A1. Es el cuerpo central y debió de tener cuatro crujías orientadas de este a oeste. Solo la más meridional se conserva y todo parece indicar que perteneció al pórtico de acceso desde el sur. Ésta tiene planta rectangular, con unas dimensiones de 15,22 por 3,23 m. En el muro meridional se abre un vano centrado, con una luz aproximada de $2,9 \mathrm{~m}$. A su lado occidental encontramos los restos de un pilar conservado in-situ, compuesto por varios sillares de piedra con un ancho de $43 \mathrm{~cm}$ y que identificamos como uno de los pilares del pórtico que se abría hacia el sur. Dos ventanas se sitúan en los extremos, hoy tapiadas. El muro septentrional presenta un vano centrado similar y alineado con el anterior. Se conservan los encastres de las gorroneras, resueltos mediante dintelillos de madera, testimonio inequívoco de que la sala contigua se abría al antiguo patio interior a través de este pórtico (Fig. 23). Otros dos vanos se disponen en sus extremos, cegados en la última reforma. También existen puertas en los frentes cortos, comunicando con los cuerpos laterales (A2 y A4).

Este espacio estuvo cubierto por bóvedas de cañón y en ellas observamos dos fases diferenciadas. La primera se resuelve con una única bóveda de cañón longitudinal, que más tarde es modificada por una composición de 5

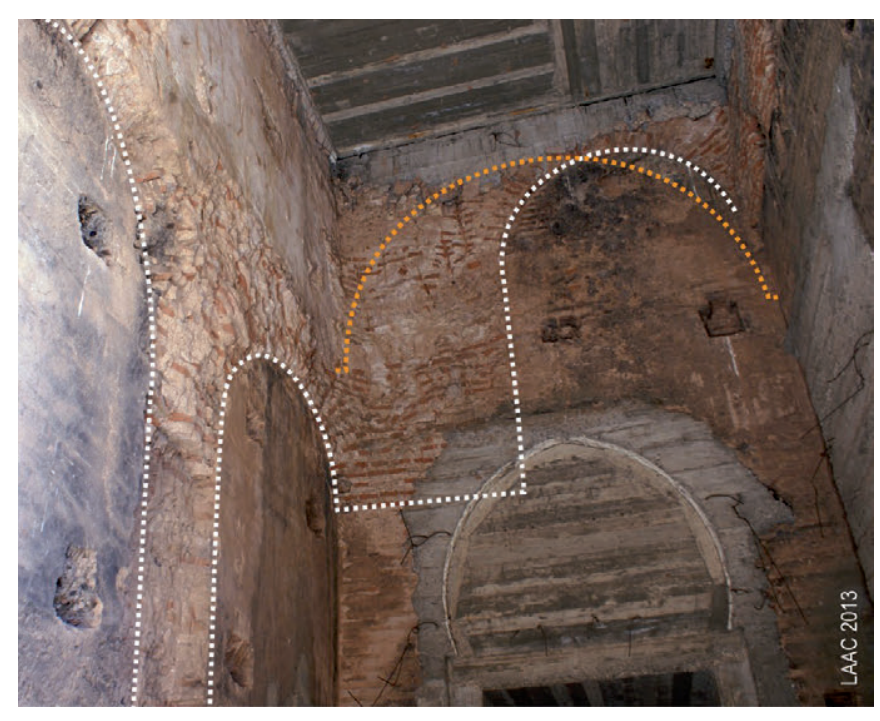

Fig. 24. Dar al-Hana. Edificio residencial. Bóvedas de la crujía de acceso (véase situación en la Fig. 22.A1). Se ha marcado con línea naranja el luneto de la bóveda longitudinal, posteriormente modificada por la secuencia de bóvedas de la segunda fase, señaladas con línea blanca 
bóvedas transversales sobre machones adosados al muro norte, sobre la que cabalga una segunda bóveda longitudinal (Fig. 24). Esta segunda fase sólo puede documentarse por las huellas que dejó en los paramentos, dado que fue eliminada por la obra de Paccard. No podemos precisar, sin embargo, si la presencia de ambas soluciones se debe a fases cronológicamente distintas o si se trata de modificaciones en el proyecto inicial durante el curso de las obras.

Su muro septentrional es a la vez la única estructura conservada de la segunda crujía, a la que se accedería desde el pórtico. Los demás muros de este cuerpo han sido arrasados por la obra contemporánea, conservándose tan sólo el primer tramo de los muros laterales de la segunda crujía. Éstos nos indican que este espacio estuvo cubierto por bóvedas de arista. Si en su frente septentrional hubo un pórtico simétrico al descrito, no lo podemos asegurar, aunque por las fotografías históricas sabemos que existió un importante vano centrado, con gorroneras, equivalente al de la crujía sur (Fig.10).

A2. Se sitúa al este del anterior. Es un gran espacio de 7,45 $\mathrm{m}$ de ancho, organizado en 4 naves transversales que se intersecan con una longitudinal centrada, todas ellas de 3,30 m de luz, que estuvieron cubiertas por bóvedas de arista (Fig. 25). En sus muros más largos se abren 4 puertas: dos en el muro oeste, que comunican con la zona central, y dos en el este que dan acceso a un cuerpo de escaleras (A3).

A3. Poco podemos decir de este cuerpo debido a que la obra de Paccard lo destruyó casi en su totalidad, sustituyendo la escalera antigua por otra moderna y aumentando el ancho de su ámbito.

A4. En la zona occidental se emplaza un espacio de dimensiones similares a las de su homólogo oriental, aunque en este caso se cubre con una sola bóveda. Un muro transversal lo divide en dos mitades. El propio funcionamiento estructural de esta bóveda, que no necesitaría apoyos intermedios, y el reducido grosor de este muro, $60 \mathrm{~cm}$, indican que se trata de una simple compartimentación. En la mitad sur, sin embargo, encontramos el arranque de un importante muro de 1,45 $\mathrm{m}$ de espesor, que no parece tener relación directa con la estructura de esta sala. En los laterales de la bóveda, para salvar el encuentro con éste, se realizan sendos nichos bajo arcos de descarga.

A5. Más hacia el oeste hay otro complejo estructural en el que se inserta un cuerpo de escaleras que rodea por el norte y el este una crujía de $3 \mathrm{~m}$ de anchura que presenta una entreplanta.

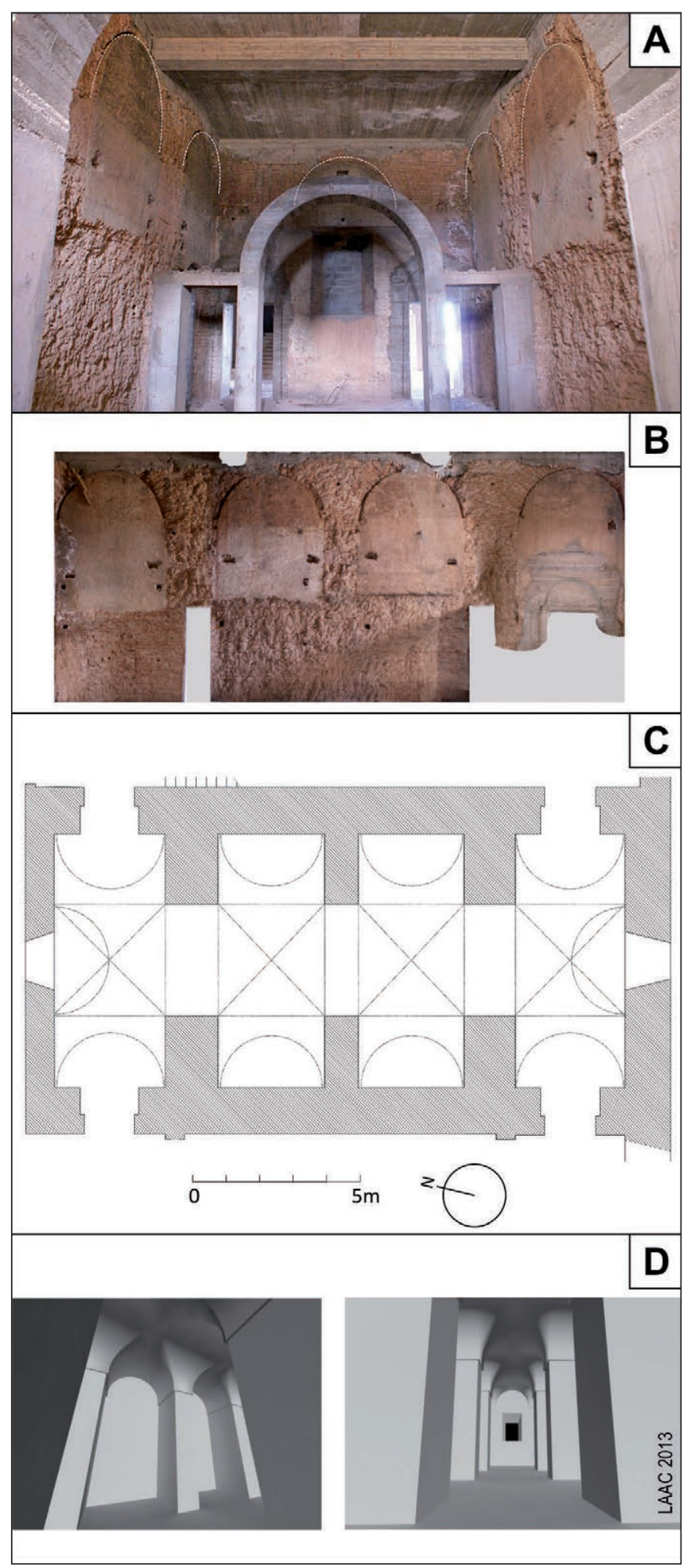

Fig. 25. Dar al-Hana. Edificio residencial. (A) Vista de su estado actual. Puede observarse la grave afección que el proyecto moderno causó en las estructuras antiguas. Se han indicado sobre la fotografía los lunetos de las bóvedas que cubrían este espacio. (B) Ortofotografía del alzado este. (C) Restitución de la planta. (D) Reconstrucción virtual 
Sectores laterales (B y C). A ambos lados del sector central se emplazaban dos núcleos secundarios. Solamente la fotografía antigua nos informa de sus características, pues el proyecto de Paccard los destruyó casi en su totalidad. Tienen una fábrica significativamente más pobre, de tapia de tierra, con un espesor homogéneo, en torno a $50 \mathrm{~cm}$. La organización de ambos es muy similar: cuatro crujías, con un ancho de $3,3 \mathrm{~m}$, rodean un patio central, el cual mide 6,2 por $9,7 \mathrm{~m}$.

A modo de recapitulación, podemos decir que el análisis tipológico y constructivo nos llevan a dar una cronología homogénea, de época saadí, tanto a las estructuras del interior de edificio como a los restos que se encuentran soterrados en sus inmediaciones, si bien podemos observar que existen otras que posiblemente pertenecieron al palacio almohade.

Las plantas altas. En la discusión sobre la posible existencia de cuerpos altos hemos de conjugar los datos aportados por las fuentes literarias con los obtenidos en el análisis arqueológico y estructural de los muros conservados.

Un testimonio de época saadí nos describe el edificio en 1631, siendo el único procedente de una fuente occidental que habla del palacio de la Masarra:

\begin{abstract}
"Este joven príncipe [Moulay al-Walid] [...] está al presente con su favorito el caíd Ayagena en su palacio de placer de Monserrat, soberbiamente construido pero de una sola planta al estilo del país y (algo que os dejaría atónitos) sin ventanas ningunas, contentos de la luz que les da una única gran puerta”42.
\end{abstract}

La mención explícita de la existencia de una sola planta resulta llamativa dado que hay varios indicios que hacen pensar que el edificio contó con otros cuerpos en altura. Antes de discutirlos, es necesario distinguir entre las plantas altas del sector central y las de los laterales, pues se trata de casos muy diferentes.

En los núcleos laterales existe una planta alta en la actualidad, fruto del proyecto contemporáneo, que reproduce básicamente la que existió previamente. A ella se accede desde los descansillos de las respectivas escaleras. La altura libre de los espacios de estos cuerpos secundarios es bastante reducida en comparación con los del cuerpo principal, limitándose a unos 3,68 m,

\footnotetext{
42 Noticia publicada en la Gazette de France del 5 de noviembre de 1631 (sin paginar). [en línea], http://gallica.bnf.fr/ark:/12148/cb32780022t/date1631.
}

por lo que en la altura del cuerpo bajo de aquél, de 6,80 $\mathrm{m}$, tienen cabida las dos plantas de éstos (Fig. 22). Estos pisos estuvieron resueltos con alfarjes planos y armaduras de madera, rasgo diferenciador respecto al central, donde se emplea la bóveda de cañón. Descartamos que por encima de ellos haya habido una tercera planta o que existiesen espacios en alto de un desarrollo considerable, dada la reducida capacidad portante de sus muros y el carácter subsidiario de estas zonas.

El caso del sector central es totalmente distinto. La gran solidez de su estructura, la altura uniforme de la plataforma generada por el sistema de bóvedas y la presencia de dos cajas de escaleras ofrecen pruebas suficientes de que se concibió como basamento de una planta superior que habría alcanzado un gran desarrollo.

Desafortunadamente el proyecto de Paccard destruyó lo que se conservaba de las coronaciones del edificio. En la fotografía de 1917 no se aprecian restos de ninguna estructura emergente que pueda corresponderse con las de una planta alta.

El testimonio del escritor y crítico de arte Leandre Vaillat, que visitó el Agdal a finales de la década de 1920 , permite pensar que existió un proyecto de planta superior, cuyas obras llegaron a iniciarse. Subido a la terraza del edificio, observó el arranque de los muros que habrían definido los ámbitos de esa planta que no llegó a construirse:

\begin{abstract}
"Sur la terrasse où je suis [...] je vois la tranche des pierres de taille qui devaient être la base du premier étage. Voici les trois pièces, avec le renfoncement du lit, le seuil des portes de dégagement, en chicane, le point de départ des trois arcades qui devaient encadrer la vue, la galerie sur l'eau. Tout cela n'a jamais existé. Le maçon s'est arrêté ou plutôt on l'a arrêté, faute d'argent, faute de ténacité, une fantaisie chassant l'autre; mais on voit le support de ce qui aurait pu être. On dirait d'un plan d'architecte, tracé en larges traits, à même le sol dur de cette terrasse" (Vaillat 1930: 454)
\end{abstract}

Así pues, Vaillat identificó claramente las trazas de la disposición de la planta alta del cuerpo central del

\footnotetext{
43 Traducción: "Sobre la terraza en la que estoy [...] veo la cara de las piedras talladas [la tranche des pierres de taille] que debían de ser la base del primer piso. He aquí las tres piezas, con el lecho rehundido, el umbral de las puertas de acceso, en recodo, el punto de arranque de las tres arcadas que debían encuadrar la vista, la galería sobre el agua. Todo eso no ha existido nunca. El albañil se ha parado, o más bien lo han parado, faltos de dinero, faltos de tenacidad, una fantasía detrás de otra; pero se ve el soporte de lo que habría podido ser. Se diría que estamos ante un plano de arquitecto, trazado a grandes rasgos, en el mismo suelo duro de esta terraza".
} 
edificio de Dar al-Hana: tres piezas vivideras, los umbrales de las entradas en recodo y las tres arcadas que constituirían una galería mirador sobre la alberca.

A pesar de que no tenemos vestigios materiales que nos permitan conocer con más detalle su organización espacial, podemos aportar algunos argumentos para proponer una hipótesis de reconstrucción de la misma. Siguiendo un criterio de lógica estructural, debemos considerar que el trazado y ubicación de los grandes muros conservados en la planta baja están directamente relacionados con el que habrían tenido los de la planta alta. Incluso, podemos apreciar que si solamente consideramos aquellos muros con mayor capacidad portante obtenemos combinaciones espaciales significativas. Esto se hace especialmente notorio en el cuerpo oriental (A2) del sector central. El esquema estructural de esta sala es bastante elocuente. Si obviamos el muro central, de espesor sensiblemente menor al resto, obtenemos que los grandes muros de carga dibujan un espacio central, de planta cuadrada, con un lado de aproximadamente $7,4 \mathrm{~m}$, flanqueado por el norte y el sur por dos espacios menores rectangulares. Creemos que nos encontramos ante la infraestructura destinada a soportar una composición de qubba con saletas laterales, solución ampliamente conocida en los espacios nobles de la arquitectura palatina islámica. Aunque en el cuerpo central (A1) y en el occidental (A4) no tenemos indicios suficientes para poder continuar con esta analogía, por el principio de simetría cabría pensar que el espacio representativo que acabamos de describir en el lado oriental tendría un equivalente en el occidental, estuviese formalizado del mismo modo o no.

Con estos criterios tendríamos una distribución aproximadamente simétrica de espacios nobles en la planta alta, separados por un patio en cuyo frente septentrional se abriría el mirador descrito por Vaillat (1930: 454). Así, observamos una interesante dualidad compositiva: mientras que en la organización espacial de la planta baja prima el eje norte-sur, en el cuerpo alto lo hace el este-oeste.

Otro aspecto que enriquece la composición arquitectónica es el tratamiento de los accesos a esta planta alta: mientras que la escalera oriental comunica tanto con el complejo central (A2) como con el exterior, a la occidental solamente se llega desde el núcleo secundario occidental (B), evidenciando una clara diferenciación funcional. Asimismo, los desembarcos de éstas se producen en ángulos opuestos de la planta alta, dando paso en ambos casos a saletas anexas a los salones principales.
EI edificio desaparecido. A partir de los datos expuestos se puede formular la hipótesis de que la superficie ocupada por los restos documentados en el interior de este edificio no es más que una parte de la que abarcó la gran residencia que allí hubo, demolida casi en su totalidad con anterioridad a 1767 pero todavía reconocible por viajeros occidentales siglo y medio después de que la describiera Al-Fishtali en torno a 1600 (1964: 178). Las estructuras conservadas en pie, cuyo análisis se acaba de presentar, pertenecerían al frente septentrional de un gran edificio que se extendía hacia el sur, sobresaliendo de la línea amurallada en forma de apéndice rectangular. De él formarían parte los numerosos muros enterrados que se han documentado, tanto los seccionados por la zanja como los que afloran en superficie. Puede calcularse que el complejo construido al que pertenecieron alcanzaría los 170 × $100 \mathrm{~m}$, un tamaño algo menor que el del palacio del Badi', cuyo patio mide 135 por $110 \mathrm{~m}$. Las menciones que hacen las fuentes cronísticas ensalzando el tamaño del gran palacio del Agdal resultarían ser más veraces de lo que se sospechaba.

Esta gran residencia habría contado con un patio central, atravesado en su eje norte-sur por el canal ${ }^{44}$ que alimenta la alberca (Fig. 19). A este patio se abrirían el pórtico y la crujía meridional del cuerpo principal. La presencia de un gran patio, que garantizaría la luz y ventilación necesarias, explicaría además que estuviese completamente cerrado al exterior, como describe una fuente de $1631^{45}$; esta disposición ha sido la habitual en la arquitectura residencial islámica hasta época colonial.

Este edificio presentaría así una doble vocación en sus relaciones con el exterior, manifiesta especialmente en sus salones principales, que debemos entender ubicados en el sector norte. Éstos podrían abrirse a través del doble pórtico tanto hacia el sur, mirando al patio y disfrutando de su carácter más íntimo y protegido, como al norte, hacia la apertura visual que ofrecía la alberca, sin olvidar su goce directo. Esa dualidad también se experimentaría en el disfrute de la presencia vegetal próxima, en el interior del patio, mientras que hacia el otro lado la alberca necesariamente impide la presencia de cuadros de cultivo próximos ${ }^{46}$.

\footnotetext{
44 Este esquema es el mismo que observamos en el Generalife, usando el canal de agua como elemento vertebrador de la composición.

45 Noticia publicada en la Gazette de France del 5 de noviembre de 1631 (sin paginar) [en línea], http://gallica.bnf.fr/ark:/12148/cb32780022t/date1631

46 Casos similares de salones con doble apertura tanto a un patio cerrado como a una gran alberca los encontramos en la almunia omeya al-Rumaniya (a. 973) de Córdoba, y en el gran núcleo residencial de Dar al-Bahr, o Palacio del Lago, de la Qal'a Bani Hammad, construida por la dinastía hammadí entre 1007 y 1105 en la actual Argelia.
} 
La residencia almohade debía de hallarse en avanzado estado de ruina en época saadí. La falta de alineación del edificio saadí respecto a la alberca, a todas luces una anomalía en una obra estatal de esta importancia, puede explicarse si consideramos que las ruinas almohades condicionaron parcialmente la construcción de la nueva residencia. Los saadíes habrían restaurado la finca almohade para desarrollar sobre ella un ambicioso proyecto que contemplaba el gran palacio descrito por Al-Fishtali y por la fuente europea de 1631. El edificio saadí habría seguido los mismos principios compositivos del palacio almohade, repitiendo el esquema de gran apéndice proyectado hacia el sur. Apoyando esta idea encontramos las mencionadas anomalías del frente sur de la muralla de Dar al-Hana, que serían coherentes con este argumento si consideramos que en su tramo central se encontraría con el cuerpo emergente del palacio, impidiendo completar un paño rectilíneo de trazado similar a los demás.

Este segundo palacio, a su vez, habría sufrido dos fenómenos de destrucción acontecidos en fechas muy alejadas entre sí:

- El primero debió de suceder a la caída de la dinastía saadí. Supuso la desaparición de la mayor parte de su superficie construida, perdiéndose todo el sector que se extendía hacia el sur, fuera de la línea de la muralla, el cual habría sido abandonado a su suerte y sufrido un intenso expolio. El frente septentrional del palacio, dado que se adentraba en el recinto de Dar al-Hana, fue segregado del resto y protegido dentro del perímetro amurallado.

A pesar de la restauración de la finca por los alauitas, ésta no alcanzaría a la arquitectura en ruinas de sus edificios residenciales, ya que se habría limitado a realizar un mínimo acondicionamiento de algunas de las construcciones previas, entre ellas las caballerizas por su interés como espacio agropecuario, y a levantar de nueva planta tan sólo el hangar de la barca y las instalaciones industriales del recinto. De esta forma se estaban primando los aspectos productivos sobre los residenciales, toda vez que Dar al-Bayda había asumido las funciones que anteriormente cumplía Dar al-Hana.

- El segundo sucedió en los años 80 del pasado siglo y supuso la destrucción parcial del único sector de la obra saadí que se había salvado de la primera demolición. En este momento el causante de los daños fue la edificación del nuevo palacio construido por Paccard.
Tampoco este proyecto llegaría a conseguir una reactivación de la vida palatina de Dar al-Hana, al quedar inconcluso.

A pesar de las grandes mutilaciones que ha sufrido, este edificio sigue constituyendo una de las construcciones más notables de la finca y su presencia al borde de la gran alberca deja traslucir una parte del magnífico panorama que el conjunto palatino debió de ofrecer en épocas pasadas (Figs. 10 y 11).

\subsection{La alberca}

Es un gran reservorio cuyo vaso tiene unas dimensiones interiores de 208 x $181 \mathrm{~m}\left(37.648 \mathrm{~m}^{2}\right)$ y una profundidad de 2,20 $\mathrm{m}$, lo que supone una capacidad de unos 83.000 $\mathrm{m}^{3}$ (Figs. 18 y 19). Desempeña un papel regulador del riego y su importancia estriba en la capacidad de retener gran cantidad de agua que pueda ser utilizada durante el estiaje. Tradicionalmente estaba llena en el mes de marzo y se hallaba vacía hacia finales de octubre.

La alberca se alimentaba por un canal que la acometía desde el sur, centrado en su eje de simetría, de un ancho de $65 \mathrm{~cm}$ que alcanza los $75 \mathrm{~cm}$ en la embocadura. Las fuentes de época saadí describen un gran palacio situado en este punto bajo el cual pasaba la canalización. El desagüe se efectúa por el lado norte mediante un orificio practicado en el fondo, regulado por una compuerta, del que parte una acequia de tierra que distribuye el agua por la finca.

El vaso de la alberca lo forma una estructura cuyos muros tienen unos 5,60 m de grosor. Su frente septentrional es el que presenta mayor alzado, llegando a alcanzar los 3,50 $\mathrm{m}$ de altura respecto al suelo del andén perimetral que hay en su base. En el centro de este frente existe hoy una rampa que da acceso a la plataforma. Se tiene constancia, sin embargo, de que se trata de una intervención reciente, pues a finales del siglo XIX aparece descrita una amplia escalinata en este punto (Harris 1889: 197; 1895:37). Aunque la pendiente del terreno en el que está situada no supera el $0,75 \%$, sus enormes dimensiones obligaron a los constructores a realizar desmontes en su frente meridional para alojar el vaso. El frente septentrional, peligrosamente expuesto a la presión de la masa de agua, fue provisto de contrafuertes cúbicos en las esquinas, que miden $9 \mathrm{~m}$ de lado y se proyectan hacia el exterior $2,30 \mathrm{~m}$.

Conocemos pocos detalles sobre las características estructurales de la alberca, pues solo son visibles la superficie externa del vaso y el pavimento del andén que recorre su borde superior. Aunque las caras exteriores están enlucidas es posible comprobar que se trata de 
una obra de tapia de hormigón en la que se aprecian numerosas reparaciones superficiales realizadas con ladrillo y mortero que deben de corresponder a la última restauración importante, de mediados del siglo XIX, y a obras menores de mantenimiento posteriores. No se puede descartar que existan refacciones más antiguas y de mayor calado, como por ejemplo la construcción de un forro perimetral que añadiera solidez a la fábrica original almohade, aunque tales obras nunca pudieron realizarse con posterioridad a época saadí, como se argumenta a continuación.

El acceso al fondo del vaso queda resuelto por ocho juegos de escaleras, dispuestas en los ángulos y en los centros de sus lados (Fig. 19). Tienen un ámbito de 1,15 $\mathrm{m}$ de ancho, y se construyen mediante zancas abovedadas. Presentan traza simétrica, con un escalón superior ampliado a modo de plataforma, mientras que los demás tienen una huella de $35 \mathrm{~cm}$.

El pavimento del andén es un simple mortero de cal asentado sobre una gruesa capa de hormigón, visible gracias a una canalización subterránea que recorre el andén occidental y que hoy se halla abierta en alguno de sus tramos.

Adosado a la base de la alberca hay un andén perimetral conservado en el frente norte que aloja una canalización en su borde que facilitaba la irrigación de los huertos inmediatos.

Por sus dimensiones y cronología el paralelo más cercano de la alberca de Dar al-Hana es la de la Menara (198 x 195 m), obra también de origen almohade. Ésta última presenta contrafuertes de esquina más desarrollados y otros menores dispuestos en los lados este y oeste que no existen en la de Dar al-Hana. Otras albercas más pequeñas, localizadas en la llanura de Tasitante en mayo de 2013 (Fig. 1), presentan características compartidas como la presencia de andenes perimetrales y contrafuertes. En algún caso, como el del Sahridj al-Baqar, éstos forman un frente a todo lo largo del muro norte del vaso; en otros se limitan exclusivamente a las esquinas de su frente septentrional.

La alberca de Dar al-Hana garantiza la disponibilidad de agua durante todo el año en las zonas de la finca situadas al norte de ella, siempre que su aprovisionamiento funcione adecuadamente, algo que debe tener lugar durante el invierno. El Agdal, tal como lo conocemos, no podría existir sin ella. La supervivencia de las especies arbóreas más resistentes, los olivos, exige en este medio que se rieguen al menos una vez al mes en la época de estiaje, entre marzo y octubre ambos incluidos, como estipulaba el contrato de arrendamiento entre las autoridades del Protectorado y el arrendador de la finca en 1922 (El Faïz 1996: 60).

El papel que desempeña la alberca dentro del conjunto de Dar al-Hana no se limita al aspecto funcional. Tiene una gran importancia compositiva en el proyecto arquitectónico y constituye el elemento central del complejo palatino de Dar al-Hana, en torno al cual se articulan tanto sus edificios como las zonas de cultivo. No cabe duda de que su enorme tamaño, su imponente construcción y la equilibrada distribución de las edificaciones de su entorno constituían motivo de ostentación y causaban gran asombro a sus visitantes, como sigue sucediendo hoy. La gran alberca estaba cargada de connotaciones estéticas, lúdicas y simbólicas.

\subsection{El apéndice oriental de la alberca}

La presencia de diversas estructuras arqueológicas adosadas al frente oriental de la gran alberca aporta algunos datos acerca de la antigüedad de sus alzados exteriores. Lo descubierto son muros de tapia rica en cal que delimitan un cuadrado perfecto de $14,5 \mathrm{~m}$ de lado, emplazado en el eje director que cruza Dar al-Hana de este a oeste (Figs. 19 y 26). La descripción que hiciera Al-Fishtali de la gran alberca a principios del siglo XVII permite entender la función de estas estructuras. Según el autor a la alberca se le adosaban al este y oeste dos fuentes de surtidor central (jusas, sing. jussa) "bellas y enormes, cuya agua vierte en una conducción de corriente muy fuerte" (Al-Fishtali 1964: 178). A la luz de este texto los

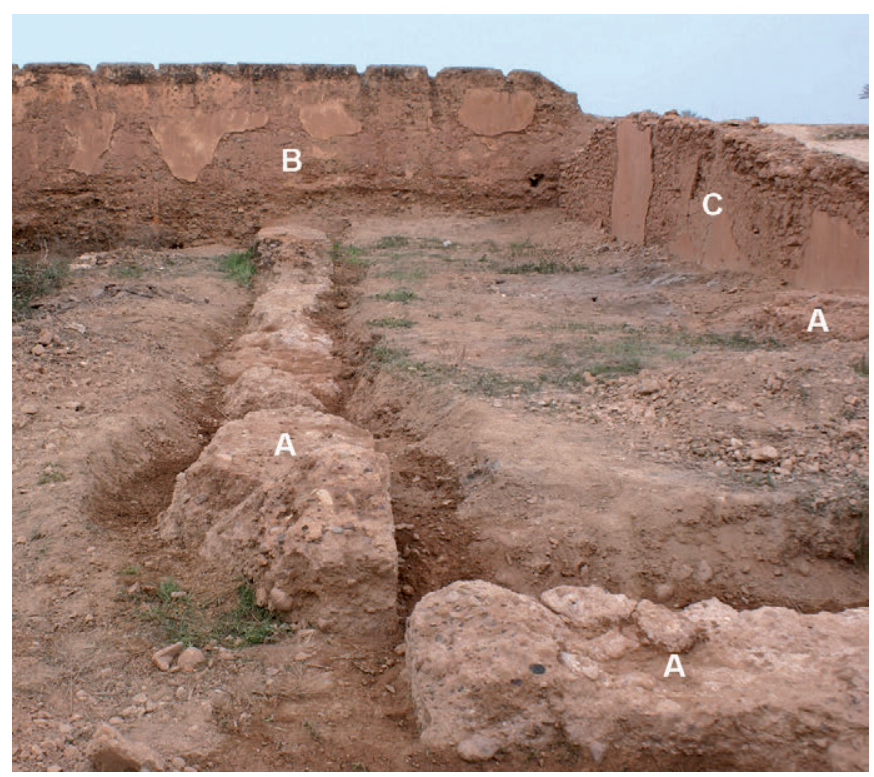

Fig. 26. Dar al-Hana. Cimentaciones (A) pertenecientes a una estructura hidráulica adosada al muro oriental de la alberca de Dar al-Hana (B). A la derecha, la rampa de acceso actual (C) al andén de la alberca, construida sobre los restos arqueológicos 
restos arqueológicos pueden interpretarse como muros de contención pertenecientes a una plataforma en la que habría una alberca con una fuente ornamental en su interior. Dado que estas estructuras de época saadí aparecen adosadas a la cara exterior de la gran alberca, su vaso es contemporáneo o anterior a los restos adosados. Independientemente del valor suntuario de estas fuentes, las alberquillas tendrían un papel funcional relacionado con la regulación del riego de los cultivos aledaños. La simetría que indica el texto no ha podido ser corroborada arqueológicamente, pues en el frente occidental de la alberca no existe resto alguno en superficie.

Puede establecerse un paralelismo entre estas estructuras y la fuente existente en el costado oriental de la alberca de la Menara, aunque en este último caso la fuente está integrada en una doble escalinata de acceso al andén de la alberca.

\subsection{Nave del hangar de la barca}

Se trata de una obra sencilla, de planta rectangular, con unas dimensiones de 20,30 por $5,50 \mathrm{~m}$, consistente en una crujía cubierta por tejado a un agua. Está adosada a la cara interna de la tapia de cierre de la antigua residencia meridional, en su ángulo nororiental. Su función es la de contener la barca con la que el sultán navegaba por la alberca. Se conservan todavía los restos de una antigua barca, incluida su maquinaria de vapor. Probablemente sea la única intervención constructiva de carácter recreativo realizada por los alauíes en Dar al-Hana.

\subsection{Edificio de Caballerizas}

Se sabe que en 1577 el sultán 'Abd al-Malik I, estando en su palacio de Dar al-Hana, le mostró al embajador Hogan "sus caballos y otros objetos de valor que tenía por su casa" (Hogan 1918: 245). A este dato hay que añadir la información proporcionada por otro texto de 1677 en el que se habla de los alardes y escaramuzas que tenían lugar en un campo en las inmediaciones del palacio (Da Silva 1864: 108). Las caballerizas eran una necesidad de la vida cortesana.

Este gran edificio, una de las mayores construcciones de la finca, se ubica en la esquina nororiental de Belfkih, en las inmediaciones del recinto de Dar al-Hana. Presenta un volumen prismático de planta rectangular con unas dimensiones de 44,8 por $54,8 \mathrm{~m}$. El espacio interior se organiza en una batería de nueve naves paralelas cubiertas con bóvedas de cañón realizadas íntegramente en ladrillo (Fig. 27). En su frente sur se localizan tres vanos de acceso. La puerta principal se ubica en el
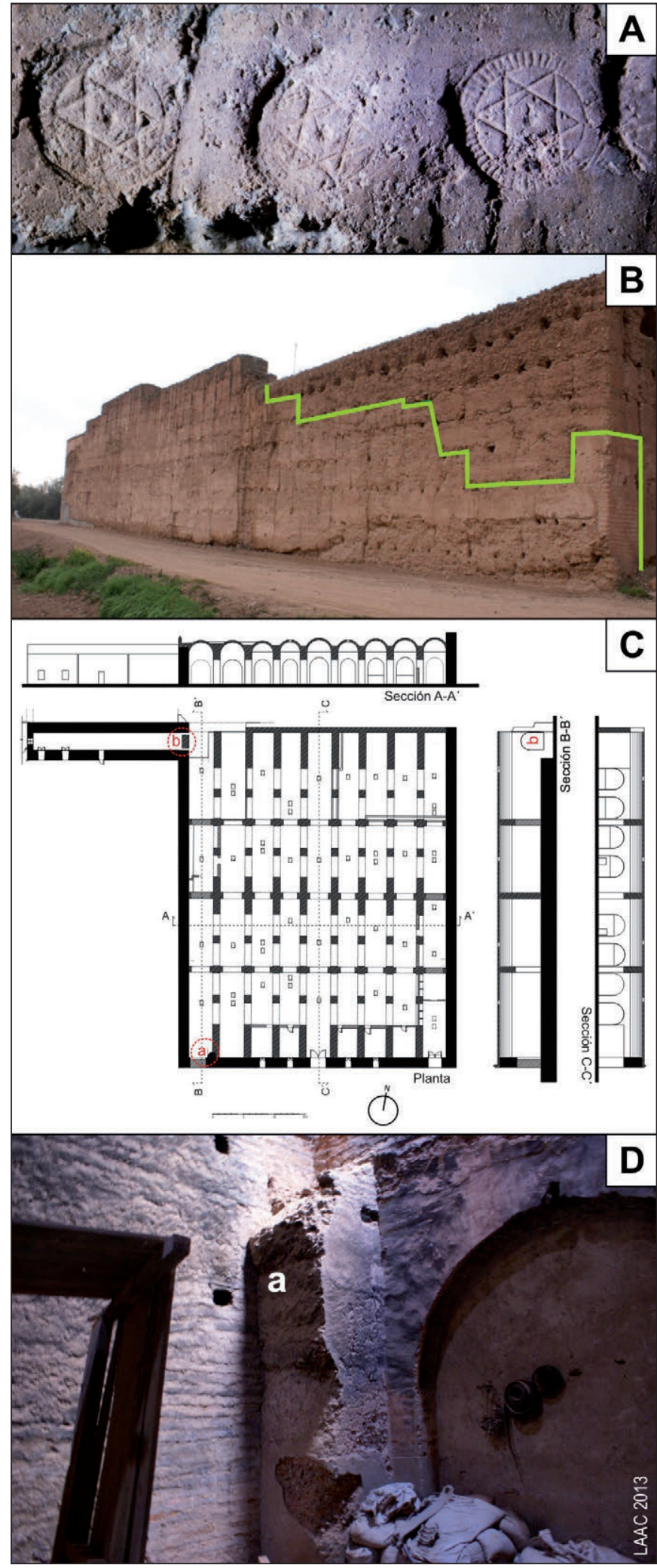

Fig. 27. Dar al-Hana. Edificio de Caballerizas. (A) Improntas, realizadas en fresco, de faluses acuñados entre los años 1863 y 1873 durante el reinado de Muhammad IV. (B) Frente oriental. Se ha señalado la interfaz entre dos fases constructivas diferentes en la fábrica de tapia, caracterizadas por una distinta composición y técnica constructiva. (C) Levantamiento. (D) Fotografía del machón del sector suroriental (a) 
eje de simetría de la fachada, dando entrada directa a la nave central. Se ha detectado otro vano, hoy cegado, en el extremo occidental de este mismo frente, flanqueado por los restos de un machón de tapia (a). Un tercer vano se abre en el extremo opuesto, para dar acceso a un espacio que se ha segregado recientemente ocupando el primer tramo de la crujía oriental.

La comunicación directa con el palacio se haría a través de un pasillo abovedado que parte de la esquina noroccidental del edificio, a modo de apéndice; allí se ha localizado un vano de acceso cegado posteriormente (Fig. 28).

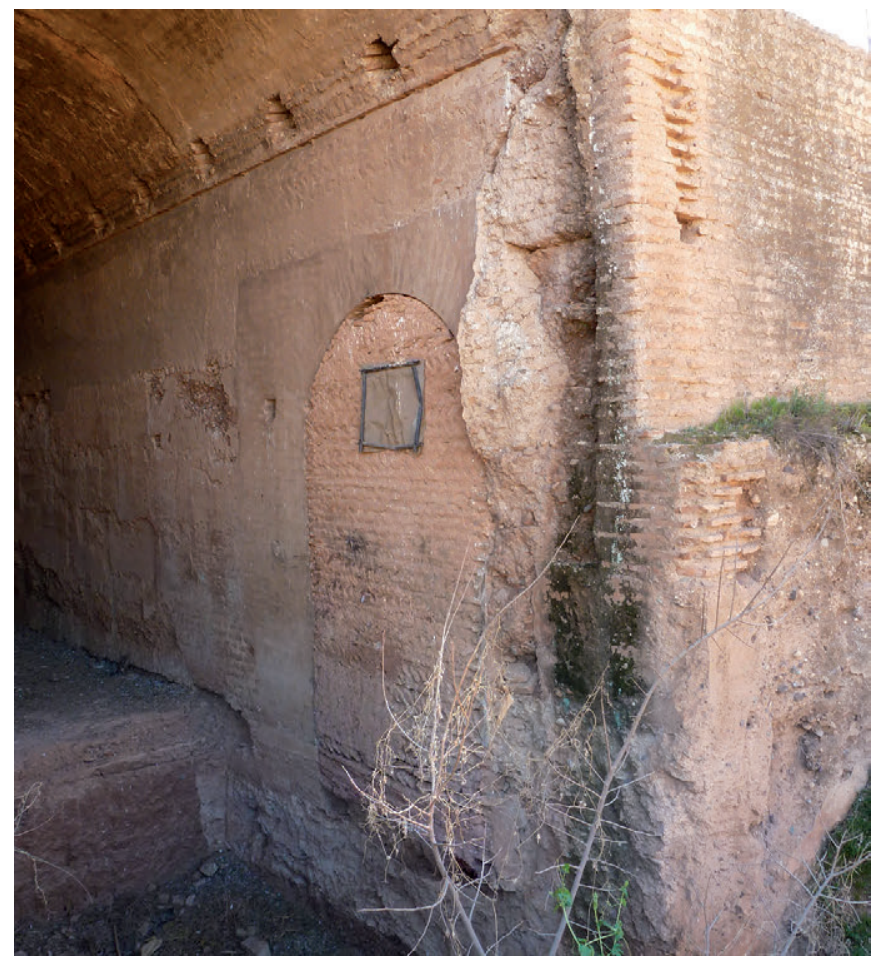

Fig. 28. Dar al-Hana. Caballerizas. Detalle del vano que lo comunicaba con el palacio saadí a través de un pasillo abovedado. Fue tapiado en época alauí. Véase su situación en la Fig. 27.C

Se aprecian como mínimo dos fases en su construcción. La primera se caracteriza por el uso de potentes fábricas de tapia, en los muros este, sur y oeste de la envolvente exterior, y en el machón mencionado (a). Éstos pertenecerían al edificio fundacional, presumiblemente saadí, que posteriormente fue amortizado con el trazado de las bóvedas y los muros interiores, en fábrica de ladrillo. Esta segunda fase puede datarse con bastante precisión gracias al hallazgo de improntas, realizadas en fresco, de faluses acuñados entre los años 1863 y 1873 durante el reinado de Muhammad IV (Fig. 27.A). En ese mismo momento se procedería al tapiado del vano de comunicación (b) con el edificio residencial, que ya no tendría sentido al desaparecer la mayor parte de éste.

Actualmente es un gran almacén polifuncional en el que se guardan todo tipo de maquinas y aperos destinados al mantenimiento de la finca.

\section{CONCLUSIONES}

Los resultados de los trabajos de investigación que hemos realizado en el Agdal de Marrakech y en la llanura de su entorno han permitido avanzar en el conocimiento de la finca. A continuación presentamos de manera concisa las conclusiones a las que hemos llegado:

- La prospección arqueológica de la llanura de Tasltante, inmediata al Agdal, ha permitido localizar en el entorno de Marrakech un paisaje periurbano salpicado de fincas entre las que se encontraban la Menara y el Agdal.

- Todas ellas, incluida el Agdal, seguían un mismo modelo organizativo y un mismo patrón de implantación. Además tenían una serie de características comunes: emplazamiento extramuros; existencia de una red hidráulica; presencia de al menos una alberca; tenían una clara función productiva y residencial; su diseño solía ser regular; disponían de una cerca perimetral y estaban asociadas al majzén y a las élites urbanas.

- De entre todas ellas, la única finca que ha llegado viva conservando su coherencia tipológica ha sido la Menara.

- Tanto la ciudad palatina (la kasba) como la finca del Agdal fueron diseñadas como parte de un mismo proyecto califal emprendido por Abu Ya' qub Yusuf.

- La finca del Agdal se implantó frente a la kasba almohade, siguiendo un eje norte-sur, que venía a sustituir el anterior eje este-oeste, compuesto por el antiguo alcázar almorávide y la Menara.

- La finca del Agdal se emplazó a una distancia de $1 \mathrm{~km}$ de la kasba almohade, aunque la puerta septentrional de su área palatina (Dar al-Hana) quedaba más alejada, a una distancia de algo más de $2 \mathrm{~km}$.

- El límite norte de la finca almohade debió de coincidir aproximadamente con la ubicación de Dar al-Bayda, mientras que el frente sur bordeaba el recinto del Dar al-Hana y su edificio residencial. Los límites oriental y occidental coincidirían con los actuales. Consideramos que la antigua muralla localizada bajo parte del frente occidental de la muralla exterior pertenece a la fase fundacional.

- La finca almohade sufre un periodo de decadencia tras el traslado, en 1244, de la capitalidad a Fez. 
- El recinto amurallado de Dar al-Hana encierra el área palatina, espacio diferenciado dentro de una finca más extensa que las fuentes escritas describen unánimemente como inmensa. Allí es donde mejor se han conservado los elementos tipológicosy estructurales de lafinca fundacional, aunque su materialidad es mayoritariamente saadí.

- El conjunto palatino estaba presidido por un gran edificio residencial, emplazado en su extremo meridional. Éste sobresalía hacia el sur, proyectándose hacia el exterior a modo de apéndice. A él pertenecerían tanto las estructuras conservadas en el interior del edificio actual como los restos arqueológicos conservados en las inmediaciones.

- El complejo palatino presenta un proyecto arquitectónico unitario y de gran coherencia interna, que somete tanto la organización general del conjunto como la particular de cada uno de sus elementos a un elaborado trazado basado en los principios de axialidad, ortogonalidad y simetría.

- Estos principios, heredados del proyecto almohade, son extensibles al conjunto de la finca, y se mantienen en los sucesivos procesos de transformación y crecimiento que ha experimentado tanto hacia el norte, hasta ponerse en contacto con la kasba, como hacia el sur.

- En su momento de mayor expansión el Agdal alcanzó una superficie aproximada de 528 ha, incluyendo la zona meridional denominada Agdal Barrani, hoy segregada del conjunto.

- La finca almohade sufre un periodo de abandono tras el traslado, en 1244, de la capitalidad a Fez, que supuso su abandono y la ruina de la casi totalidad de sus construcciones.

- La dinastía saadí emprende una restauración a gran escala del Agdal, respetando en gran medida el trazado almohade pero construyendo de nueva planta la mayor parte de sus edificios y los recintos amurallados.

- En época alauí se produce un crecimiento y revivificación de la finca, que atiende mayoritariamente a los aspectos productivos. Las funciones palatinas se desplazan al nuevo complejo áulico de Dar al-Bayda, en detrimento de Dar al-Hana.

- En su momento de mayor expansión el Agdal alcanzó una superficie aproximada de 528 ha, incluyendo la zona meridional denominada Agdal Barrani, hoy segregada del conjunto.

- Al menos, desde la restauración alauí la finca quedó dividida en once parcelas, que necesitaban de una cierta gestión coordinada debido a que dependían de una red hidráulica compartida.
- Se detectan, a grandes rasgos, dos tipos de parcelas, diferenciadas por su tamaño, su compartimentación interna y el tipo de cultivo a que estaban destinadas. Las situadas en la zona occidental, excepto la de Haj Lahcen, forman una banda homogénea, con cuadros de cultivo de menor superficie, donde se concentraban los cultivos con una elevada demanda de agua.

\section{AGRADECI MI ENTOS}

Este trabajo se ha realizado en el marco del proyecto de investigación titulado "La arquitectura residencial de al-Andalus: análisis tipológico, contexto urbano y sociológico. Bases para la intervención patrimonial” (HAR2011-29963), cuyo investigador principal es Julio Navarro Palazón. Forma parte del Plan Nacional de $\mathrm{I}+\mathrm{D}+\mathrm{i}$ y se enmarca en el VI Plan Nacional de Investigación Científica, Desarrollo e Innovación Tecnológica 2008-2011.

La prospección arqueológica que ha dado lugar al presente trabajo es parte de un proyecto más amplio denominado "Proyecto de restauración del jardín del Agdal de Marrakech" encaminado a la recuperación integral del sitio. Fue auspiciada por la Fundación de Cultura Islámica (FUNCI), con la participaron de las siguientes administraciones marroquíes: Comuna Urbana Mechouar-Kasbah, Región de Marrakech-Tensif-El Haouz y el Institut National de la Recherche Agronomique du Maroc (INRA).

El equipo de investigación ha estado compuesto por los siguientes miembros: Julio Navarro Palazón (arqueólogo) director del grupo; Hamid Triki (historiador) responsable de la revisión sistemática de las fuentes escritas; Manuel Pérez Asensio y Paula Sánchez (arqueólogos) encargados de los análisis y de la caracterización de las murallas; José Manuel Torres (arqueólogo) responsable de la prospección hidráulica y colaborador con Hamid Triki en el análisis de las fuentes escritas; Fidel Garrido (arquitecto), Juan Luis Benítez (arquitecto técnico), Juan Antonio Hernández (delineante y fotógrafo) y Manuel Rodríguez (estudiante de último año de arquitectura) se ocuparon de los trabajos de documentación arquitectónica.

\section{FUENTES}

Akansus, Muhammad Ibn Ahmad 1918: Al-Jaysh al-'Aramram. Fez. Bidé de Maurville, F. J. H. 1775: Relation de l'affaire de Larache. Amsterdam.

Chénier, L. de 1787: Recherches historiques sur les maures et histoire de l'empire de Maroc. Paris. 
Chénier, L. de 1943: Journal du Consulat Général de France à Maroc (17671785), paraphé par Louis Chénier. Ed. de Ch. Penz. Casablanca.

Da Silva Pereira, A. 1864: "Relación de Antonio da Silva Pereira", en Cunha, Luís Maria do Couto Alburquerque, Memorias para a historia da praça de Mazagam. Academia Real das Sciencias, Lisboa.

Des Cars, Duque 1890: Mémoires du Duc des Cars publiés par son neveu le Duc des Cars, Paris.

Al-Fishtali, 'Abd-al-Aziz ibn Muhammad ibn Ibrahim al-Sinhaji 1964: Manahil al-safa fi ajbar al muluk al-shurafa. Ed. de Abdallah Guennoun. Universidad Muhammad V, Rabat.

Fumey, E. (trad.) 1907: "Chronique de la dynastie alaouie du Maroc". Archives Marocaines, X (número monográfico).

Gaudefroy-Demombynes, M. (1927): Masalik el Absar fi Mamalik el Amsar. I. L'afrique, moins l'Égypte. Librairie Orientaliste Paul Geuthner, Paris.

Harris, Walter. B. 1889: The Land of an African Sultan. Travels in Morocco. 1887, 1888, and 1889. Sampson Low, Marston, Searle, \& Rivington, London.

Harris, Walter. B. 1895: Tafilet. The narrative of a journey of exploration in the Atlas Mountains and the Oases of the North-West Sahara. William Blackwood and Sons, Edinburgh \& London.

Hogan, E. 1918: Les Sources Inédites de l’Histoire du Maroc, Par Le Comte Henry de Castries. Primera serie, Dinastía Saadí, Inglaterra, Tomo I, 239249. París-Londres.

Höst, G. 1781: Nachrichten von Marokos und Fes, im Lande selbst gesammlet, in den Jahren 1760 bis 1768. Copenhague.

Houdas, O. 1889: Nozhet-elhadi, histoire de la dynastie saadienne au Maroc (1511-1670), par Mohammed Esseghir ben Elhadj ben Abdallah Eloufrani, Ernest Leroux Éditeur, Paris.

Huici, A. (trad.) 1951: Al Hulal al-Mausiyya. Crónica árabe de las dinastías almorávide, almohade y benimerín. Editora Marroquí, Tetuán.

Huici, A. (trad.) 1953: Colección de crónicas árabes de la Reconquista, Vol. II. Al-Bayan al-mugrib fi ijtisar ajbar muluk al-andalus wa al-Magrib por Ibn 'Idari al-Marrakusi. Los Almohades. Editora Marroquí, Tetuán.

Ibn Idhari al-Marrakushi, Abu al-Abbas Ahmad ibn Muhammad 1985: Kitab al-bayan al-mugrib fi ajbar al-Andalus wa-l-Magrib. Qism al-Muwahhidin. Ed. de M. I. al-Katani, M. Zanibar, M. ibn Taouit y 'A. Zamama. Dar al-Garb al-Islami, Beirut.

Ibn Marzuq, Muhammad ibn Ahmad 1981: Al-Musnad al-sahih al-hasan fi ma'athir mawlana Abi al-Hasan. Ed. de Ma Jesús Viguera. SNED, Alger.

Ibn al-Qattan, Abu al-Hasan Ali ibn Mohammed 1990: Nazhm al-Jumman li-tartib ma-salafa min ajbar al-zaman. Ed. de M. 'A. Makki. Dar al-Garb al-Islami, Beirut.

Ibn Sahib al-Salà, 'Abd al-Malik 1969: Al-Mann bil-Imama. Estudio preliminar, traducción e índices por Ambrosio Huici Miranda. Anubar, Valencia.

Al-Idrisi, Abu 'Abd Allah Muhammad 1968: Description de l'Afrique et de l’Espagne. Trad. de R. Dozy y M. J. de Goege. E. J. Brill, Leyden.

Al-Ifrani, Muhammad Sagir 1998: Nuzhat al-hadi bi-ajbar muluk al-qarn alhadi. Ed. 'Abd al-Latif al-Sadili. Matba'at al-Nayah al-Yadida, Rabat.

Le Gendre, Th. 1911: Les Sources Inédites de l'Histoire du Maroc, Par Le Comte Henry de Castries. Primera serie, Dinastía Saadí, Francia, Tomo III, 691-740. París.

León el Africano, J. 2004: Descripción general del África y de las cosas peregrinas que allí hay. Fanjul, S. (traducción, introducción, notas e índices). Fundación el Legado Andalusí. Granada.

Lévi-Provençal, É. 1928: Documents inédits d’histoire almohade. Librairie Orientaliste Paul Geuthner, Paris.

Al-Maqqari, Ahmad ibn Muhammad 1983: Rawdat al-as al-'atira al-'anfas fi dhikr man laqaytu-hu min a'lam al-hadratayn Murrakush wa Fas. AlMatba'at al-Malikiya, Rabat.

Matham, A. 1913: Sources Inédites de l’Histoire du Maroc, Par Le Comte Henry de Castries. Primera serie, Dinastía Saadí, Países Bajos, Tomo IV, 584-647. Paris-La Haya.

Mocquet, J. 1909: Les Sources Inédites de l’Histoire du Maroc, Par Le Comte Henry de Castries. Primera serie, Dinastía Saadí, Francia, Tomo II, 383ss. Paris.
Mouette, G. 1924: Les Sources Inédites de l'Histoire du Maroc, Par Le Comte Henry de Castries. Segunda serie, Dinastía Filalí, Francia, Tomo II, 1-200. Paris.

Al-Nasiri, Ahmad ibn Jalid 2001-2005: Kitab al-Istiqsa li-ajbar duwal al-Magrib al-Aqsà. Mansurat Wizarat al-Taqafa wa-l-Ittisal, Casablanca [1ª ed.1894].

Pellow, Th. 1890: The adventures of Thomas Pellow, of Penryn, mariner... T. Fisher Unwin, London [ $1^{\mathrm{a}}$ ed. 1739].

Saad Zagloul, 'A. (ed.) 1985: Kitab al-istibsar fi 'aja ìb al-amsar. Les Éditions Maghrébines, Casablanca.

Saldanha, A. de 1997: Crónica de Almançor, Sultão de Marrocos (15781603). Estudio crítico, introducción y notas por António Dias Farinha. Instituto de Investigação Científica Tropical. Lisboa.

Al-'Umari, Shihāb al-Din Abu al-'Abbas Ahmad b. Fadl Allah 1988: Routes toward insight into the capital empires. Masalik al-absar fi mamalik alamsar by Ibn Fadlallah al-'Umari. Ed. de F. Sezgin, A. Jokhosha, y E. Neubauer. Frankfurt.

Washington, Lt. 1831: "Geographical Notice of the Empire of Morocco", Journal of the Royal Geographic Society of London, 1, 123-155 y mapa fuera de texto.

Zamama, 'A. y Zakkar, S. (eds.) 1979: Kitab al-hulal al-mawshiyya fi dhikr al-ajbar al-marrakushiyya. Dar al-Rasad al-Haditha, Dar al-Bayda.

\section{BI BLI OGRAFÍ A}

Benbiba, M. 1987: "Les rhettaras du Haouz de Marrakech", Eau et developpement, 3, 38-41.

Berque, J. 1978: Structures sociales du Haut-Atlas, suivi de Retour aux Seksawa. P.U.F., Paris.

Braun, C. 1974: Teheran, Marrakesch und Madrid. Ihre Wasserversorgung mit Hilfe von Qanaten. Eine stadtgeographische Konvergenz auf kulturhistorischer Grundlage. Ferd. Dümmlers Verlag. Bonn.

Deverdun, G. 1956: Inscriptions arabes de Marrakech. Éditions Techniques Nord-Africaines, Rabat.

Deverdun, G. 1959: Marrakech des origines à 1912. Éditions Techniques Nord-Africaines. Rabat.

El Faïz, M. 1996: Les jardins historiques de Marrakech. Mémoire écologique d'une ville impériale. EDIFIR. Firenze.

El Faïz, M. 2000a: Jardins de Marrakech. Actes Sud. Arles.

El Faïz 2000b: "L'Agdal e i giardini di Marrakech nella storia della città", en Lucioni, M., et al.: L'Agdal di Marrakech, 12-30. Fondazione Benetton Studi Ricerche. Treviso.

El Faïz, M. 2007: "The Garden Strategy of the Almohad Sultans and Their Successors (1157-1900)", en M. Conan (ed.), Middle East Garden Traditions: Unity and Diversity, 96-111. Dumbarton Oaks Research Library and Collection. Washington.

El Faïz, M. y Ruf, Th. 2006: "La gestion collective de l'eau est-elle encore posible dans le N'fis à l'ouest de Marrakech?", en Caron, P., Jamin, J. Y., Richard, A. y Ruf, T. (eds.): Coordinations hydrauliques et justices sociales. Actes du séminaire, novembre 2004, Montpellier, France. Cirad, Montpellier. [en línea], http://hal.ird.fr/docs/00/15/43/99/PDF/El_FaizRuf_VF2.pdf

El Faï, M. y Ruf, Th. 2010: "An Introduction to the Khettara in Morocco: Two Contrasting Cases”, en Scheneier-Madanes, G. y Courel, M.-F. (coords.)Water and sustainability in arid regions: bridging the gap between physical and social sciences, 151-163. Springer, Dordrecht. [en línea], http://www.springerlink. com/content/978-90-481-27757/\#section=617483\&page $=1$ \&locus $=24$

Ennaji, M. y Herzenni, A. 1987: "L'irrigation des terres makhzen dans le Haouz de Marrakech sous le regne de Hassan premier", Revue ANAFIDE, 68-69, 221-232. [en línea], http://www.anafide.org/Revu\%201987.html

González, R. 2002: "Morfología agraria y prospecciones hidráulicas del Valle del Ourika-Aghmat (Provincia de Tahannawt)", en González, R.: Las formas de los paisajes mediterráneos, 355-371. Universidad de Jaén, Jaén.

Hinz, W. 2013: "Dhirā'”, en Bearman, P., Bianquis,Th., Bosworth C. E., Donzel, E. van y Heinrichs, W. P. (eds.), Encyclopaedia of Islam, Second Edition. Brill Online. [en línea], http://referenceworks.brillonline.com/entries/encyclopaedia-of-islam-2/dhira-SIM_1825. [consultado el 25/10/2013]. 
Luccioni, J. 1982: Les fondations pieuses habous au Maroc, depuis les origines jusqu'a 1956. Imprimerie Royale, Rabat.

Luciani, D., Boschiero, P., Latini, L. y Fondazione Benetton 2000: L'Agdal di Marrakech. Fondazione Benetton Studi Ricerche, Treviso.

Madani, T. 2005: "La question du partage de l'eau entre amont et aval dans le monde rural marocain médiéval", en: Water management in medieval rural economy. Les usages de l'eau en milieu rural au Moyen Âge. Ruralia V, Supplementum 17, 68-72. Institute of Archaeology, Academy of Sciences of the Czech Republic, Prague.

Madani, T. 2012: L’hydraulique dans le monde musulman médiéval. Academia Scientiarum Fennica, Helsinki.

Meunié, J., Terrasse, H. y Deverdun, G. 1952: Recherches archéologiques à Marrakech. Arts et métiers graphiques, 54. Publications de l'Institut des Hautes Études Marocaines. Paris.

Meunié, J., Terrasse, H. y Deverdun, G. 1957: Nouvelles recherches archéologiques à Marrakech. Arts et métiers graphiques, 62. Publications de 1'Institut des Hautes Études Marocaines. Paris.

Mezzine, L. 1998: "Le droit coutumier", en Grammet, I. y de Meersman, M., Splendeurs du Maroc, 68-75. Musée royal de l'Afrique central, Tervuren,

Morsy, M. 1983: La relation de Thomas Pellow. Une lecture du Maroc au $18^{\mathrm{e}}$ siècle. Éditions Recherche sur les Civilisations, Paris.

Mouline, N. 2009: Le califat imaginaire d'Ahmad al-Mansur. Pouvoir et diplomatie au Maroc au XVIe siècle. P.U.F., Paris.
Navarro, J., Garrido, F y Torres, J. M., en prensa: "El Agdal de Marrakech. Hidráulica y producción de una finca real (ss. XII-XX)”, en Ramallo, S. F. y Ros, M. (eds.): Phicaria II. Encuentro internacional del Mediterráneo. Uso y gestión de recursos naturales en medios semiáridos del ámbito mediterráneo. Universidad de Murcia, Murcia.

Parroche, A.-P. 1925: Connaissance des eaux de la région de Marrakech. Imprimerie de l'Académie et des Facultés, Bordeaux.

Pascon, P. 1970: "Théorie générale de la distribution des eaux et de l'occupation des terres dans le Haouz de Marrakech". Revue de Géographie du Maroc, 18, 3-19.

Pascon, P. 1977: Le Haouz de Marrakech. Éditions Marocaines et Internationales. Rabat.

Rosenberger, B. y Triki, H. 1973: "Famines et épidémies au Maroc aux XVIe et XVIIe siècles", Hespéris-Tamuda, XIV, 109-176.

Rosenberger, B. y Triki, H. 1974: "Famines et épidémies au Maroc aux XVIe et XVIIe siècles (suite)", Hespéris-Tamuda, XV, 5-104.

Triki, h. 1995: "Marrakech: Retrato histórico de una metrópolis medieval. (Siglos XI-XIII)", en López Guzmán, R. (coord.), La arquitectura del Islam occidental, 93-106. El Legado Andalusí. Lunwerg Editores, Barcelona.

Vaillat, L. 1930: "Les jardins de Marrakech", La Revue Hebdomadaire, 39, 439-458.

Wilbaux, Q. 2001: La médina de Marrakech. Formation des espaces urbains d'une ancienne capitale du MarocL'Harmattan, Paris. 